\title{
Interventions to improve water quality and supply, sanitation and hygiene practices, and their effects on the nutritional status of children (Review)
}

Dangour AD, Watson L, Cumming O, Boisson S, Che Y, Velleman Y, Cavill S, Allen E, Uauy R

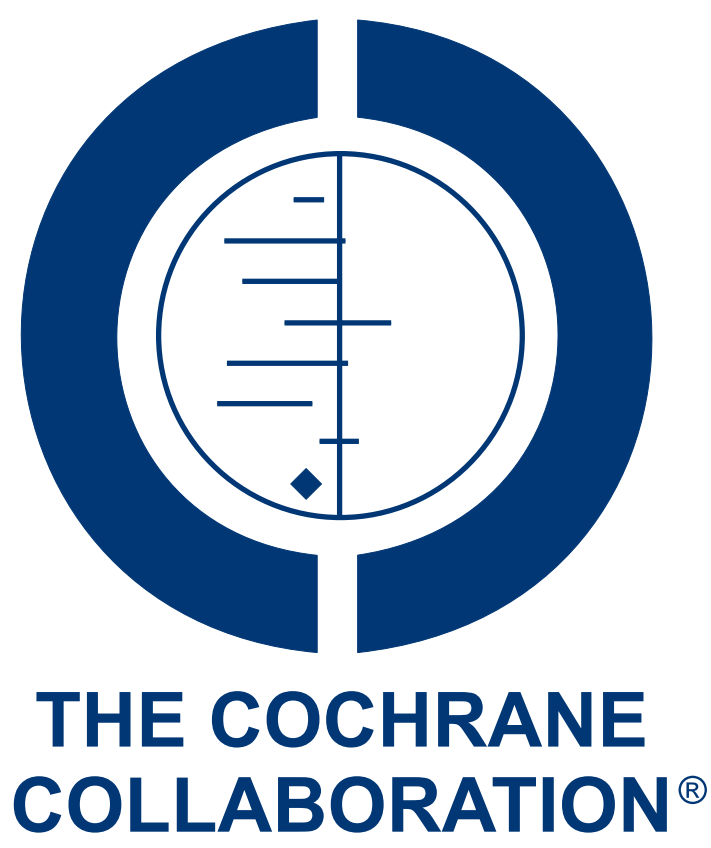

This is a reprint of a Cochrane review, prepared and maintained by The Cochrane Collaboration and published in The Cochrane Library 2013, Issue 8

http://www.thecochranelibrary.com

\section{WILEY}

Interventions to improve water quality and supply, sanitation and hygiene practices, and their effects on the nutritional status of children 
TABLE OF CONTENTS

HEADER . . . . . . . . . . . . . . . . . . . . . . . . . . . . . . . . . . . . . . . . . . . .

ABSTRACT . . . . . . . . . . . . . . . . . . . . . . . . . . . . . . . . . . . . . . . . . . . 1

PLAIN LANGUAGE SUMMARY . . . . . . . . . . . . . . . . . . . . . . . . . . . . . . . . . . . . . . . . . . . . .

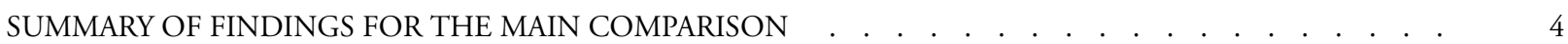

BACKGROUND . . . . . . . . . . . . . . . . . . . . . . . . . . . . . . . . . . . . 6

Figure 1. . . . . . . . . . . . . . . . . . . . . . . . . . . . . . . . . . . . . . 7

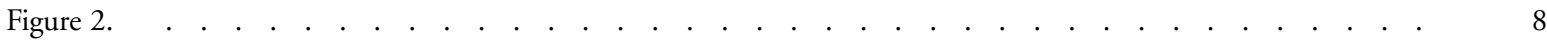

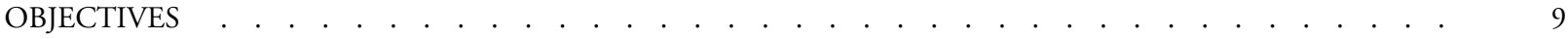

METHODS . . . . . . . . . . . . . . . . . . . . . . . . . . . . . . . . . . . . . . 9

RESULTS . . . . . . . . . . . . . . . . . . . . . . . . . . . . . . . . . . . . . . . 12

Figure 3. . . . . . . . . . . . . . . . . . . . . . . . . . . . . . . . . . . . . . 13

Figure $4 . \quad$. . . . . . . . . . . . . . . . . . . . . . . . . . . . . . . . . . . . . . . . . 16

Figure 5. . . . . . . . . . . . . . . . . . . . . . . . . . . . . . . . . . . . . 19

Figure 6. . . . . . . . . . . . . . . . . . . . . . . . . . . . . . . . . . . . . 19

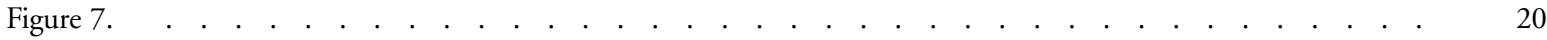

Figure 8. . . . . . . . . . . . . . . . . . . . . . . . . . . . . . . . . . . . . . $\quad .20$

Figure 9. . . . . . . . . . . . . . . . . . . . . . . . . . . . . . . . . . . . . . 21

Figure 10. . . . . . . . . . . . . . . . . . . . . . . . . . . . . . . . . . 21

Figure 11. . . . . . . . . . . . . . . . . . . . . . . . . . . . . . . . . . . . . . 22

Figure 12. . . . . . . . . . . . . . . . . . . . . . . . . . . . . . . . . . . . . 22

Figure 13. . . . . . . . . . . . . . . . . . . . . . . . . . . . . . . . . . . . . . 23

Figure 14. . . . . . . . . . . . . . . . . . . . . . . . . . . . . . . . . . . . . . 24

Figure 15. . . . . . . . . . . . . . . . . . . . . . . . . . . . . . . . . . . . . . . . . .

Figure 16. . . . . . . . . . . . . . . . . . . . . . . . . . . . . . . . . . . . . . . 25

Figure 17. . . . . . . . . . . . . . . . . . . . . . . . . . . . . . . . . . . . 25

DISCUSSION . . . . . . . . . . . . . . . . . . . . . . . . . . . . . . . . . . . . . . . . . .

AUTHORS' CONCLUSIONS . . . . . . . . . . . . . . . . . . . . . . . . . . . . . . . . . . . .

ACKNOWLEDGEMENTS . . . . . . . . . . . . . . . . . . . . . . . . . . . . . . . . . . . . . . . . . .

REFERENCES . . . . . . . . . . . . . . . . . . . . . . . . . . . . . . . . . . . . . . . . . 27

CHARACTERISTICS OF STUDIES . . . . . . . . . . . . . . . . . . . . . . . . . . . . . . . . . . . . . . . . . .

DATA AND ANALYSES . . . . . . . . . . . . . . . . . . . . . . . . . . . . . . . . . . . . . . . . . . . . . . . 66

Analysis 1.1. Comparison 1 Weight-for-age, Outcome 1 Weight-for-age (all studies). . . . . . . . . . . . . . 68

Analysis 1.2. Comparison 1 Weight-for-age, Outcome 2 Weight-for-age (RCTs only). . . . . . . . . . . . . 69

Analysis 1.3. Comparison 1 Weight-for-age, Outcome 3 Weight-for-age (gender). . . . . . . . . . . . . . 70

Analysis 1.4. Comparison 1 Weight-for-age, Outcome 4 Weight-for-age (age group). . . . . . . . . . . . . 71

Analysis 2.1. Comparison 2 Weight-for-height, Outcome 1 Weight-for-height (all studies). . . . . . . . . . . . 72

Analysis 2.2. Comparison 2 Weight-for-height, Outcome 2 Weight-for-height (RCTs only). . . . . . . . . . . 73

Analysis 2.3. Comparison 2 Weight-for-height, Outcome 3 Weight-for-height (gender). . . . . . . . . . . . 74

Analysis 2.4. Comparison 2 Weight-for-height, Outcome 4 Weight-for-height (age group). . . . . . . . . . . 75

Analysis 3.1. Comparison 3 Height-for-age, Outcome 1 Height-for-age (all studies). . . . . . . . . . . . . . . . 76

Analysis 3.2. Comparison 3 Height-for-age, Outcome 2 Height-for-age (RCTs only). . . . . . . . . . . . . . . . . 77

Analysis 3.3. Comparison 3 Height-for-age, Outcome 3 Height-for-age (gender). . . . . . . . . . . . . . . . . 78

Analysis 3.4. Comparison 3 Height-for-age, Outcome 4 Height-for-age (age group). . . . . . . . . . . . . . . . . 79

Analysis 4.1. Comparison 4 Weight, Outcome 1 Weight (all studies). . . . . . . . . . . . . . . . . . . . . 80

Analysis 4.2. Comparison 4 Weight, Outcome 2 Weight (RCTs only). . . . . . . . . . . . . . . . . . . . . . . $\quad 81$

Analysis 5.1. Comparison 5 Height, Outcome 1 Height (all studies). . . . . . . . . . . . . . . . . . . . . . 82

Analysis 5.2. Comparison 5 Height, Outcome 2 Height (RCTs only). . . . . . . . . . . . . . . . . . . . . . . . 83

ADDITIONAL TABLES . . . . . . . . . . . . . . . . . . . . . . . . . . . . . . . . . . . . . . . . .

APPENDICES . . . . . . . . . . . . . . . . . . . . . . . . . . . . . . . . . . . . . . . . . 86

HISTORY . . . . . . . . . . . . . . . . . . . . . . . . . . . . . . . . . . . . . . . . . . . . . . . . . .

CONTRIBUTIONS OF AUTHORS . . . . . . . . . . . . . . . . . . . . . . . . . . . . . . . . . . . . . . . . . . . .

Interventions to improve water quality and supply, sanitation and hygiene practices, and their effects on the nutritional status of children (Review)

Copyright $\odot 2013$ The Cochrane Collaboration. Published by John Wiley \& Sons, Ltd. 
DECLARATIONS OF INTEREST . . . . . . . . . . . . . . . . . . . . . . . . . . . . . . . . . . . . . . . . . . . . .

SOURCES OF SUPPORT . . . . . . . . . . . . . . . . . . . . . . . . . . . . . . . . . . . . . . . . . . . .

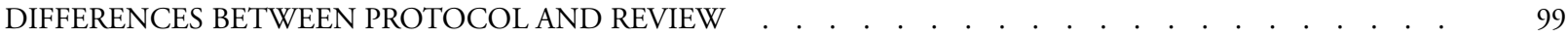

Interventions to improve water quality and supply, sanitation and hygiene practices, and their effects on the nutritional status of children ii (Review)

Copyright $\odot 2013$ The Cochrane Collaboration. Published by John Wiley \& Sons, Ltd. 


\title{
[Intervention Review]
}

\section{Interventions to improve water quality and supply, sanitation and hygiene practices, and their effects on the nutritional status of children}

\author{
Alan D Dangour ${ }^{1}$, Louise Watson ${ }^{1}$, Oliver Cumming ${ }^{2}$, Sophie Boisson ${ }^{3}$, Yan Che $^{4}$, Yael Velleman ${ }^{5}$, Sue Cavill ${ }^{6}$, Elizabeth Allen ${ }^{7}$, \\ Ricardo Uauy ${ }^{1}$ \\ ${ }^{1}$ Department of Population Health, London School of Hygiene \& Tropical Medicine, London, UK. ${ }^{2}$ Environmental Health Group, \\ London School of Hygiene \& Tropical Medicine, London, UK. ${ }^{3}$ Department of Disease Control, London School of Hygiene \& \\ Tropical Medicine, London, UK. ${ }^{4}$ Centre for Clinical Research and Training, Shanghai Institute of Planned Parenthood Research \\ (SIPPR), Shanghai, China. ${ }^{5}$ Policy and Campaigns, WaterAid, London, UK. ${ }^{6}$ Technical Support Unit, WaterAid, London, UK. \\ ${ }^{7}$ Medical Statistics Department, London School of Hygiene \& Tropical Medicine, London, UK
}

Contact address: Alan D Dangour, Department of Population Health, London School of Hygiene \& Tropical Medicine, Keppel Street, London, WC1E 7HT, UK. Alan.Dangour@1shtm.ac.uk.

Editorial group: Cochrane Public Health Group.

Publication status and date: New, published in Issue 8, 2013.

Review content assessed as up-to-date: 12 November 2012.

Citation: Dangour AD, Watson L, Cumming O, Boisson S, Che Y, Velleman Y, Cavill S, Allen E, Uauy R. Interventions to improve water quality and supply, sanitation and hygiene practices, and their effects on the nutritional status of children. Cochrane Database of Systematic Reviews 2013, Issue 8. Art. No.: CD009382. DOI: 10.1002/14651858.CD009382.pub2.

Copyright (C) 2013 The Cochrane Collaboration. Published by John Wiley \& Sons, Ltd.

\begin{abstract}
A B S T R A C T
Background

Water, sanitation and hygiene (WASH) interventions are frequently implemented to reduce infectious diseases, and may be linked to improved nutrition outcomes in children.
\end{abstract}

Objectives

To evaluate the effect of interventions to improve water quality and supply (adequate quantity to maintain hygiene practices), provide adequate sanitation and promote handwashing with soap, on the nutritional status of children under the age of 18 years and to identify current research gaps.

\section{Search methods}

We searched 10 English-language (including MEDLINE and CENTRAL) and three Chinese-language databases for published studies in June 2012. We searched grey literature databases, conference proceedings and websites, reviewed reference lists and contacted experts and authors.

\section{Selection criteria}

Randomised (including cluster-randomised), quasi-randomised and non-randomised controlled trials, controlled cohort or crosssectional studies and historically controlled studies, comparing WASH interventions among children aged under 18 years.

Interventions to improve water quality and supply, sanitation and hygiene practices, and their effects on the nutritional status of children I (Review)

Copyright $\odot 2013$ The Cochrane Collaboration. Published by John Wiley \& Sons, Ltd. 


\section{Data collection and analysis}

Two review authors independently sought and extracted data on childhood anthropometry, biochemical measures of micronutrient status, and adherence, attrition and costs either from published reports or through contact with study investigators. We calculated mean difference (MD) with 95\% confidence intervals (CI). We conducted study-level and individual-level meta-analyses to estimate pooled measures of effect for randomised controlled trials only.

\section{Main results}

Fourteen studies (five cluster-randomised controlled trials and nine non-randomised studies with comparison groups) from 10 lowand middle-income countries including 22,241 children at baseline and nutrition outcome data for 9,469 children provided relevant information. Study duration ranged from 6 to 60 months and all studies included children under five years of age at the time of the intervention. Studies included WASH interventions either singly or in combination. Measures of child anthropometry were collected in all 14 studies, and nine studies reported at least one of the following anthropometric indices: weight-for-height, weight-for-age or height-for-age. None of the included studies were of high methodological quality as none of the studies masked the nature of the intervention from participants.

Weight-for-age, weight-for-height and height-for-age $\mathrm{z}$-scores were available for five cluster-randomised controlled trials with a duration of between 9 and 12 months. Meta-analysis including 4,627 children identified no evidence of an effect of WASH interventions on weight-for-age z-score (MD 0.05; 95\% CI -0.01 to 0.12). Meta-analysis including 4,622 children identified no evidence of an effect of WASH interventions on weight-for-height z-score (MD 0.02; 95\% CI -0.07 to 0.11). Meta-analysis including 4,627 children identified a borderline statistically significant effect of WASH interventions on height-for-age z-score (MD 0.08; $95 \%$ CI 0.00 to 0.16 ). These findings were supported by individual participant data analysis including information on 5,375 to 5,386 children from five clusterrandomised controlled trials.

No study reported adverse events. Adherence to study interventions was reported in only two studies (both cluster-randomised controlled trials) and ranged from low $(<35 \%)$ to high $(>90 \%)$. Study attrition was reported in seven studies and ranged from $4 \%$ to $16.5 \%$. Intervention cost was reported in one study in which the total cost of the WASH interventions was USD 15/inhabitant. None of the studies reported differential impacts relevant to equity issues such as gender, socioeconomic status and religion.

\section{Authors' conclusions}

The available evidence from meta-analysis of data from cluster-randomised controlled trials with an intervention period of 9-12 months is suggestive of a small benefit of WASH interventions (specifically solar disinfection of water, provision of soap, and improvement of water quality) on length growth in children under five years of age. The duration of the intervention studies was relatively short and none of the included studies is of high methodological quality. Very few studies provided information on intervention adherence, attrition and costs. There are several ongoing trials in low-income country settings that may provide robust evidence to inform these findings.

\section{PLAIN LANGUAGE SUMMARY}

The effect of interventions to improve water quality and supply, provide sanitation and promote handwashing with soap on physical growth in children

In low-income countries an estimated 165 million children under the age of five years suffer from chronic undernutrition causing them to be short in height and 52 million children suffer from acute undernutrition causing them to be very thin. Poor growth in early life increases the risks of illness and death in childhood. The two immediate causes of childhood undernutrition are inadequate dietary intake and infectious diseases such as diarrhoea. Water, sanitation and hygiene (WASH) interventions are frequently implemented to reduce infectious diseases; this review evaluates the effect that WASH interventions may have on nutrition outcomes in children. The review includes evidence from randomised and non-randomised interventions designed to (i) improve the microbiological quality of drinking water or protect the microbiological quality of water prior to consumption; (ii) introduce new or improved water supply or improve distribution; (iii) introduce or expand the coverage and use of facilities designed to improve sanitation; or (iv) promote handwashing with soap after defecation and disposal of child faeces, and prior to preparing and handling food, or a combination of these interventions, in children aged under 18 years.

We identified 14 studies of such interventions involving 22,241 children at baseline and nutrition outcome data for 9,469 children. Meta-analyses of the evidence from the cluster-randomised trials suggests that WASH interventions confer a small benefit on growth in

Interventions to improve water quality and supply, sanitation and hygiene practices, and their effects on the nutritional status of children 2 (Review)

Copyright () 2013 The Cochrane Collaboration. Published by John Wiley \& Sons, Ltd. 
children under five years of age. While potentially important, this conclusion is based on relatively short-term studies, none of which is of high methodological quality, and should therefore be treated with caution. There are several large, robust studies underway in lowincome country settings that should provide evidence to inform these findings. 
Water, sanitation and hygiene interventions compared with usual practice for child nutrition outcomes

Population: households

Settings: rural and urban communities in low- and middle-income countries

Interventions: to improve water quality and supply, sanitation and hygiene practices

Comparison: usual practice

Quality of evidence: none of the included studies were of high methodological quality

\begin{tabular}{|c|c|c|}
\hline & $\begin{array}{l}\text { Relative effect } \\
(95 \% \mathrm{CI})\end{array}$ & $\begin{array}{l}\text { No of participants } \\
\text { (studies) }\end{array}$ \\
\hline $\begin{array}{l}\text { Weight-for-age pooled estimate (RCTs } \\
\text { only) }\end{array}$ & MD $0.05(-0.01$ to 0.12$)$ & $4627(5)$ \\
\hline Du Preez 2010 (cRCT) & MD $0.21(-0.07$ to 0.49$)$ & 332 \\
\hline Du Preez 2011 (cRCT) & MD $-0.01(-0.23$ to 0.21$)$ & 525 \\
\hline McGuigan 2010 (cRCT) & MD $0.26(-0.01$ to 0.53$)$ & 760 \\
\hline Luby 2004 (cRCT) & MD $0.01(-0.10$ to 0.12$)$ & 873 \\
\hline Luby 2006 (Soap) (cRCT) & MD $0.05(-0.13$ to 0.23$)$ & 533 \\
\hline Luby 2006 (Soap \& Floc) (cRCT) & MD 0.07 (-0.11 to 0.25$)$ & 550 \\
\hline Luby 2006 (Floc \& Bleach) (cRCT) & MD $0.03(-0.12$ to 0.18$)$ & 1054 \\
\hline Ahmed 1993 & $\begin{array}{l}P<0.05 \text { at end for a difference } \\
\text { between groups (favouring intervention) }\end{array}$ & 298 \\
\hline Arnold 2009 & MD $-0.06(-0.23$ to 0.11$)$ & 877 \\
\hline Bowen 2012 & MD $-0.06(-0.27$ to 0.15$)$ & 461 \\
\hline Hasan 1989 & $\begin{array}{l}\text { No statistically significant differences } \\
\text { between intervention and control group }\end{array}$ & 405 \\
\hline Langford 2011 & MD $-0.24(-0.76$ to 0.28$)$ & 88 \\
\hline $\begin{array}{l}\text { Weight-for-height pooled estimate (RCTs } \\
\text { only) }\end{array}$ & MD $0.02(-0.07$ to 0.11$)$ & $4622(5)$ \\
\hline Du Preez 2010 (cRCT) & MD $0.08(-0.20$ to 0.36$)$ & 332 \\
\hline Du Preez 2011 (cRCT) & MD $-0.11(-0.30$ to 0.08$)$ & 522 \\
\hline
\end{tabular}

Interventions to improve water quality and supply, sanitation and hygiene practices, and their effects on the nutritional status of children

(Review)

Copyright $\odot 2013$ The Cochrane Collaboration. Published by John Wiley \& Sons, Ltd. 


\begin{tabular}{|c|c|c|}
\hline McGuigan 2011 (cRCT) & MD $0.15(-0.15$ to 0.45$)$ & 760 \\
\hline Luby 2004 (cRCT) & MD 0.03 (-0.32 to 0.38$)$ & 873 \\
\hline Luby 2006 (Soap) (cRCT) & MD 0.02 (-0.20 to 0.24$)$ & 533 \\
\hline Luby 2006 (Soap \& Floc) (cRCT) & MD 0.06 (-0.16 to 0.28$)$ & 549 \\
\hline Luby 2006 (Floc \& Bleach) (cRCT) & MD 0.02 (-0.20 to 0.24$)$ & 1053 \\
\hline Arnold 2009 & MD -0.07 (-0.28 to 0.14$)$ & 872 \\
\hline Hasan 1989 & $\begin{array}{l}\text { No statistically significant differences } \\
\text { between intervention and control group }\end{array}$ & 405 \\
\hline Langford 2011 & MD -0.11 (-0.53 to 0.31$)$ & 88 \\
\hline $\begin{array}{l}\text { Height-for-age pooled estimate (RCTs } \\
\text { only) }\end{array}$ & MD 0.08 (0.00 to 0.16$)$ & $4627(5)$ \\
\hline Du Preez 2010 (cRCT) & MD 0.28 (-0.06 to 0.62$)$ & 332 \\
\hline Du Preez 2011 (cRCT) & MD 0.11 (-0.19 to 0.41$)$ & 525 \\
\hline McGuigan 2011 (cRCT) & MD 0.22 (-0.04 to 0.48$)$ & 760 \\
\hline Luby 2004 (cRCT) & MD -0.01 (-0.37 to 0.35$)$ & 873 \\
\hline Luby 2006 (Soap) (cRCT) & MD 0.08 (-0.13 to 0.29$)$ & 534 \\
\hline Luby 2006 (Soap \& Floc) (cRCT) & MD 0.06 (-0.12 to 0.24$)$ & 549 \\
\hline Luby 2006 (Floc \& Bleach) (cRCT) & MD 0.04 (-0.08 to 0.16$)$ & 1054 \\
\hline Arnold 2009 & MD 0.04 (-0.19 to 0.27$)$ & 876 \\
\hline Bowen 2012 & MD -0.08 (-0.29 to 0.13$)$ & 461 \\
\hline Fenn 2012 & MD 0.22 (0.11 to 0.33$)$ & 1899 \\
\hline Hasan 1989 & $\begin{array}{l}\text { No statistically significant differences } \\
\text { between intervention and control group }\end{array}$ & 405 \\
\hline Langford 2011 & MD $-0.13(-0.54$ to 0.28$)$ & 88 \\
\hline
\end{tabular}

CI: confidence interval; $\mathbf{C R C T}$ : cluster-randomised controlled trial; MD: mean difference; RCT: randomised controlled trial; Floc: flocculent disinfectant 


\section{B A C K G R O U N D}

Water, sanitation and hygiene (WASH) interventions such as provision of clean piped drinking water, enhanced facilities for excreta disposal and the promotion of handwashing with soap are frequently implemented to improve health and reduce infectious disease incidence and may be linked to child development outcomes. There are no published systematic reviews investigating the impact of WASH interventions on medium- to long-term markers of health in childhood, such as measures of physical growth and nutritional sufficiency. This review assesses the strength of evidence linking WASH interventions with measures of child nutritional status.

\section{Description of the condition}

In 2010 it was estimated that undernutrition (insufficient energy intake) affected approximately 925 million people worldwide (FAO 2010), and the global estimates of people with specific nutrient insufficiencies (for example iron and iodine) are in excess of 2 billion (SCN 2004). Insufficient intake of dietary energy, minerals and vitamins is estimated to be the underlying cause of $45 \%$ of all child deaths (approximately 3.1 million deaths per year) (Black 2013). This figure includes estimates of the negative effects of undernutrition on pregnant women, which can cause poor foetal growth (intra-uterine growth retardation) and low birthweight. The period from conception to 24 months of age is widely recognised as a critical window for the prevention of undernutrition (Black 2013). Millennium Development Goal 4 (MDG 4) is to reduce by two-thirds the mortality rate of children under five years of age, and ensuring good nutritional status is crucial for the attainment of this goal.

Globally, an estimated 26\% of children under the age of five years (165 million) suffer from chronic undernutrition manifested as short height for their age (or stunting) and 8\% (52 million) suffer from acute undernutrition manifested by extreme thinness or wasting (low weight-for-height); by far the largest numbers of undernourished children live in South Asia and Sub-Saharan Africa (UNICEF/WHO/World Bank 2012). The long-term consequences of chronic undernutrition include reduced school attendance and diminished health and economic potential. One target for Millennium Development Goal 1 (MDG 1) is to reduce by half the proportion of people who suffer from hunger, but to date progress towards this goal has been slow (UNICEF/WHO/World Bank 2012).

Nutritional status in children is normally evaluated by assessing physical growth performance (via anthropometry) or micronutrient status (clinical signs of deficiency or blood measures). Various standardised methods are available for the assessment of nutritional status. There are both direct and indirect causes of undernutrition in children. The two immediate causes of undernutrition are inadequate dietary intake and disease, which interact in a complex manner and manifest as either chronic undernutrition (stunting) or in acute situations as extreme thinness (wasting). Underlying these immediate causes are a multitude of indirect factors that contribute to nutritional status, such as food security, childcare practices, maternal education, access to health services and water, hygiene and sanitation conditions. Ultimately, these factors are embedded in the larger political, economic, social and cultural environment.

\section{Description of the intervention}

The integral role in health of safe water, sanitary disposal of human waste and personal hygiene has long been recognised (Esrey 1992). One target for Millennium Development Goal 7 (MDG 7) is to reduce by half the proportion of people without access to safe drinking water and basic sanitation. Activities linked to this goal aim to increase access to improved drinking water and sanitation. However, the possible benefits to health and nutrition of meeting the MDG 7 safe water and sanitation targets are rarely discussed. Currently approximately 2.5 billion people do not have access to improved sanitation, that is sanitation which ensures the hygienic separation of human excreta from human contact, and they rely on facilities such as unsafe flush or pour flush (to the street, yard, plot, open sewer, ditch or other location), a pit latrine without a slab or platform, a bucket and hanging latrine. Approximately 1.1 billion people have no sanitation facilities at all and practice open defecation (WHO/UNICEF 2012). Approximately 783 million people do not have access to improved drinking water sources (WHO/UNICEF 2012). Progress towards MDG 7 is on track for access to safe water but will fall well short for provision of basic sanitation (WHO/UNICEF 2012) and there are major differences between and within countries and regions.

Water, sanitation and hygiene (WASH) interventions are defined in this review as follows:

- Water quality is any intervention to improve the microbiological quality of drinking water, including removing or inactivating microbiological pathogens (via household, community or water source level water treatment systems involving filtration, sedimentation, chemical treatment, heat treatment or ultraviolet (UV) radiation) and protecting the microbiological quality of water prior to consumption (residual disinfection, protected distribution, improved storage). The effects of chemical contaminants (i.e. arsenic, fluoride) are not included in this review.

- Water quantity or supply is any intervention to provide a new or improved water supply or improved distribution (installation of a new hand pump or household connection), or both.

- Sanitation is any intervention to introduce or expand the provision or use of facilities for excreta disposal (flush or pour flush to piped sewer system, septic tank or pit latrine; ventilated 
improved pit (VIP) latrine; pit latrine with slab; or composting toilet).

- Hygiene is any intervention that promotes adoption of, or increased practice of, handwashing with soap after defecation and disposal of child faeces, prior to preparing and handling food and before eating (group discussions, media campaigns, leaflets, songs, pictorial stories, dramas etc.).

\section{How the intervention might work}

The conceptual framework linking poor water supply and quality, poor sanitation and hygiene with child nutritional status identifies both direct pathways, namely diarrhoea (Briend 1990; Guerrant
2008), environmental enteropathy (Humphrey 2009) and nematode infections (Pruss-Ustun 2006); and indirect pathways, namely the time taken to collect water at long distances from the home, the purchase of water from water vendors and contamination of groundwater by heavy metals (Figure 1). The direct pathways relate to the body's ability to respond to infection or parasitic infestation and the impact of these assaults on nutritional status and health. Indirect pathways relate more to the ability of families to provide safe and clean living environments and have time to provide adequate care to their children. This review will focus only on the evidence that WASH interventions act through the direct pathways namely, diarrhoea, environmental enteropathy and nematode infections (Figure 2).

Figure I. Conceptual framework showing how poor water, sanitation and hygiene might impact child nutritional status, directly and indirectly

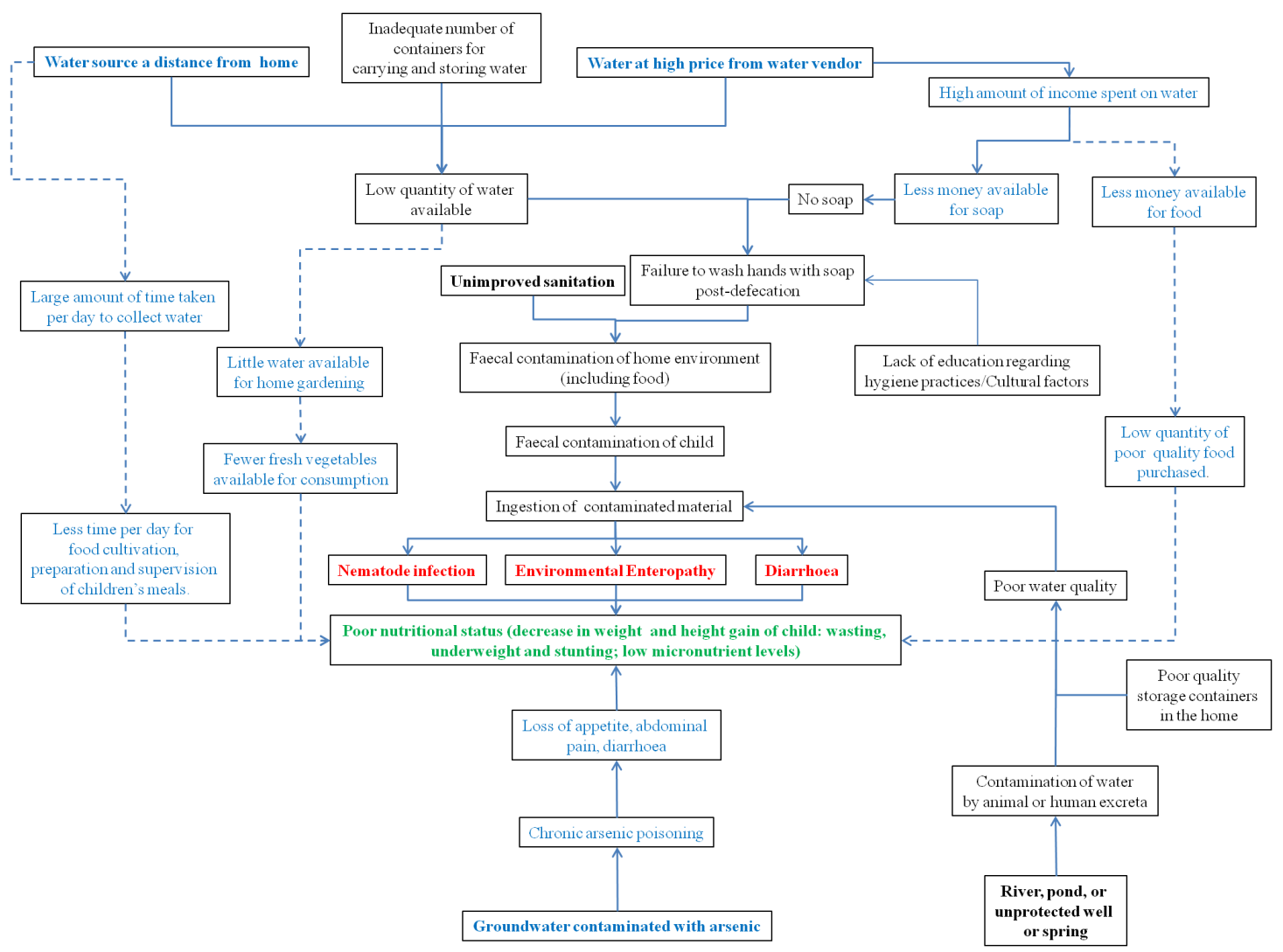

Interventions to improve water quality and supply, sanitation and hygiene practices, and their effects on the nutritional status of children 
Figure 2. Conceptual framework showing how poor water, sanitation and hygiene might directly impact child nutritional status

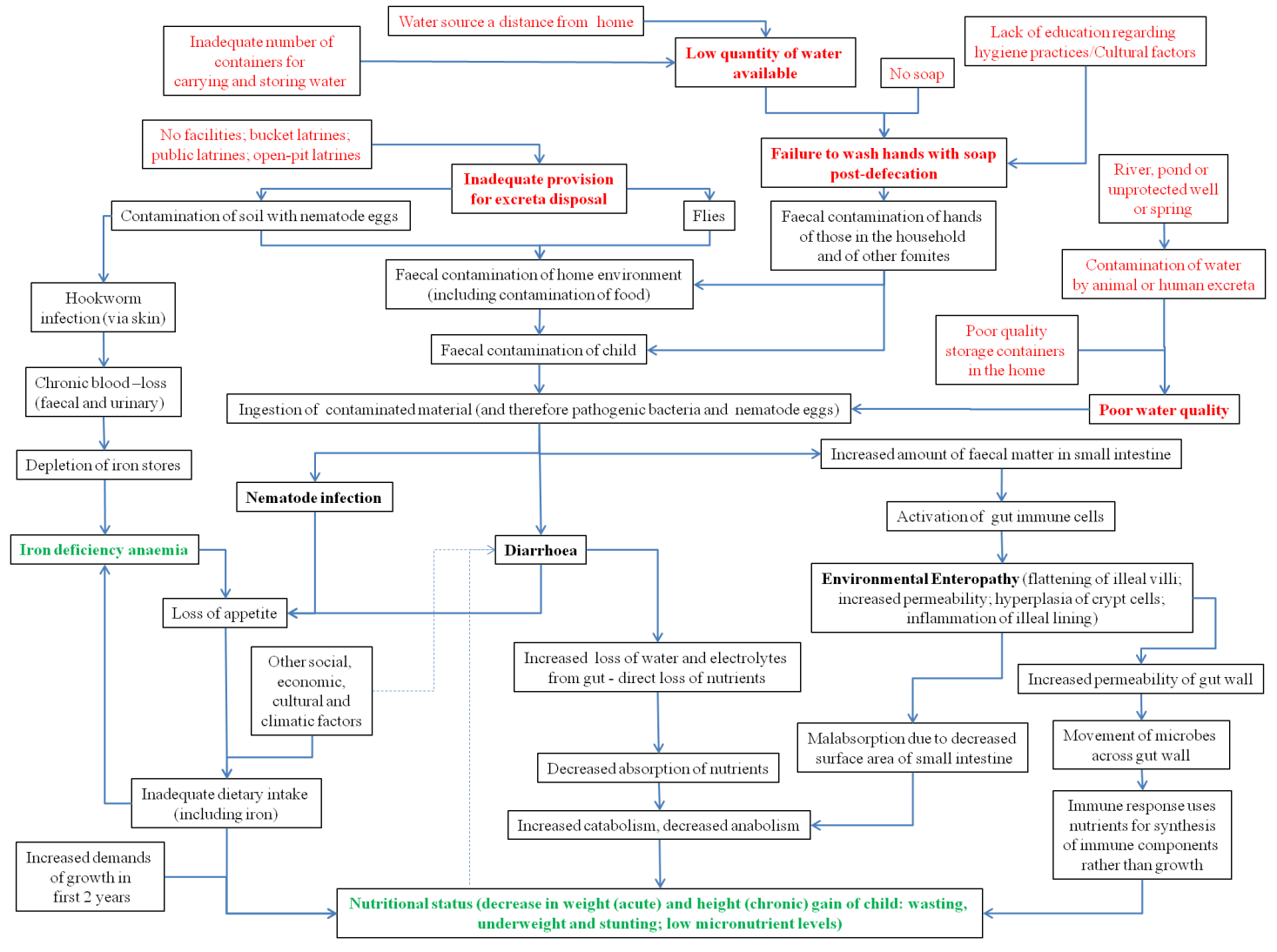

\section{Why it is important to do this review}

Several Cochrane reviews have been published on the impact of WASH interventions on diarrhoea incidence.

Clasen 2006 reviewed the impact of improved water quality on diarrhoea incidence. The review contained 30 trials and 53,000 individuals. Meta-analysis identified that interventions that improve the quality of water reduce diarrhoea incidence for populations of all ages and children under five years. Interventions at the household level were more effective than those implemented at water sources.

Clasen 2010 reviewed the impact of improved disposal of human excreta on diarrhoea incidence. The review included 13 trials and 33,400 individuals. Meta-analysis identified that interventions that improve disposal of human excreta reduce diarrhoea incidence.

Ejemot 2008 reviewed the impact of the promotion of handwashing on diarrhoeal incidence. The review included 14 trials and 7711 individuals. Meta-analyses identified that interventions that promote handwashing reduce diarrhoea incidence.
The association between diarrhoea and other enteric infections and child nutritional outcomes is complex but recent analysis of cohort data suggests that repeated diarrhoea incidence in the first two years of life significantly increases the risks of being stunted by age two years (Checkley 2008; Guerrant 2008; Pruss-Ustun 2006).

Cochrane reviews published to date of the impact of WASH interventions have focused only on diarrhoea incidence, and there are no published reviews of the effect of WASH interventions on child nutritional status. The current review is designed to evaluate the strength of evidence linking WASH interventions with measures of child nutritional status. Potential indirect effects of improved nutritional status (such as school performance and school attendance) are not included in the review. By linking up the distinct WASH and nutrition evidence bases in a Cochrane review, the role of WASH interventions in improving child health and nutrition will be identified and future research priorities can be established. 


\section{O B J E C T IVES}

To evaluate the effect of interventions to improve water quality and supply (adequate quantity to maintain hygiene practices), provide adequate sanitation and promote handwashing with soap, on the nutritional status of children under the age of 18 years and to identify current research gaps.

\section{MET HODS}

\section{Criteria for considering studies for this review}

\section{Types of studies}

Randomised (including cluster-randomised), quasi-randomised and non-randomised controlled trials, controlled before and after studies (cohort or cross-sectional), interrupted time series (ITS) and historically controlled studies.

\section{Types of participants}

Children aged under 18 years.

\section{Types of interventions}

\section{Intervention}

1. Any intervention aimed at improving the microbiological quality of drinking water, including:

i) removing or inactivating microbiological pathogens via household, community or water source level water treatment systems (filtration, sedimentation, chemical treatment, heat treatment, UV radiation), or both;

ii) protecting the microbiological quality of water prior to consumption (residual disinfection, protected distribution, improved storage).

2. Any intervention aimed at introducing a new or improved water supply or improved distribution (installation of a hand pump or household connection), or both.

3. Interventions aimed at introducing or expanding the coverage and use of facilities designed to improve sanitation, i.e. to reduce direct and indirect contact with human faeces (pourflush, composting or water sealed flush toilet, piped sewer system, septic tank, simple pit latrines, VIP latrine or use of a potty or scoop for the disposal of child faeces).

4. Interventions aimed at the promotion of handwashing with soap after defecation, disposal of child faeces and prior to preparing and handling food (group discussions, media campaigns, leaflets, songs, pictorial stories, dramas etc.).

5. Any combination of the WASH interventions listed above.

\section{Control}

1. Water quality: study participants who have continued with usual practice, or a less stringent version of the intervention (i.e. new protected well but no household disinfection on top of this).

2. Water supply: study participants who have continued with usual practice.

3. Sanitation: study participants who have continued to practice open defecation or who continue with usual practice regarding excreta disposal rather than following the prescribed intervention.

4. Hygiene: no handwashing promotion; study participants who continued with usual practice.

There was no minimum duration of intervention.

\section{Types of outcome measures}

\section{Primary outcomes}

- Child nutritional status as measured by anthropometry: weight-for-age (underweight), weight-for-height (wasting), height-for-age (stunting).

\section{Secondary outcomes}

- Child nutritional status as measured by anthropometry: weight, height, mid-upper arm circumference, skinfold thickness, percent body fat, birthweight, body mass index (BMI).

- Child nutritional status as measured by nutrient status: haemoglobin, serum ferritin, soluble transferrin receptor, serum retinol, serum zinc, urinary iodine, clinical signs of nutrient deficiency.

\section{Search methods for identification of studies}

\section{Electronic searches}

We searched the following databases using a keyword search and $\mathrm{MeSH}$ terms. We adapted search terms according to the requirements or individual databases.

- Cochrane Public Health Group Special Register

- MEDLINE (general medicine)

- MEDLINE In-Process

- Web of Science (including Science Citation Index Expanded (SCI-EXPANDED) 1970 to present; Social Sciences Citation Index (SSCI) 1970 to present; Conference Proceedings Citation Index-Science (CPCI-S) 1990 to present; Conference Proceedings Citation Index - Social Science \& Humanities (CPCI-SSH) 1990 to present)

- EMBASE (general medicine)

- Econlit (economics)

Interventions to improve water quality and supply, sanitation and hygiene practices, and their effects on the nutritional status of children 
- Global Health (public health)

- Greenfile (environment)

- CAB Abstracts (applied life sciences)

- Trial registers (CENTRAL, metaRegister of Controlled Trials (mRCT))

- Grey literature (www.nyam.org/library/online-resources/ grey-literature-report/; http://indexmedicus.afro.who.int/; http:/ /www.bireme.br/php/index.php; www.hellis.org; www.emro.who.int/HIS/VHSL/; http://wprim.wpro.who.int/ iah/I/index.htm; 3ie Impact; http://scholar.google.co.uk/)

- Chinese-language databases available under the China National Knowledge Infrastructure (CNKI-CAJ) (Fung 2008):

- Chinese Biomedical Literature database (CBM)

- China National Knowledge Infrastructure (CNKI)

- VIP information/Chinese Scientific Journals database

We prepared search strategies in English (Appendix 1) and Chinese (Appendix 2). There were no language or date restrictions. We handsearched reference lists of key articles for any additional relevant articles. We contacted subject experts and study authors and asked them to provide additional information and further relevant references.

We performed an initial literature search in July 2011, followed by an update search in June 2012 .

\section{Searching other resources}

We contacted the following researcher groups and organisations for information on unpublished and ongoing trials: Public-Private Partnership for Handwashing with Soap (http:/ /www.globalhandwashing.org/); IRC International Water and Sanitation Centre (http://www.irc.nl/); Department of Child and Adolescent Health and Development (WHO) (http:/ /www.who.int/maternal ' child adolescent/en/); World Bank ( http://www.worldbank.org/); World Bank Water and Sanitation Programme (http://water.worldbank.org/related-topics/ water-and-sanitation-program); World Health Organization (WHO) (http://www.who.int/en/) and United Nations Children's Fund (UNICEF) (http://www.unicef.org.uk/); International Centre for Diarrhoeal Disease Research, Bangladesh (ICDDR,B) (http://www.icddrb.org/); Water, Sanitation and Health Programme (WHO) (http://www.who.int/ water sanitation 'health/en/); Environmental Health Project (USAID) (http://www.ehproject.org/); Foodborne and Diarrheal Diseases Branch, Centers for Disease Control and Prevention (CDC) ( http://www.cdc.gov/foodborne/about fddb.htm); USAID (http:/ /www.usaid.gov/) and UK Department for International Development (DFID) (http://www.dfid.gov.uk/).

We also searched the following for relevant abstracts:

- Waterlines journal;

- International Water Association and the Water, Engineering and Development Centre (Loughborough University, UK);
- public health conferences (e.g. American Public Health Association; European Public Health Association).

\section{Data collection and analysis}

\section{Selection of studies}

Two authors (LW and SB) reviewed the titles and abstracts retrieved through the English-language search strategy independently in order to identify and select potentially relevant studies using pre-defined inclusion criteria, and the full text of all articles selected by either team member were retrieved for a full-text review. One author (YC) reviewed the results of the Chinese-language search, undertook the same process and summarised the article in English; LW and SB reviewed the summaries to independently determine study eligibility. Where there was a difference of opinion, disagreement was resolved through discussion with a third review author (ADD). All studies which initially appeared to meet the inclusion criteria but upon inspection of the full text did not meet inclusion criteria are detailed in the Characteristics of excluded studies table with reasons for exclusion. We contacted authors of 12 potentially eligible excluded studies (in English and Chinese) that did not report nutrition outcomes and asked them to provide information on the availability of nutrition outcome data. All authors responded, and one author (two studies) provided additional unpublished data (Luby 2004; Luby 2006).

\section{Data extraction and management}

Two authors (LW and SB) independently extracted data from all relevant articles; LW contacted authors to supply missing data where possible. The data extraction forms were based on the data collection form from the Cochrane Effective Practice and Organisation of Care (EPOC) Group and Cochrane Public Health Group, modified for use in this review. Quality criteria questions for the different study designs were built into this form. Any discrepancies between the two review authors were resolved by a third author (ADD). LW entered the extracted data into Review Manager 5 (RevMan 2012). Multiple papers reporting results from one study were considered as one study. We used a standard approach where comparisons of multiple reports and publications of the same study were checked for contradictions and completeness and the data used once.

\section{Assessment of risk of bias in included studies}

Two review authors (LW and SB) independently assessed the risk of bias of included studies using the EPOC 'Risk of bias' tool for studies with a separate control group. This tool includes additional items to assess the risk of selection bias and subsequent confounding ("were baseline outcome measurements similar?" and 
"were baseline characteristics similar?"), as well as an additional item to consider the likelihood of contamination ("was the study adequately protected against contamination?”). We also supplemented the EPOC 'Risk of bias' tool with another additional item to address whether the study authors appropriately adjusted for important confounders in their analysis. We assessed studies for each item with answers of 'Low' indicating low risk of bias, 'High' indicating high risk of bias and 'Unclear' indicating either lack of information or uncertainty over the potential for bias. We contacted study authors for additional information where possible. Any discrepancies were resolved by a third author (ADD).

\section{Measures of treatment effect}

We present treatment effect sizes for continuous outcomes and report them using their original scale. All measures of effect are presented with $95 \%$ confidence intervals (CI).

\section{Unit of analysis issues}

The unit of analysis was the individual. We adjusted data derived from the five cluster-randomised controlled trials (Du Preez 2010; Du Preez 2011; McGuigan 2011; Luby 2004; Luby 2006) to allow for the clustered design.

\section{Dealing with missing data}

We contacted authors of included studies requesting missing information and received responses to all our queries. Through this process we were sent data sets including nutrition outcomes in children from three studies (Du Preez 2010; Du Preez 2011; McGuigan 2011), only one of which had previously been reported (Du Preez 2011). We also contacted authors of 12 potentially eligible excluded studies (in English and Chinese) that did not report nutrition outcomes and were sent two further data sets of previously unpublished data (Luby 2004; Luby 2006). Study authors also provided unpublished trial protocols when available.

\section{Assessment of heterogeneity}

Clinical heterogeneity caused by differences in participant characteristics is likely to be moderate as studies only included poorly nourished children from low- or middle-income countries. We assessed statistical heterogeneity using the $\mathrm{I}^{2}$ statistic according to guidance of the Cochrane Handbook for Systematic Reviews of Interventions (Higgins 2011 Sections 9.5 to 9.6).

\section{Assessment of reporting biases}

Nutritional outcome measures have only rarely been assessed in WASH studies to date and when they are measured they are often classified as secondary outcomes. In our review, we identified four studies in which nutritional status measures had been collected but had not been reported in the published literature. We contacted the principal investigators of these studies and they immediately provided us with full access to these unreported data. Despite a rigorous search, it is possible that other WASH studies have collected nutrition data that have not been reported.

\section{Data synthesis}

We conducted data synthesis of study outcomes by group (intervention and control) using Review Manager 5. We created forest plots without meta-analysis including all possible studies by outcome to enable visual inspection of the available data. Substantial heterogeneity in the designs of studies included in the review limited the amount of meta-analysis possible. Meta-analysis combining randomised and non-randomised studies is not recommended (Higgins 2011) and formal meta-analysis was therefore restricted to include only the five identified cluster-randomised controlled trials (Du Preez 2010; Du Preez 2011; Luby 2004; Luby 2006; McGuigan 2011). All trials were primarily designed to reduce diarrhoea incidence, and diarrhoea incidence lies on the direct causal pathway between WASH and nutrition outcomes in children. The pooling of different WASH interventions in meta-analysis allowed the combined impact of WASH interventions to be assessed. We summarised the remaining nine studies using a narrative synthesis. Our analysis of the effect of the intervention is reported for each study separately (Effects of interventions).

Study authors provided raw anthropometric data for five cluster-randomised controlled trials (Du Preez 2010; Du Preez 2011; Luby 2004; Luby 2006; McGuigan 2011) from which anthropometric indices (weight-for-age, weight-for-height and height-forage) were calculated using the WHO Anthro software (available at: http://www.who.int/childgrowth/en/). For these trials, we calculated means and cluster-adjusted standard deviations (SD) in Stata version 12 (http://www.stata.com/stata12/) prior to analysis in Review Manager 5. Study-level meta-analysis included data on 4622 to 4627 children (depending on outcome) who had baseline and final measures in the included cluster-randomised controlled trials.

Three studies included more than one intervention arm (Bowen 2012; Luby 2004; Luby 2006):

Bowen 2012 had two intervention arms: handwashing with soap and handwashing with soap plus treatment of drinking water with flocculent disinfectant. The overall effect of intervention versus control was examined by pooling the individual effect of each of these intervention arms (mean and SD) and weighting the pooled values for the numbers within each arm.

Luby 2004 had two intervention arms: handwashing with antibacterial soap, and handwashing with plain soap. In study-level metaanalysis the overall effect of intervention versus control was examined by pooling the individual effect of each intervention arm (mean and SD) and weighting the pooled values for the numbers within each arm. 
Luby 2006 had four intervention arms: handwashing with soap, handwashing with soap plus treatment of drinking water with flocculent disinfectant, treatment of drinking water with bleach and treatment of drinking water with flocculent disinfectant. In study-level meta-analysis we combined the effect of water quality interventions (treatment of drinking water with bleach and treatment of drinking water with flocculent disinfectant), and compared this with promotion of handwashing with soap, promotion of handwashing with soap and treatment of drinking water with flocculent disinfectant, and the control arm. Overall values were weighted for the numbers within each arm. In our analysis, Luby 2006 included three intervention groups (soap, soap plus flocculent disinfectant and flocculent disinfectant and bleach) and for this study the shared group (control) was split into three to provide three reasonably independent comparisons (see Cochrane Handbook for Systematic Reviews of Interventions, Section 16.5.4).

We conducted individual participant data (IPD) analysis in Stata version 12 using the raw data provided from the five cluster-randomised controlled trials only (Du Preez 2010; Du Preez 2011; Luby 2004; Luby 2006; McGuigan 2011). In IPD analysis, we estimated the effect of WASH interventions on weight-for-age, weight-for-height and height-for-age, height and weight using analysis of covariance models (i.e. final follow-up measure adjusted for baseline measure) additionally adjusting for age at baseline, duration of treatment and sex. The analysis used random-effects models to allow for both within-study and within-cluster variability, where cluster is the unit of randomisation in each study. Heterogeneity of treatment effects across trials was tested by including a random slope for the intervention. Children with missing data were removed from the analysis. In IPD analysis we pooled the data from studies with more than one intervention arm to allow comparison of outcome of children in intervention and control arms. IPD meta-analysis included data on 5375 to 5386 children (depending on outcome) who had baseline and at least one followup measure in the five included cluster-randomised controlled trials.

We conducted the analyses on an intention-to-treat basis. We collated a 'Summary of findings' table, providing information on primary outcomes, effect sizes and quality of information.

\section{Subgroup analysis and investigation of heterogeneity}

We conducted pre-specified subgroup analysis by sex and age group (two years and under and two to five years) for those studies eligible for inclusion in meta-analysis. All of the studies in the review were six months or longer in duration, conducted in lowor middle-income countries and conducted in a mixture of rural, peri-urban and urban locations, and only one study included children aged over five years, precluding analysis by other pre-specified subgroups (duration of intervention, country setting, community location, age group over five years).

\section{Sensitivity analysis}

We planned to carry out a sensitivity analysis on studies judged to be at a low risk of bias. However, no sensitivity analysis was conducted as no included study was judged to be free of bias.

\section{R E S U L T S}

\section{Description of studies}

See Characteristics of included studies, Characteristics of ongoing studies and outline of included studies (Table 1). Luby 2006 is included as three independent comparisons: Luby 2006 (Soap); Luby 2006 (Soap \& Floc); Luby 2006 (Floc \& Bleach) (see Data synthesis above).

\section{Results of the search}

The search strategy up to June 2012 identified 20,458 titles and abstracts: 17,492 from the English search, 20 from grey literature searching and author contacts, and 2966 from Chinese literature. After de-duplication and first assessment by two authors, we obtained 71 for further assessment. Following assessment by two authors, 54 were discarded. Fourteen studies (described in 17 reports) met the inclusion criteria. Of the 17 included reports, 15 were published in journals, one was a UNDP/World Bank report and one was a book chapter. All of the included studies were published in English. The study selection process is outlined in Figure 3.

Interventions to improve water quality and supply, sanitation and hygiene practices, and their effects on the nutritional status of children 
Figure 3. Study flow diagram.

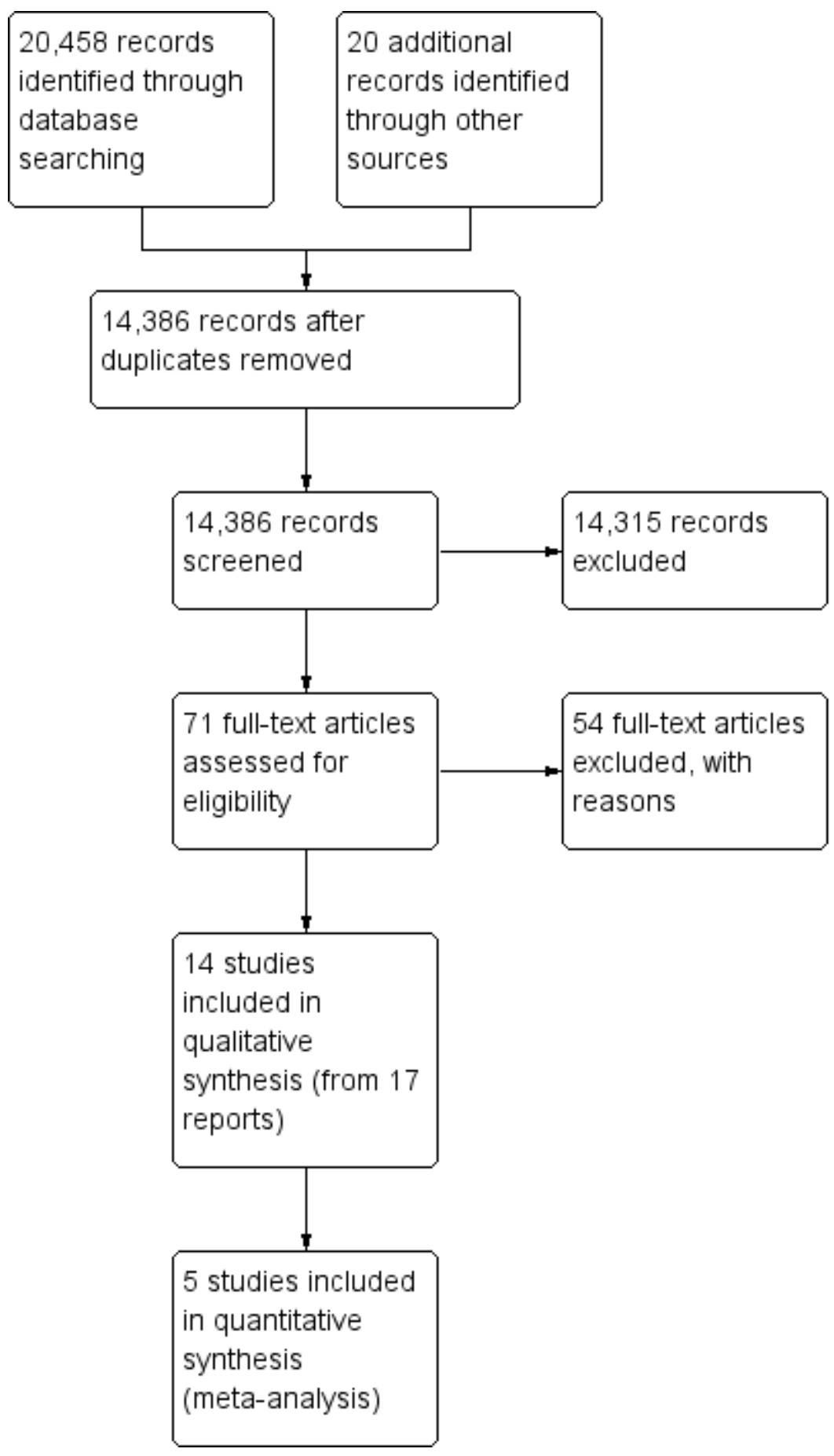

Interventions to improve water quality and supply, sanitation and hygiene practices, and their effects on the nutritional status of children 
In addition, five ongoing studies were identified through contact with experts (Characteristics of ongoing studies).

\section{Included studies}

\section{Study characteristics}

All included studies were conducted in low-income or middleincome country settings. Three studies were conducted in Pakistan (Bowen 2012; Luby 2004; Luby 2006), two studies in Bangladesh (Ahmed 1993; Hasan 1989), two in Guatemala (Arnold 2009; Guzman 1968), one in Kenya (Du Preez 2011), one in Ethiopia ( Fenn 2012), one in Nigeria (Huttly 1990), one in Nepal (Langford 2011), one in Cambodia (McGuigan 2011), one in South Africa ( Du Preez 2010) and one in Chile (Schlesinger 1983). Seven studies were in rural settings (Ahmed 1993; Arnold 2009; Fenn 2012; Guzman 1968; Hasan 1989; Huttly 1990; McGuigan 2011), six in urban settings (Bowen 2012; Du Preez 2010; Langford 2011; Luby 2004; Luby 2006; Schlesinger 1983) and one in both rural and urban settings (Du Preez 2011).

Five studies were cluster-randomised controlled trials (Du Preez 2010; Du Preez 2011; Luby 2004; Luby 2006; McGuigan 2011), one study was a follow-up study of a cluster-randomised controlled trial (Bowen 2012), three studies were longitudinal studies with control groups (Guzman 1968; Langford 2011; Schlesinger 1983), three studies were repeated cross-sectional studies with control groups (Ahmed 1993; Hasan 1989; Huttly 1990), one study was a controlled before and after study (Fenn 2012) and one was a crosssectional study with a matched historical control group (Arnold 2009).

Study duration ranged from 6 to 60 months. Two interventions were implemented for six months (Ahmed 1993; Langford 2011), two interventions for nine months (Bowen 2012; Luby 2006), four interventions for 12 months (Du Preez 2010; Du Preez 2011; Luby 2004; McGuigan 2011), one intervention for 20 months ( Schlesinger 1983), one intervention for 30 months (Huttly 1990), one intervention for 36 months (Arnold 2009), one intervention for 48 months (Hasan 1989) and one intervention for 60 months (Guzman 1968).

Anthropometric measures were reported in 10 studies (Ahmed 1993; Bowen 2012; Arnold 2009; Du Preez 2011; Fenn 2012; Guzman 1968; Hasan 1989; Huttly 1990; Langford 2011; Schlesinger 1983). Four studies did not report anthropometric measures (Du Preez 2010; Luby 2004; Luby 2006; McGuigan 2011), but study authors provided raw anthropometric data collected in these studies on request. One study additionally reported blood haemoglobin concentration (Bowen 2012) (a biochemical measure of iron nutriture). In addition to nutritional status, other outcomes reported included episodes of diarrhoea, acute respiratory infections, other infections, knowledge, attitudes and prac- tice of hygiene practices, and self-reported water, sanitation and hygiene practices. Nutritional status was reported as an outcome of secondary importance in all of the studies and none of the studies reported differential impacts relevant to equity issues such as gender, socioeconomic status and religion.

\section{Participants}

All studies included children aged under five years, although one study (Bowen 2012) that followed up participants three years after the end of a cluster-randomised trial included children who were up to eight years old. Interventions were directed to households that contained young children and outcomes of interest were assessed in children only. The number of children for whom nutrition outcome data were available ranged between studies from 88 (Langford 2011) to 2115 (Luby 2006) and in total 22,241 children were included at baseline.

\section{Interventions}

Details of the WASH interventions implemented in the included studies are provided in Table 1. Three studies (Du Preez 2010; Du Preez 2011; McGuigan 2011) reported interventions to improve the quality of water, one study (Guzman 1968) reported a sanitation intervention, three studies (Ahmed 1993; Langford 2011; Luby 2004) reported interventions to improve hygiene, three studies (Arnold 2009; Bowen 2012; Luby 2006) reported a dual water quality and hygiene intervention, one study (Schlesinger 1983) reported a dual intervention on water quantity and sanitation, one study (Huttly 1990) reported an intervention including water quality, quantity and hygiene, one study (Fenn 2012) reported an intervention including water quantity, sanitation and hygiene elements, and one study (Hasan 1989) included all four WASH elements (water quality, quantity, sanitation and hygiene).

Process and implementation data were poorly reported in the included studies. Targeting and coverage was reported in four studies. Ahmed 1993 reported that $98 \%$ of the intervention group were targeted with the hygiene programme in Bangladesh. Arnold 2009 reported that "the majority" of intervention households were targeted by the intervention in Guatemala. Hasan 1989 reported $90 \%$ coverage of latrines and hygiene interventions in Bangladesh. Huttly 1990 reported 96\% coverage of boreholes in Nigeria. Adherence to intervention was reported in two studies. Du Preez 2010 reported less than 35\% adherence to a solar disinfection (SODIS) intervention in South Africa, and McGuigan 2011 reported more than $90 \%$ adherence to a SODIS in Cambodia. Study attrition was assessed for seven studies (Bowen 2012; Du Preez 2010; Du Preez 2011; Langford 2011; Luby 2004; Luby 2006; McGuigan 2011) and ranged from $16.5 \%$ (Bowen 2012) to $4 \%$ (Du Preez

Interventions to improve water quality and supply, sanitation and hygiene practices, and their effects on the nutritional status of children 
2011). The designs of the other seven studies precluded assessment of attrition.

Intervention cost was reported in one study in Bangladesh (Hasan 1989). The cost for the installation of hand pumps in Bangladesh was USD 6.89/inhabitant, for latrines was USD 4.67/inhabitant and for the hygiene education USD 3.60/inhabitant. The total cost of WASH interventions was USD 15/inhabitant.

\section{Excluded studies}

See Characteristics of excluded studies. Fifty-three studies were ex- cluded for the following reasons: incorrect study design (24 studies), no nutritional outcome (11 studies), no control group (seven studies), reporting of baseline information only (four studies) and use of an intervention not included in this review (six studies).

\section{Risk of bias in included studies}

We assessed risk of bias at outcome level for each study. For detailed information on the risk of bias of individual studies see the 'Risk of bias' tables for each study and the 'Risk of bias' summary (Figure 4). None of the included studies was considered to be at low risk of bias. 
Figure 4. 'Risk of bias' summary: review authors' judgements about each risk of bias item for each included study.

\begin{tabular}{|c|c|c|c|c|c|c|c|c|c|c|}
\hline & 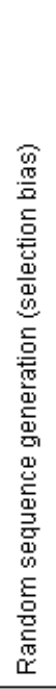 & 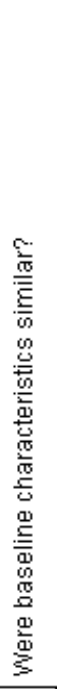 & 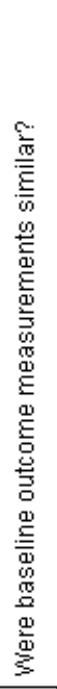 & 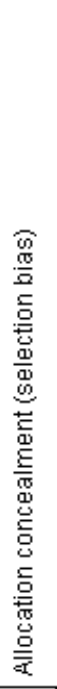 & 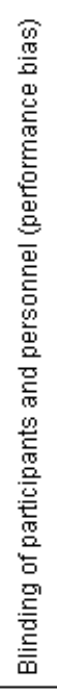 & 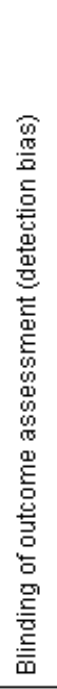 & 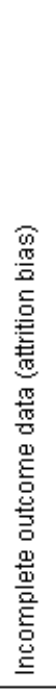 & 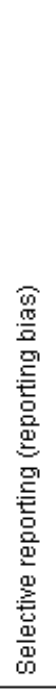 & 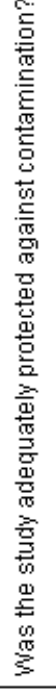 & 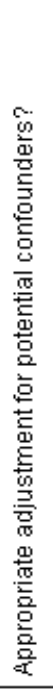 \\
\hline Anmed 1993 & 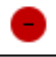 & + & + & 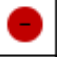 & & $?$ & $?$ & $?$ & + & $\oplus$ \\
\hline Arnold 2009 & ) & $?$ & $?$ & 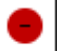 & & $?$ & $?$ & $?$ & $?$ & $\odot$ \\
\hline Bowen 2012 & + & + & ? & & & $?$ & + & $?$ & ? & $?$ \\
\hline Du Preez 2010 & 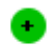 & + & 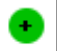 & & & $?$ & 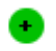 & $\odot$ & $?$ & $?$ \\
\hline Du Preez 2011 & $\oplus$ & + & + & & & $?$ & + & + & $?$ & $?$ \\
\hline Fenn 2012 & & + & + & C & & $?$ & ? & $?$ & ? & $?$ \\
\hline Guzman 1968 & & $\odot$ & $?$ & & & $?$ & $?$ & $?$ & + & $?$ \\
\hline Hasan 1989 & & - & 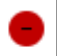 & & & $?$ & - & $?$ & $?$ & $?$ \\
\hline Huttly 1990 & & + & - & & & $?$ & - & $?$ & $?$ & $?$ \\
\hline Langford 2011 & + & + & 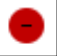 & & & $?$ & + & $?$ & - & $?$ \\
\hline Luby 2004 & + & + & ? & & & & + & & ? & $?$ \\
\hline Luby 2006 & 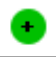 & + & ? & & & - & + & & ? & $?$ \\
\hline Luby 2006 (Floc \& Bleach) & + & + & $?$ & & & - & + & & $?$ & $?$ \\
\hline Luby 2006 (Soap) & 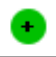 & + & ? & & & - & + & & $?$ & $?$ \\
\hline Luby 2006 (Soap \& Floc) & $\oplus$ & + & $?$ & & & 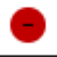 & + & - & $?$ & $?$ \\
\hline McGuigan 2011 & + & + & 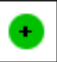 & & & - & + & 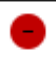 & $?$ & $?$ \\
\hline Schlesinger 1983 & & & 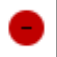 & & & $?$ & + & $?$ & ? & $?$ \\
\hline
\end{tabular}

Interventions to improve water quality and supply, sanitation and hygiene practices, and their effects on the nutritional status of children 


\section{Allocation}

We judged sequence generation to be adequate (by coin flipping and random number generation) in seven studies (Bowen 2012; Du Preez 2010; Du Preez 2011; Langford 2011; Luby 2004; Luby 2006; McGuigan 2011). None of the studies were considered at low risk of bias for allocation concealment.

\section{Blinding}

Participants were not masked from the intervention in any of the studies, and we judged all studies to be at high risk of performance bias. Insufficient information was provided to make judgements about detection bias in any of the studies and we graded all studies as unclear.

\section{Incomplete outcome data}

The designs of several of the studies, such as repeat cross-sectional studies and the cross-sectional study with the matched historical control group, precluded assessment of attrition bias. We judged eight studies to be of low risk of attrition bias (Bowen 2012; Du Preez 2010; Du Preez 2011; Langford 2011; Luby 2004; Luby 2006; McGuigan 2011; Schlesinger 1983).

\section{Selective reporting}

We assessed the trial registries and protocols (where available) of the five cluster-randomised controlled trials; we were not able to identify study protocols for the nine other studies. The trial registries or protocols of four cluster-randomised controlled trials (Du Preez 2010; McGuigan 2011; Luby 2004; Luby 2006) stated that they would collect child nutritional status information and did not report these data in the primary research publications.

\section{Other potential sources of bias}

There were no other potential sources of bias identified.

\section{Effects of interventions}

See: Summary of findings for the main comparison

Ahmed 1993 was a repeat cross-sectional study among 370 households in Bangladesh. Compared to children in the control households, a hygiene promotion intervention significantly reduced the percentage of very underweight children (weight-for-age $<-3 \mathrm{z}-$ scores) under the age of 24 months.

Arnold 2009 was a cross-sectional study with a matched historical control group among 877 children under five years of age in Guatemala. Compared to children in the historical control, a water quality and handwashing intervention had no effect on weight- for-age z-score (mean difference (MD) -0.06; 95\% confidence interval (CI) -0.23 to 0.11 ), weight-for-height $\mathrm{z}$-score (MD -0.07; 95\% CI -0.28 to 0.14 ), height-for-age z-score (MD 0.04; 95\% CI -0.19 to 0.27 ) or mid-upper arm circumference (cm) (MD -0.01; 95\% CI -0.17 to 0.15 ).

Bowen 2012 was a follow-up study conducted three years after the end of a cluster-randomised controlled trial among 461 children under five years of age in Pakistan. At the time of follow-up assessment children were eight years old. Compared to children in the control clusters, a water quality and hygiene intervention had no effect on weight-for-age z-score (MD -0.06; 95\% CI -0.27 to 0.15 ), height-for-age z-score (MD $0.08 ; 95 \% \mathrm{CI}-0.29$ to 0.27 ) or body mass index (BMI)-for-age z-score (MD 0.02; 95\% CI 0.18 to 0.22 ).

Du Preez 2010 was a cluster-randomised controlled trial among 824 children under five years of age in South Africa. Relevant nutrition outcome data were available for 332 children. Compared to children in the control arm, a water quality (SODIS) intervention had no effect on weight-for-age z-score (MD 0.21; 95\% CI -0.07 to 0.49 ), weight-for-height $\mathrm{z}$-score (MD $0.08 ; 95 \% \mathrm{CI}-0.20$ to 0.36 ) or height-for-age $\mathrm{z}$-score (MD 0.28 ; $95 \% \mathrm{CI}-0.06$ to 0.62 ). Du Preez 2011 was a cluster-randomised controlled trial among 1089 children under five years of age in Kenya. Relevant nutrition outcome data were available for 525 children. Compared to children in the control arm, a water quality (SODIS) intervention had no effect on weight-for-age z-score (MD - 0.01 ; 95\% CI - 0.23 to 0.21 ), weight-for-height $\mathrm{z}$-score (MD $-0.11 ; 95 \% \mathrm{CI}-0.30$ to 0.08 ) or height-for-age $\mathrm{z}$-score (MD $0.11 ; 95 \% \mathrm{CI}-0.19$ to 0.41 ). Fenn 2012 was a controlled before and after study among 2476 children under three years of age in Ethiopia. Compared to the children in the control areas, a water quantity, sanitation and hygiene intervention significantly improved height-for-age z-score (MD 0.22; 95\% CI 0.11 to 0.33 ).

Guzman 1968 was a longitudinal study among 312 children under five years of age in Guatemala. Height and weight of the children were measured during a sanitation intervention but no effects were reported.

Hasan 1989 was a repeat cross-sectional study among 405 children under three years of age in Bangladesh. Compared to the children in the control areas, a sanitation, water quantity, water quality and hygiene promotion intervention had no significant effect on weight-for-age, weight-for-height and height-for-age z-scores.

Huttly 1990 was a repeat cross-sectional study among 632 children under three years of age in Nigeria. In villages that received a water quantity, quality and hygiene education intervention, the percentage of children who were thin $(<80 \%$ of the median weightfor-height) declined significantly. No such decline was detected among children in the control villages.

Langford 2011 was a longitudinal study among 88 children under 
one year of age in Nepal. Compared to children in the control areas, a handwashing intervention had no effect on weight-for-age z-score (MD -0.24; 95\% CI -0.76 to 0.28), weight-for-height zscore (MD $-0.11 ; 95 \% \mathrm{CI}-0.53$ to 0.31 ) or height-for-age z-score (MD -0.13; 95\% CI -0.54 to 0.28).

Luby 2004 was a cluster-randomised controlled trial among 4961 children under five years of age in Pakistan. Relevant nutrition outcome data were available for 873 children. Compared to children in the control arm, a handwashing intervention had no effect on weight-for-age z-score (MD 0.01; 95\% CI -0.10 to 0.12), weightfor-height z-score (MD 0.03; 95\% CI -0.32 to 0.38 ) or heightfor-age $\mathrm{z}$-score (MD -0.01 ; $95 \% \mathrm{CI}-0.37$ to 0.35 ).

Luby 2006 (Soap) was a cluster-randomised controlled trial among 8949 children under five years of age in Pakistan. For this intervention arm, relevant nutrition outcome data were available for 533 children. Compared to children in the control arm, a handwashing intervention had no effect on weight-for-age z-score (MD 0.05; $95 \%$ CI -0.13 to 0.23 ), weight-for-height $\mathrm{z}$-score (MD 0.02; $95 \%$ $\mathrm{CI}-0.20$ to 0.24 ) or height-for-age z-score (MD 0.08; 95\% CI 0.13 to 0.29 ).

Luby 2006 (Soap \& Floc) was a cluster-randomised controlled trial among 8949 children under five years of age in Pakistan. For this intervention arm, relevant nutrition outcome data were available for 549 children. Compared to children in the control arm, a handwashing and water quality intervention had no effect on weight-for-age z-score (MD 0.07; 95\% CI-0.11 to 0.25), weightfor-height $\mathrm{z}$-score (MD 0.06 ; $95 \% \mathrm{CI}-0.16$ to 0.28 ) or heightfor-age $\mathrm{z}$-score (MD 0.06 ; $95 \% \mathrm{CI}-0.12$ to 0.24 ).

Luby 2006 (Floc \& Bleach) was a cluster-randomised controlled trial among 8949 children under five years of age in Pakistan. For this intervention arm, relevant nutrition outcome data were available for 1055 children. Compared to children in the control arm, a water quality intervention had no effect on weight-for-age $\mathrm{z}$-score (MD 0.03 ; 95\% CI -0.12 to 0.18 ), weight-for-height $\mathrm{z}$ score (MD $0.02 ; 95 \%$ CI -0.20 to 0.24 ) or height-for-age z-score (MD 0.04; $95 \%$ CI -0.08 to 0.16 ).

McGuigan 2011 was a cluster-randomised controlled trial among 928 children under five years of age in Cambodia. Relevant nutrition outcome data were available for 760 children. Compared to children in the control arm, a water quality (SODIS) intervention had no effect on weight-for-age z-score (MD 0.26; 95\% CI -0.01 to 0.53 ), weight-for-height $\mathrm{z}$-score (MD $0.15 ; 95 \% \mathrm{CI}-0.15$ to
0.45 ) or height-for-age z-score (MD $0.22 ; 95 \%$ CI -0.04 to 0.48 ). Schlesinger 1983 was a longitudinal study among 209 children under four years of age in Chile. In households that received a sanitation and water supply intervention, the percentage of underweight children (defined as a deficit for age of $10 \%$ or more below the 50th percentile of National Center for Health Statistics (NCHS) reference) did not change, while in control households the percentage of underweight children increased significantly. The 'Summary of findings' table (Summary of findings for the main comparison) lists the results of those randomised and nonrandomised studies that reported primary review outcomes, with the pooled estimate. Descriptive forest plots include a maximum of nine studies (four non-randomised and five randomised studies) on the following primary review outcomes: weight-for-age z-score, weight-for-height $\mathrm{z}$-score and height-for-age $\mathrm{z}$-score, and on the following secondary review outcomes: weight and height. Studies not included in descriptive forest plots tended to be older and either did not report outcomes in a metric appropriate for the review (Ahmed 1993; Guzman 1968; Huttly 1990; Schlesinger 1983) or incompletely reported relevant outcomes (Hasan 1989). Of the five studies not included in the forest plots, three reported a significant benefit of water, sanitation and hygiene (WASH) interventions on measures of weight in children (Ahmed 1993; Huttly 1990; Schlesinger 1983), one reported no effect (Hasan 1989) and one did not report an outcome (Guzman 1968).

\section{Weight-for-age z-score}

Weight-for-age z-score data were reported in three non-randomised studies and available for five cluster-randomised controlled trials (Figure 5). No effect on weight-for-age z-score was reported in the three non-randomised studies (Arnold 2009; Bowen 2012; Langford 2011). Meta-analysis conducted only on data from the five cluster-randomised controlled trials (Du Preez 2010; Du Preez 2011; Luby 2004; Luby 2006 (Floc \& Bleach); Luby 2006 (Soap); Luby 2006 (Soap \& Floc); McGuigan 2011) including 4627 children aged under five years (Analysis 1.2; Figure 6) identified no evidence of an effect of WASH interventions on weightfor-age $\mathrm{z}$-score (MD 0.05; 95\% CI -0.01 to 0.12 ). There was no evidence of between-study heterogeneity $\left(\mathrm{I}^{2}=0 \%\right)$. Individual participant data (IPD) meta-analysis including 5386 children identified no evidence of an effect of WASH on weight-for-age zscore (MD 0.10 z-score; $95 \%$ CI -0.04 to 0.25 ). 
Figure 5. Forest plot of comparison: Weight-for-age (all studies)

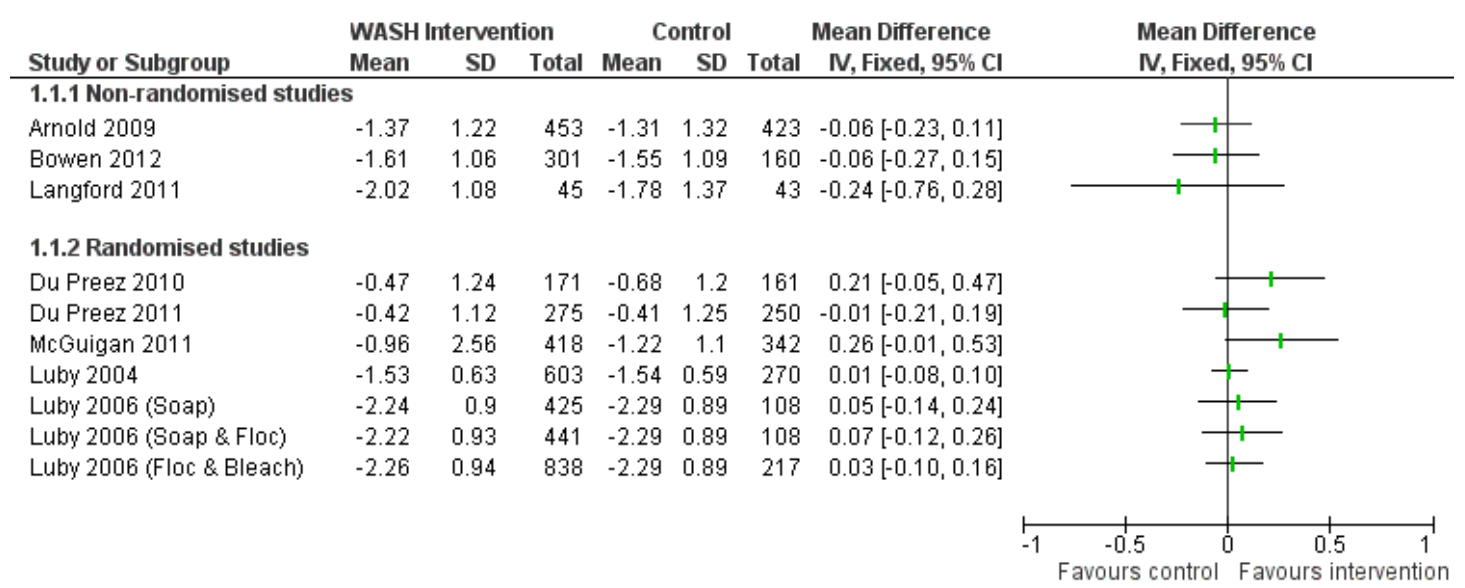

Figure 6. Forest plot of comparison: Weight-for-age (RCTs only)

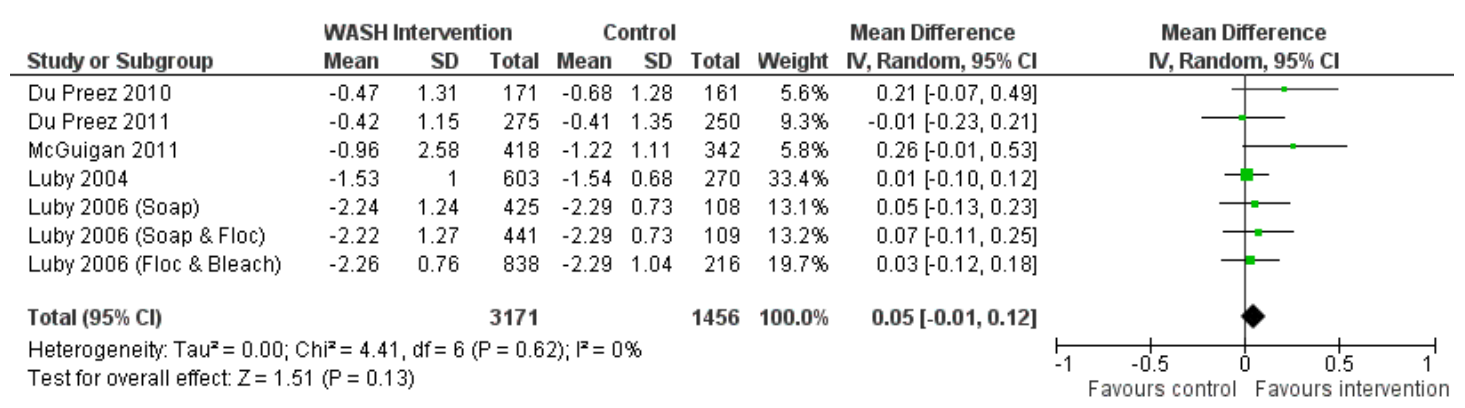

\section{Weight-for-height z-score}

Weight-for-height z-score data were reported in two non-randomised studies and available for five cluster-randomised controlled trials (Figure 7). No effect on weight-for-height z-score was reported in the two non-randomised studies (Arnold 2009; Langford 2011). Meta-analysis conducted only on data from the five cluster-randomised controlled trials (Du Preez 2010; Du Preez 2011; Luby 2004; Luby 2006 (Floc \& Bleach); Luby 2006 (Soap);
Luby 2006 (Soap \& Floc); McGuigan 2011) including 4622 children aged under five years (Analysis 2.2; Figure 8) identified no evidence of an effect of WASH interventions on weight-for-height z-score (MD 0.02; 95\% CI -0.07 to 0.11). There was no evidence of between-study heterogeneity $\left(\mathrm{I}^{2}=0 \%\right)$. IPD meta-analysis including 5375 children identified no evidence of an effect of WASH on weight-for-height z-score (MD $0.10 \mathrm{z}$-score; $95 \%$ CI -0.09 to $0.23)$. 
Figure 7. Forest plot of comparison: Weight-for-height (all studies)

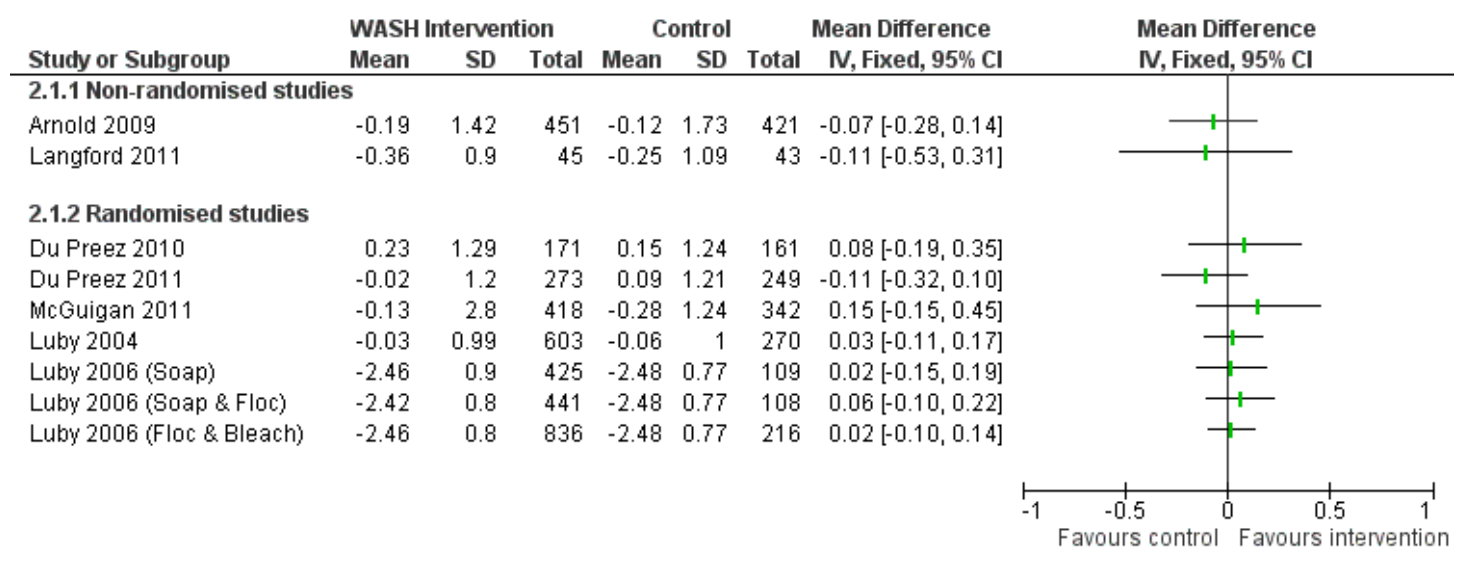

Figure 8. Forest plot of comparison: Weight-for-height (RCTs only)

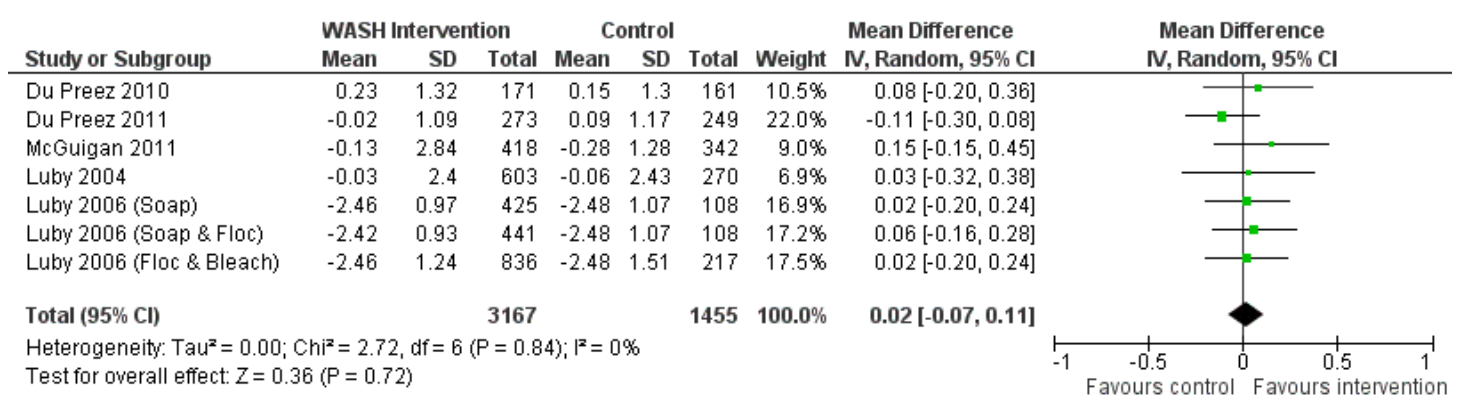

\section{Height-for-age z-score}

Height-for-age z-score data were reported in four non-randomised studies and available for five cluster-randomised controlled trials (Figure 9). No effect on height-for-age z-score was reported in three of the non-randomised studies (Arnold 2009; Bowen 2012; Langford 2011), an increase in height-for-age z-score (MD 0.22; $95 \%$ CI 0.11 to 0.33 ) was reported by Fenn 2012. Meta-analysis conducted only on data from the five cluster-randomised con- trolled trials (Du Preez 2010; Du Preez 2011; Luby 2004; Luby 2006 (Floc \& Bleach); Luby 2006 (Soap); Luby 2006 (Soap \& Floc); McGuigan 2011) including 4627 children aged under five years (Analysis 3.2; Figure 10) identified a borderline statistically significant effect of WASH interventions on height-for-age z-score (MD 0.08; 95\% CI 0.00 to 0.16 ). There was no evidence of between-study heterogeneity $\left(\mathrm{I}^{2}=0 \%\right)$. IPD meta-analysis including 5386 children identified a statistically significant effect of WASH on height-for-age z-score (MD 0.11 z-score; $95 \%$ CI 0.03 to 0.18 ).

Interventions to improve water quality and supply, sanitation and hygiene practices, and their effects on the nutritional status of children 20 (Review) 
Figure 9. Forest plot of comparison: Height-for-age (all studies)

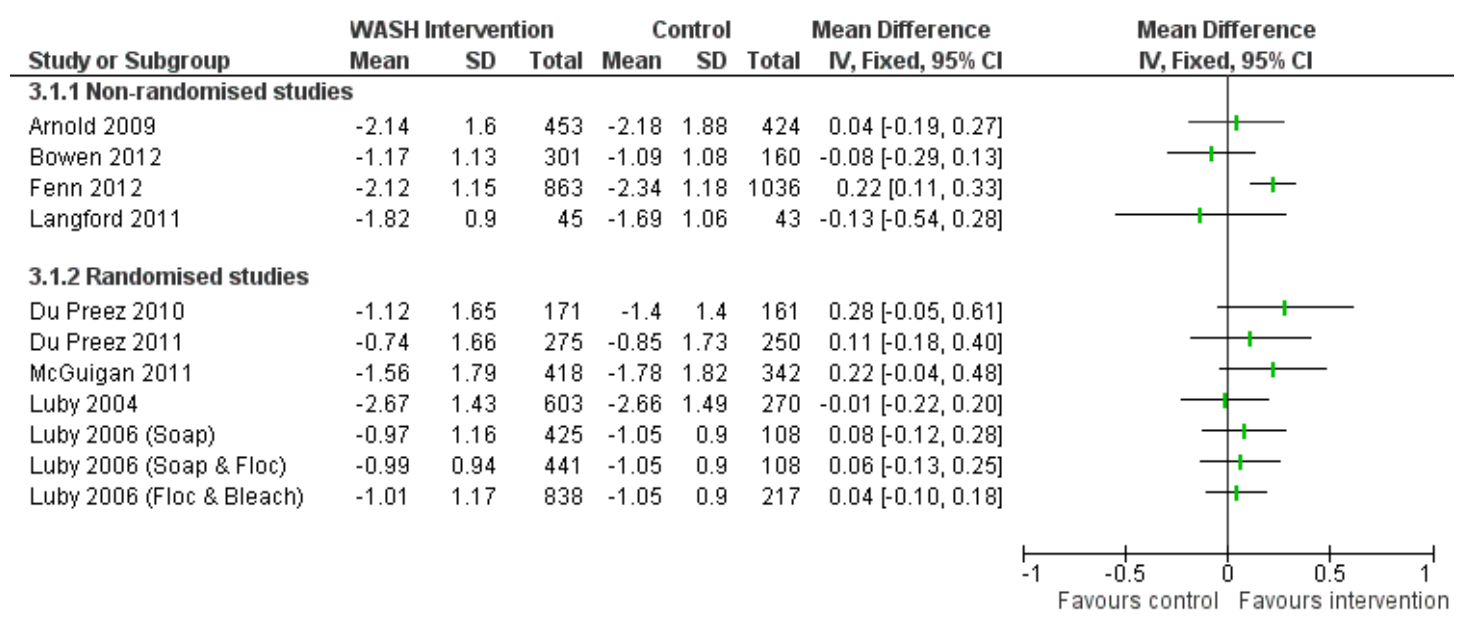

Figure 10. Forest plot of comparison: Height-for-age (RCTs only)

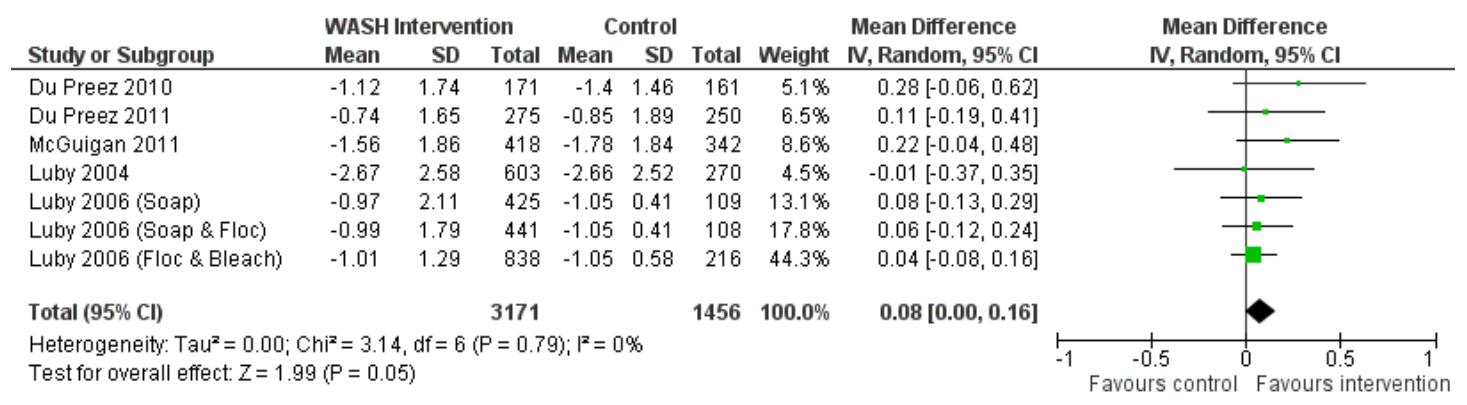

\section{Subgroup analysis}

Subgroup analyses carried out using the aggregated data suggest that there is no effect of age group (two years and under; two to five years) on weight-for-age and weight-for-height, and no evidence of an effect of gender on weight-for-height.

Subgroup analyses suggest no evidence of an effect on weight-forage for boys (MD $0.00 ; 95 \%$ CI -0.07 to 0.08 ), but demonstrated some evidence of an effect for girls (weight-for-age MD $0.11 ; 95 \%$ CI 0.01 to 0.21 ) (Analysis 1.3; Figure 11). Similarly, subgroup analyses suggest no evidence of an effect on height-for-age for boys (MD $-0.01 ; 95 \% \mathrm{CI}-0.09$ to 0.08 ), but demonstrated some evidence of an effect for girls (height-for-age MD 0.14; 95\% CI 0.04 to 0.25 ) (Analysis 3.3; Figure 12).

Interventions to improve water quality and supply, sanitation and hygiene practices, and their effects on the nutritional status of children 2 I (Review)

Copyright $\odot 2013$ The Cochrane Collaboration. Published by John Wiley \& Sons, Ltd. 
Figure I I. Forest plot of comparison: I Weight-for-age, outcome: I.3 Weight-for-age (gender).

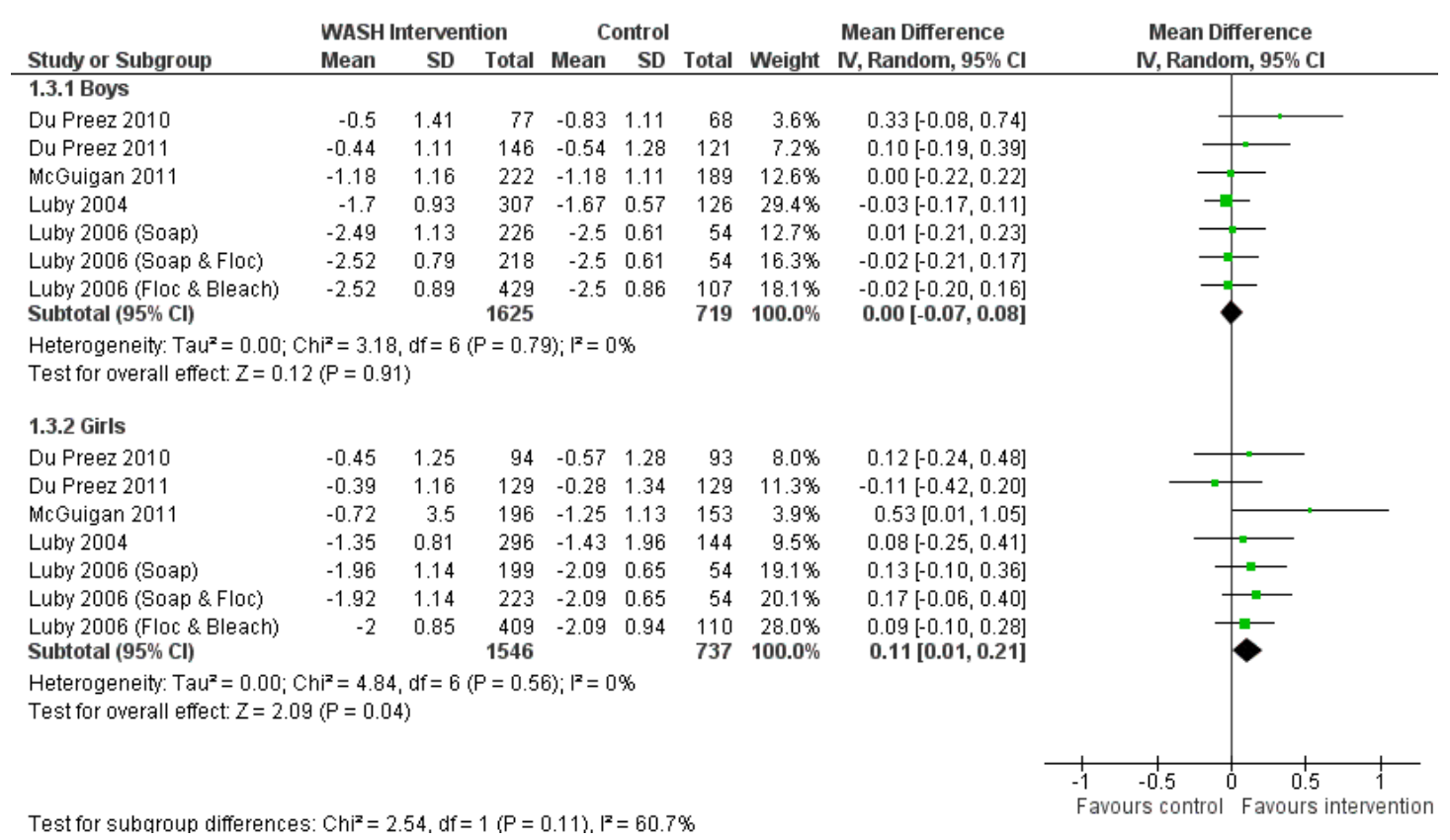

Figure 12. Forest plot of comparison: 3 Height-for-age, outcome: 3.3 Height-for-age (gender).

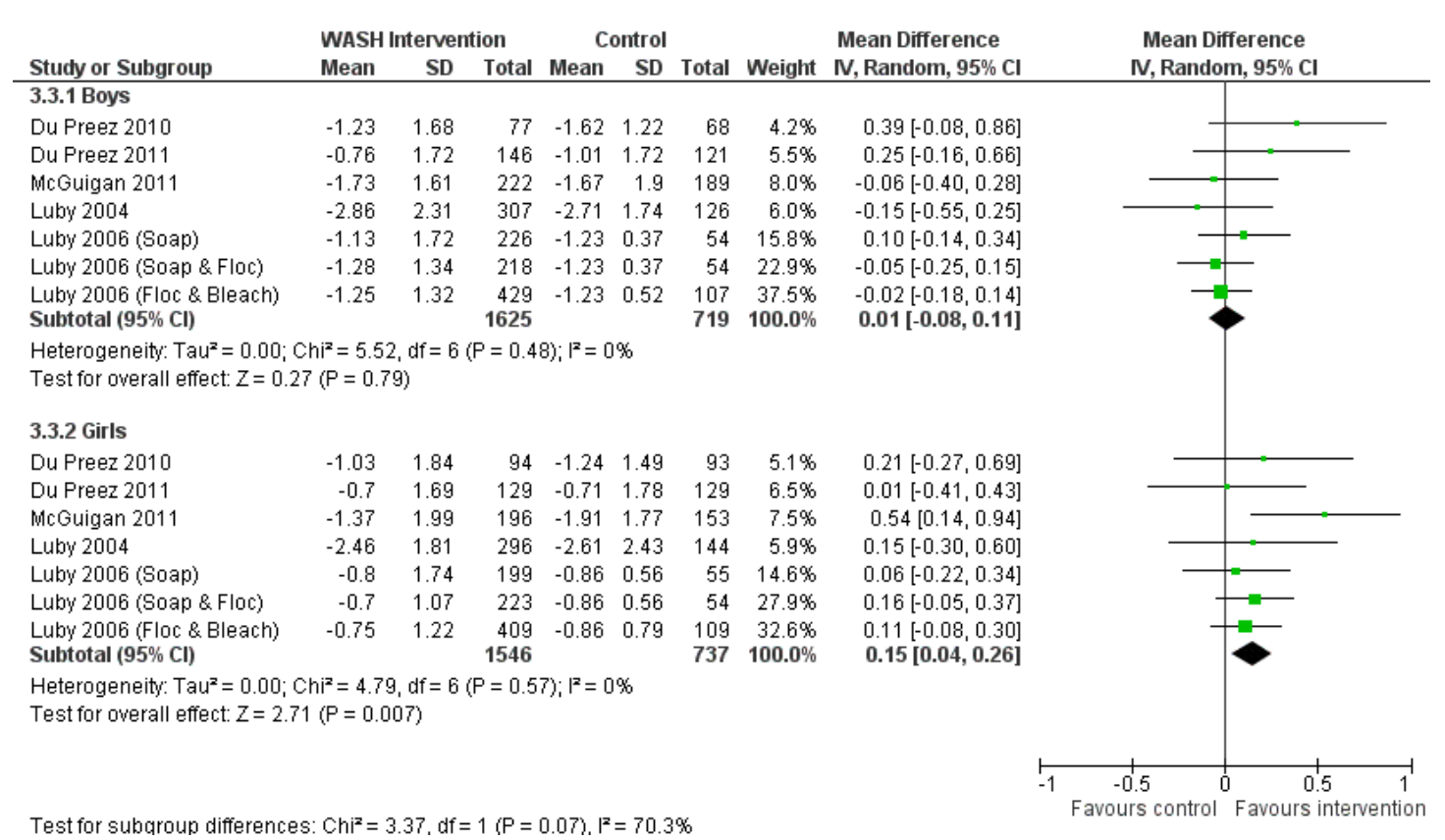

Interventions to improve water quality and supply, sanitation and hygiene practices, and their effects on the nutritional status of children 22 
Subgroup analyses identified no evidence of an effect on heightfor-age for children aged two years and under years (MD 0.05; $95 \%$ CI -0.13 to 0.22 ), but demonstrated some evidence of an effect for children aged over two years (height-for-age MD 0.06; 95\% CI 0.00 to 0.12 ) (Analysis 3.4; Figure 13).

Figure 13. Forest plot of comparison: 3 Height-for-age, outcome: 3.4 Height-for-age (age group).

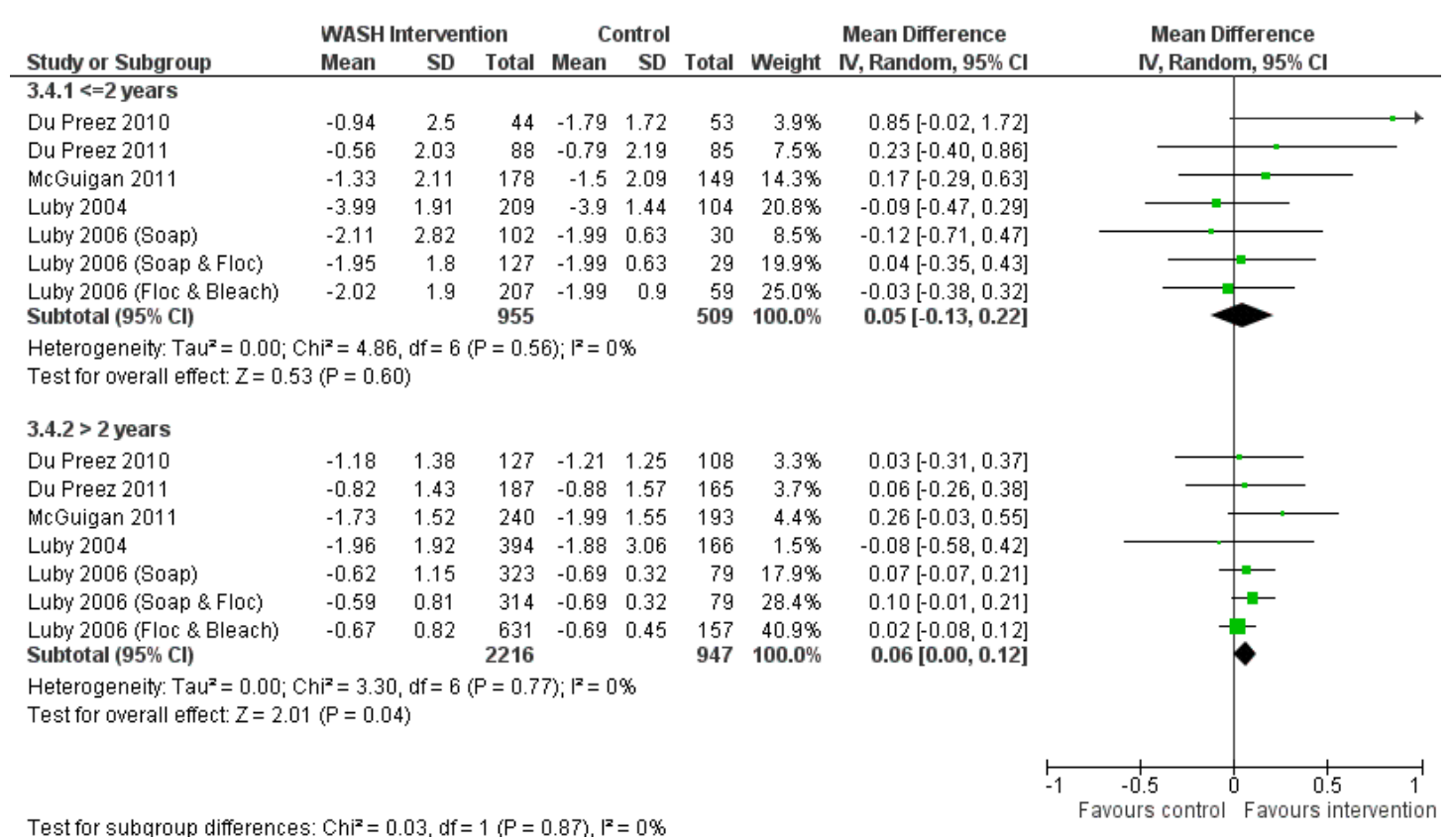

These apparent differences identified by aggregated analysis are not supported by the IPD analysis. Formal interaction tests between WASH interventions and gender were not significant at the $5 \%$ level for either weight-for-age or height-for-age. IPD analysis did, however, find a significant interaction between WASH interventions and gender for weight-for-height $(P=0.032)$, suggesting that the intervention may be more effective for girls even though the results from the corresponding stratified analyses were not statistically significant.

IPD analysis among 5386 children identified significant interactions between age group and treatment for weight-for-age $(\mathrm{P}=$ $0.002)$, suggesting that the intervention may have a greater effect on weight gain for those children aged over two years (MD two years and under: $0.01 ; 95 \% \mathrm{CI}-0.15$ to 0.16 ; MD over two years: $0.14,95 \%$ CI -0.01 to 0.28$)$.

Significant interactions were identified between age group and treatment for weight-for-height $(\mathrm{P}<0.001)$, suggesting that the intervention may have a greater effect on weight gain for those children aged over two years (MD two years and under: -0.13 ,
$95 \%$ CI -0.31 to 0.05 ; MD over two years: $0.17,95 \%$ CI 0.01 to $0.34)$.

Significant interactions were also identified between age group and height-for-age $(\mathrm{P}<0.001)$, suggesting that the intervention may have a greater effect on height growth in children aged two years and under (MD two years and under: $0.25,95 \%$ CI 0.14 to 0.35 ; MD over two years: $0.03,95 \%$ CI -0.05 to 0.12 ).

The differences in the findings between the two approaches to the subgroup analysis are unsurprising given the difference in the numbers included. In addition, the IPD analysis looks at the change in the outcome from baseline and adjusts for other factors. The confidence intervals presented in the IPD stratified analyses are estimated directly from the model with the interaction term included.

Analysis by other pre-specified subgroups was precluded as all of the studies in the review were six months or longer in duration, conducted in low- or middle-income countries, conducted in a mixture of rural, peri-urban and urban locations, and only one

Interventions to improve water quality and supply, sanitation and hygiene practices, and their effects on the nutritional status of children 23 
study included children aged over five years.

\section{Other reported nutritional outcomes}

Weight was reported in three non-randomised studies and available for five cluster-randomised controlled trials (Figure 14). Metaanalysis conducted only on data from the five cluster-randomised controlled trials including 4627 children aged under five years (Analysis 4.2; Figure 15) identified no evidence of an effect of WASH interventions on weight $(\mathrm{kg})$ (MD $0.12 ; 95 \%$ CI -0.03 to $0.27)$. There was no evidence of between-study heterogeneity $\left(\mathrm{I}^{2}=\right.$ $0 \%)$. IPD meta-analysis identified no statistically significant effect of WASH on weight (kg) (MD 0.23; 95\% CI -0.02 to 0.49).

Figure 14. Forest plot of comparison: Weight (all studies)

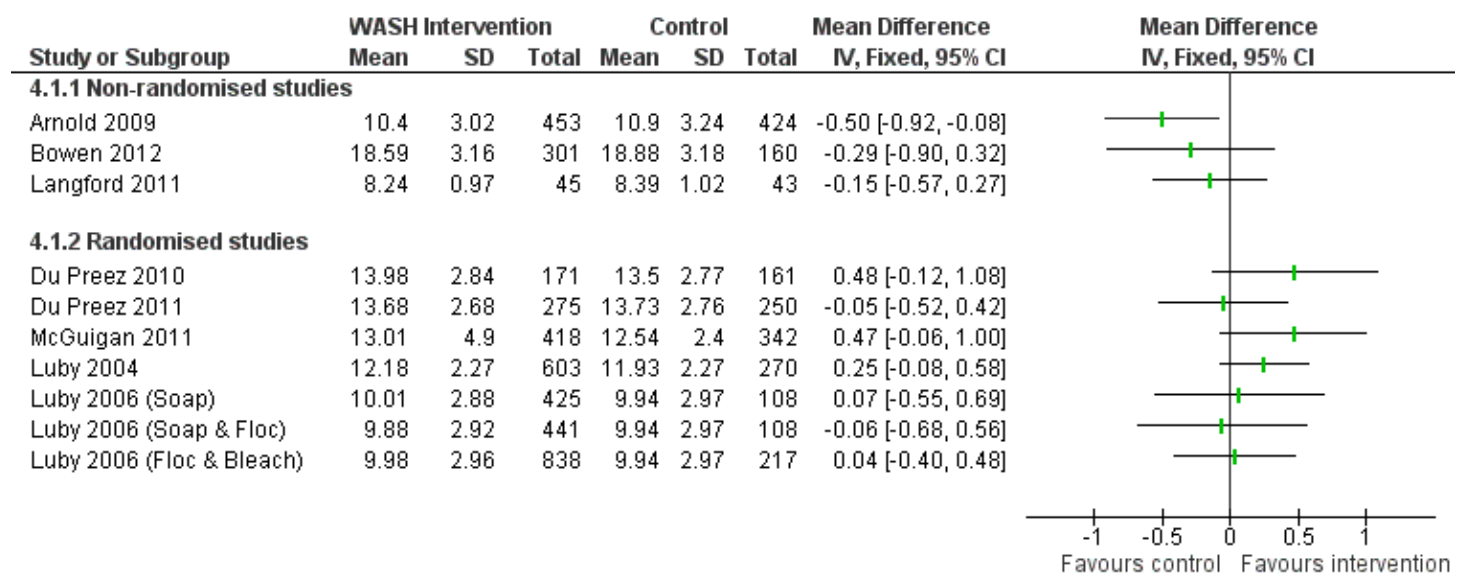

Figure I5. Forest plot of comparison: Weight (RCTs only)

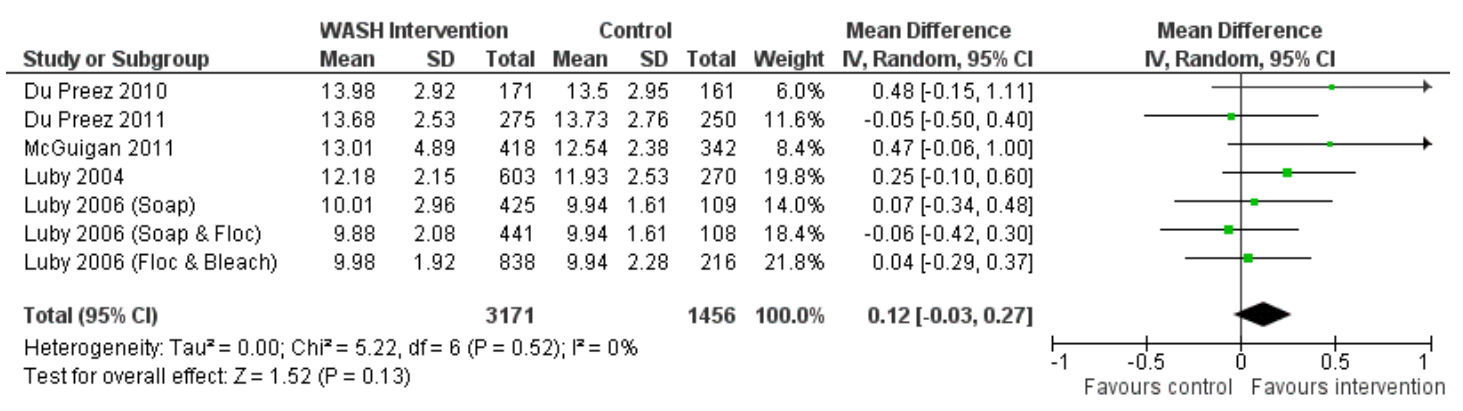

Interventions to improve water quality and supply, sanitation and hygiene practices, and their effects on the nutritional status of children 24 
Height was reported in three non-randomised studies and available for five cluster-randomised controlled trials (Figure 16). Metaanalysis conducted only on data from the five cluster-randomised controlled trials including 4627 children aged under five years (Analysis 5.2; Figure 17) identified no evidence of an effect of WASH interventions on height (cm) (MD 0.50; 95\% CI -0.10 to 1.10$)$. There was no evidence of between-study heterogeneity $\left(\mathrm{I}^{2}=0 \%\right)$. IPD meta-analysis identified a statistically significant effect of WASH on height (cm) (MD 0.53; 95\% CI 0.20 to 0.86).

Figure 16. Forest plot of comparison: Height (all studies)

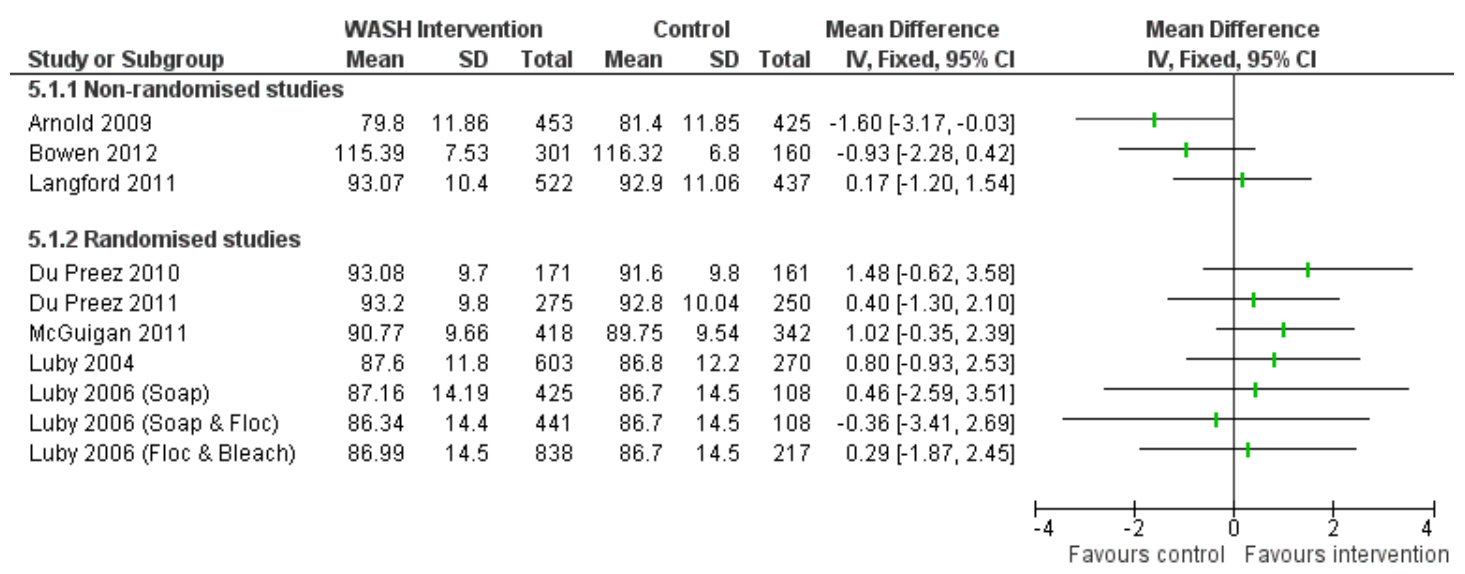

Figure I7. Forest plot of comparison: Height (RCTs only)

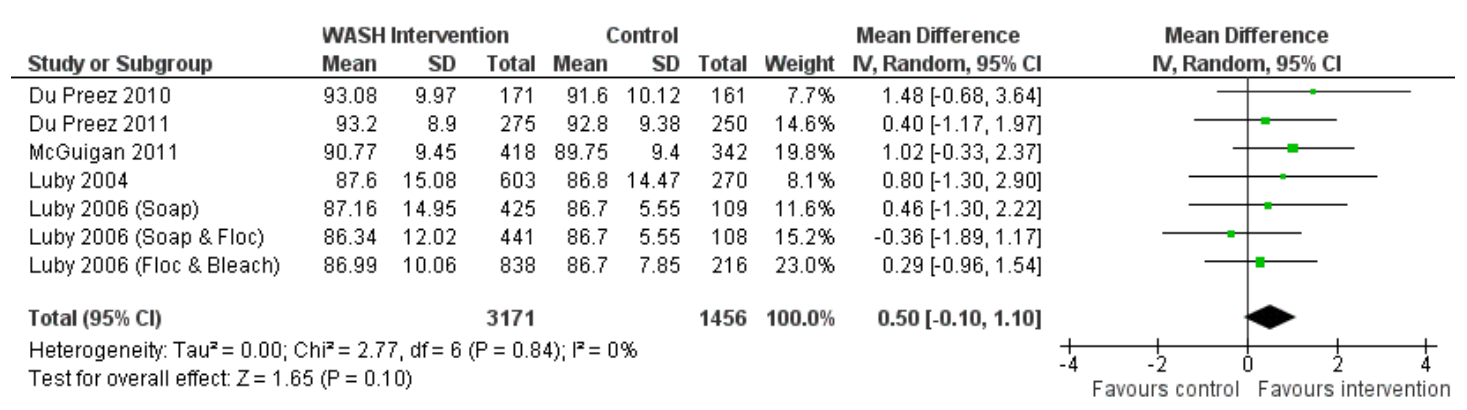

Mid-upper arm circumference was reported for 877 children under five years in one non-randomised study (Arnold 2009). There is no evidence of an effect of WASH interventions on mid-upper arm circumference (cm) (MD - 0.01 ; 95\% CI -0.17 to 0.15$)$. BMI was reported for 461 children under eight years in a follow-up evaluation of a cluster-randomised controlled trial (Bowen 2012). There is no evidence of an effect of WASH interventions on BMI $\left(\mathrm{kg} / \mathrm{m}^{2}\right.$ ) (mean difference $0.02 ; 95 \%$ CI -0.18 to 0.22 ). Blood haemoglobin concentration was reported for 461 children under

Interventions to improve water quality and supply, sanitation and hygiene practices, and their effects on the nutritional status of children 25 
eight years of age in a follow-up evaluation of a cluster-randomised controlled trial (Bowen 2012). The haemoglobin concentration of those of children in the control arm was significantly higher than those among children in the two intervention arms.

\section{DISCUSSION}

\section{Summary of main results}

Fourteen studies involving a total of 22,241 children at baseline, and nutrition outcome data for 9,469 children, are included in this review. The review included five cluster-randomised controlled trials, one three-year follow-up of a cluster-randomised controlled trial and eight non-randomised studies with comparison groups. Studies included various water, sanitation and hygiene (WASH) interventions either singly or in combination that aimed to improve the quality and quantity of water, and improve sanitation and hygiene. We assessed none of the studies included in the review to be at low risk of bias; several studies had multiple potential risks of bias, and all of the studies failed to mask the WASH intervention from participants. The primary review outcomes weight-forage, weight-for-height and height-for age were available from nine studies. Study-level and individual participant data (IPD) metaanalysis was limited to data from five cluster-randomised controlled trials that had durations of 9 to 12 months. In this metaanalysis of data from cluster-randomised controlled trials, WASH interventions (specifically solar disinfection of water, provision of soap, and improvement of water quality) were shown to slightly but significantly improve height-for-age z-scores in children under 5 years of age. In subgroup analysis of data from cluster-randomised controlled trials there was some evidence to suggest a difference in effect by gender and age group, with girls more responsive than boys in weight and height growth to WASH interventions, height growth more responsive to WASH interventions in children under 24 months of age, and weight growth more responsive to WASH interventions in children 25-60 months of age.

\section{Overall completeness and applicability of evidence}

There is suggestive evidence from cluster-randomised controlled trials of a small benefit of WASH interventions on measures of growth in childhood. The evidence from the five cluster-randomised controlled trials included in meta-analysis relates to water quality (SODIS and disinfection by bleach and flocculent disinfectant), hygiene (handwashing with soap), and an intervention including a combination of water quality (flocculent disinfectant) and hygiene (handwashing with soap). Three of the cluster-randomised controlled trials tested solar disinfection of drinking water and the findings of these trials have generated research interest (Arnold 2012; Hunter 2012). There is no evidence of the effect of other WASH interventions on nutritional outcomes in children and a major gap in the literature concerns the effect of water supply and sanitation interventions on nutrition outcomes. Nonrandomised studies provided mixed evidence on the effect of a variety of WASH interventions on nutrition outcomes. All interventions were conducted in children under the age of five years and there is no evidence of the effect of WASH interventions in children older than five years of age. All studies were conducted in low- or middle-income countries and there is no evidence of the effect of WASH interventions on children living in high-income countries. Few studies reported process and implementation data. Adherence to study interventions was reported in only two studies (Du Preez 2010; McGuigan 2011) (both cluster-randomised controlled trials) and ranged from low $(<35 \%)$ to high $(>90 \%)$; both of these studies had a follow-up time of 12 months. Study attrition was assessed in seven studies, ranging from $4 \%$ (Du Preez 2011) to $16.5 \%$ (Bowen 2012). The five cluster-randomised controlled trials included in meta-analysis were of relatively short duration (9 to 12 months) and there is no evidence available on longer-term impact or adherence to WASH interventions.

Further studies designed to measure the impact of WASH interventions on nutritional status outcomes in children are needed. The first 1000 days of life (from conception to age two years) are thought to be critical in determining growth performance in children. Future studies of the effect of WASH on nutritional status in children may benefit from a focus on early childhood growth from birth to age two years.

\section{Quality of the evidence}

The review contained reports of the effect of WASH interventions evaluated using a variety of study designs including five clusterrandomised controlled trials. We assessed none of the studies to have high methodological quality. Overall the quality of the evidence is low and further research is likely to have an important impact on confidence in the estimate and is likely to change the estimate of the effect. There are five large randomised controlled trials underway which may help improve the quality of the available evidence.

\section{Potential biases in the review process}

Every effort was made to conduct this review to the highest standards recommended in the Cochrane Handbook for Systematic Reviews of Interventions and The Cochrane Collaboration's Methodological Expectations of Cochrane Intervention Reviews criteria. Protocols were not available for most of the studies included in the review and it was therefore not possible fully to assess any potential biasses in reporting. However, during the process of the review four studies were identified that collected but did not report nutritional outcomes in children. It is possible that other studies, which we did not identify, collected data on child nutritional status that

Interventions to improve water quality and supply, sanitation and hygiene practices, and their effects on the nutritional status of children 26 
we have been unable to include in this review.

\section{Agreements and disagreements with other studies or reviews}

This is the first review looking at the impact of WASH interventions on child nutritional status.

\section{AUTHORS' CONCLUSIONS}

\section{Implications for practice}

This review provides evidence that some water, sanitation and hygiene (WASH) interventions (specifically solar disinfection of water, provision of soap, and improvement of water quality) may slightly improve height growth in children under five years of age. The quality of the evidence is generally poor and the overall estimates presented are based only on meta-analyses of data from interventions of relatively short-duration (9-12 months) from only a small selection of possible WASH interventions. These estimates are therefore not applicable to the effect that wider WASH interventions may have on child nutritional status.

\section{Implications for research}

This review has identified the paucity of rigorous evidence evaluating the effect of WASH interventions on child nutritional status. Several high-quality trials are currently ongoing, the results of which will contribute significantly to the existing evidence base linking WASH interventions to child nutritional status outcomes.

Further research questions relate to the mechanism of action of the WASH interventions. There is no evidence on long-term adherence to WASH interventions, the optimal timing of interventions in childhood or the required duration of interventions to have the greatest impact on childhood nutrition outcomes.

\section{ACKNOW LEDGEMENTS}

The authors would like to thank the review advisory team, Rebecca Stotzfus and Annette Prüss-Üstün.

This research was made possible with UK aid from the Department of International Development (DFID) as part of the SHARE research programme (www.SHAREresearch.org). The views expressed do not necessarily reflect the Department's official policies.

\section{R E F E R E N C E S}

\section{References to studies included in this review}

Ahmed 1993 \{published data only\}

* Ahmed NU, Zeitlin MF, Beiser AS, Super CM, Gershoff SN. A longitudinal study of the impact of behavioural change intervention on cleanliness, diarrhoeal morbidity and growth of children in rural Bangladesh. Social Science \& Medicine 1993;37(2):159-71.

Ahmed NU, Zeitlin MF, Beiser AS, Super CM, Gershoff $\mathrm{SN}$, Ahmed MA. Assessment of the impact of a hygiene intervention on environmental sanitation, childhood diarrhoea, and the growth of children in rural Bangladesh. Food and Nutrition Bulletin 1994;15:40-52.

Arnold 2009 \{published data only (unpublished sought but not used)\} Arnold B, Arana B, Mausezahl D, Hubbard A, Colford JM. Evaluation of a pre-existing, 3-year household water treatment and handwashing intervention in rural Guatemala. International Journal of Epidemiology 2009;38 (6):1651-61.

Bowen 2012 \{published and unpublished data\} Bowen A, Agboatwalla M, Luby S, Tobery T, Ayers T, Hoekstra RM. Association between intensive handwashing promotion and child development in Karachi, Pakistan. Archives of Pediatric \& Adolescent Medicine 2012;166(11): 1037-44.
Du Preez 2010 \{published and unpublished data\} Du Preez M, McGuigan KG, Conroy RM. Solar disinfection of drinking water in the prevention of dysentery in South African children aged under 5 years: the role of participant motivation. Environmental Science \& Technology 2010;44 (22):8744-9.

Du Preez 2011 \{published and unpublished data\} du Preez M, Conroy RM, Ligondo S, Hennessy J, ElmoreMeegan M, Soita A, et al.Randomized intervention study of solar disinfection of drinking water in the prevention of dysentery in Kenyan children aged under 5 years. Environmental Science \& Technology 1990;45(21):9315-23.

Fenn 2012 \{published data only\} Fenn B, Bulti AT, Nduna T, Duffield A, Watson F. An evaluation of an operations research project to reduce childhood stunting in a food-insecure area in Ethiopia. Public Health Nutrition 2012;15(9):1746-54. [DOI: 10.1017/S1368980012001115]

Guzman 1968 \{published data only\} Guzman MA, Scrimshaw NS, Bruch HA, Gordon JE. Nutrition and infection field study in Guatemalan villages, 1958-1964. VII. Physical growth and development of preschool children. Archives of Environmental Health 1968; 17(1):107-18.

Hasan 1989 \{published data only\} Aziz KM, Hoque BA, Huttly SR. Water supply, sanitation

Interventions to improve water quality and supply, sanitation and hygiene practices, and their effects on the nutritional status of children 27 (Review)

Copyright (C) 2013 The Cochrane Collaboration. Published by John Wiley \& Sons, Ltd. 
and hygiene education: report of a health impact study in Mirzapur, Bangladesh. WASH Report Series, Water and Sanitation Program. UNDP/World Bank, 1990.

* Hasan KZ, Briend A, Aziz KM, Hoque BA, Patwary MY, Huttly SR. Lack of impact of a water and sanitation intervention on the nutritional status of children in rural Bangladesh. European Journal of Clinical Nutrition 1989;43 (12):837-43.

Huttly 1990 \{published data only\}

Ajala M, Akujobi C, Blum D, Cairncross S, Carson D, Dosunmu-Ogunbi $\mathrm{O}$, et al.Evaluating water and sanitation projects: Lessons from Imo State, Nigeria. Health Policy and Planning 1989;4(1):40-9.

* Huttly SR, Blum D, Kirkwood BR, Emeh RN, Okeke $\mathrm{N}$, Ajala M, et al.The Imo State (Nigeria) drinking water supply and sanitation project, 2. Impact on dracunculiasis, diarrhoea and nutritional status. Transactions of the Royal Society of Tropical Medicine \& Hygiene 1990;84(2):316-21.

Langford 2011 \{published data only (unpublished sought but not used)\}

Langford R, Lunn P, Panter-Brick C. Hand-washing, subclinical infections, and growth: a longitudinal evaluation of an intervention in Nepali slums. American Journal of Human Biology 2011;23(5):621-9.

Luby 2004 \{published and unpublished data\}

Luby SP, Agboatwalla M, Painter J, Altaf A, Billhimer WL, Hoekstra RM. Effect of intensive handwashing promotion on childhood diarrhoea in high-risk communities in Pakistan: a randomised controlled trial. JAMA 2004;291 (21):2547-54

Luby 2006 \{published and unpublished data\}

Luby SP, Agboatwalla M, Painter J, Altaf A, Billhimer W, Keswick B, et al.Combining drinking water treatment and hand washing for diarrhoea prevention, a cluster randomised controlled trial. Tropical Medicine and International Health 2006;11(4):479-89.

Luby 2006 (Floc \& Bleach) \{published and unpublished data\} Luby SP, Agboatwalla M, Painter J, Altaf A, Billhimer W, Keswick B, et al.Combining drinking water treatment and hand washing for diarrhoea prevention, a cluster randomised controlled trial. Tropical Medicine and International Health 2006;11(4):479-89.

Luby 2006 (Soap) \{published and unpublished data\} Luby SP, Agboatwalla M, Painter J, Altaf A, Billhimer W, Keswick B, et al.Combining drinking water treatment and hand washing for diarrhoea prevention, a cluster randomised controlled trial. Tropical Medicine and International Health 2006;11(4):479-89.

Luby 2006 (Soap \& Floc) \{published and unpublished data\} Luby SP, Agboatwalla M, Painter J, Altaf A, Billhimer W, Keswick B, et al.Combining drinking water treatment and hand washing for diarrhoea prevention, a cluster randomised controlled trial. Tropical Medicine and International Health 2006;11(4):479-89.
McGuigan 2011 \{published and unpublished data\}

McGuigan KG, Samaiyar P, Du Preez M, Conroy R. A high compliance randomised controlled field trial of solar disinfection (SODIS) of drinking water and its impact on childhood diarrhoea in rural Cambodia. Environmental Science \& Technology 2011;45(18):7862-7.

Schlesinger 1983 \{published data only\} Schlesinger L, Weinberger J, Figueroa G, Secure T, González N, Mónckeberg F. Environmental sanitation: a nutrition intervention. Nutrition Intervention Strategies in National Development. Underwood Academy. Academic Press, Inc., 1983:241.

\section{References to studies excluded from this review}

Anderson 1981 \{published data only\}

Anderson MA. Health and nutrition impact of potable water in rural Bolivia. Journal of Tropical Pediatrics 1981;27 (7):39-46.

Anon, 1981 \{published data only\}

Anon. Infections as deterrents of child growth. Nutrition Reviews 1981;39(9):328-30.

Anon, 1990 \{published data only\}

Anon. Child health: its relationship with water supplies and hygiene practices in rural Sri Lanka. Tropical Medicine and Parasitology 1990;41(1):77-120.

Barros 2008 \{published data only\}

Barros AJD, Santos IS, Matijasevich A, Araujo CL, Gigante DP, Menezes AMB, et al.Methods used in the 1982, 1993, and 2004 birth cohort studies from Pelotas, Rio Grande do Sul State, Brazil, and a description of the socio-economic conditions of participants' families. Cadernos de Saude Publica 2008;24 Suppl 3:S371-80.

Buttenheim 2008 \{published data only\} Buttenheim A. The sanitation environment in urban slums: implications for child health. Population \& Environment 2008;30(1/2):26-47.

Checkley 2004 \{published data only\} Checkley W, Gilman RH, Black RE, Epstein LD, Cabrera L, Sterling CR, et al.Effect of water and sanitation on childhood health in a poor Peruvian peri-urban community. Lancet 2004;363(9403):1128.

Chen 2005 \{published data only\} Chen Y, Xu L. Impact of hands cleanliness on diminution of Ascardes lumbricoides reinfection in pupils. China Journal of Parasitology Disease Control 2005;18(2):132-3.

Chiang 1991 \{published data only\} Chiang A, Hernandez E, Figueras F, Maleras DM, Rodriguez X. Effect of the water supply on the nutritional state of children under 5 years old in rural locations. Revista Cubana de Alimentacion y Nutricion 1991;5(1):56-9.

Chirwa 2008 \{published data only\} Chirwa EW, Ngalawa HP. Determinants of child nutrition in Malawi. South African Journal of Economics 2008;76(4): 628-40.

Interventions to improve water quality and supply, sanitation and hygiene practices, and their effects on the nutritional status of children 28 
Cousens 1990 \{published data only\}

Cousens SN, Mertens TE, Fernando MA. The anthropometric status of children in Kurunegala district in Sri Lanka: its relation to water supply, sanitation and hygiene practice. Tropical Medicine \& Parasitology 1990;41 (1):105-14.

Daniels 1991 \{published data only\}

Daniels DL, Cousens SN, Makoae LN, Feachem RG. A study of the association between improved sanitation facilities and children's height in Lesotho. European Journal of Clinical Nutrition 1991;45(1):23-32.

Dong 2009 \{published data only\}

Dong X, Xu W, Li L. Effect of handwashing intervention on kindergarten children in Tianjin. Chinese Journal of School Health 2009

Esrey 1988 \{published data only\}

Esrey SA, Habicht JP, Latham MC, Sisler DG, Casella G. Drinking water source, diarrhoeal morbidity, and child growth in villages with both traditional and improved water supplies in rural Lesotho, southern Africa. American Journal of Public Health 1988;78(11):1451-5.

Esrey 1992 \{published data only\}

Esrey SA, Habicht JP, Casella G. The complementary effect of latrines and increased water usage on the growth of infants in rural Lesotho. American Journal of Epidemiology 1992;135(6):659-66.

Esrey 1996 \{published data only\}

Esrey SA. Water, waste, and well-being: a multi-country study. American Journal of Epidemiology 1996;143(6): $608-23$.

Etiler 2004 \{published data only\} Etiler N, Velipasaoglu S, Aktekin, M. Risk factors for overall and persistent diarrhoea in infancy in Antalya, Turkey: a cohort study. Public Health 2004;118(1):62-9.

Farah 2007 \{published data only\}

Farah N, Samina S, Ali SS. Effects of water and sanitation on childhood nutrition in Pakistan. Pakistan Paediatric Journal 2007;31(2):69-74.

Fernandez 1969 \{published data only\}

Fernandez NA, Burgos JC, Asenjo CF, Rosa IR. Nutrition survey of two rural Puerto Rican areas before and after a Community Improvement Program. American Journal of Clinical Nutrition 1969;22:1639-51.

Fikree 2000 \{published data only\} Fikree FF, Rahbar MH, Berendes HW. Risk factors for stunting and wasting at age six, twelve and twenty-four months for squatter children of Karachi, Pakistan. Journal of the Pakistan Medical Association 2000;50(10):341-8.

Gokhale 1994 \{published data only\}

Gokhale MK, Chiplonkar SA, Sukhatme PV. Effect of environmental factors on growth and morbidity of urban Montessori children receiving supplementation. Ecology of Food and Nutrition 1994;31(3/4):269-76.

Guerrant 1983 \{published data only\}

Guerrant RL, Kirchhoff LV, Shields DS. Prospective study of diarrhoeal illness in northeastern Brazil: Patterns of disease, nutritional impact, etiologies, and risk factors. Journal of Infectious Diseases 1983;148(6):986-97.

Hartinger 2011a \{published data only\}

Hartinger S, Hattendorf J, Lanata C, Gil A, Verastegui $\mathrm{H}$, Mausezahl D. Integrating home-based environmental interventions (IHIP): A community-randomised trial to improve indoor air pollution, drinking water quality and child nutrition in rural Peru. Tropical Medicine and International Health. Conference: 7th European Congress on Tropical Medicine and International Health Barcelona Spain 2011;6:354-5.

Hartinger 2011b \{published data only\}

Hartinger SM, Lanata CF, Hattendorf J, Gil AI, Verastegui $\mathrm{H}$, Ochoa $\mathrm{T}$, et al.A community randomised controlled trial evaluating a home-based environmental intervention package of improved stoves, solar water disinfection and kitchen sinks in rural Peru: Rationale, trial design and baseline findings. Contemporary Clinical Trials 2011;32(6): 864-73.

Hebert 1984 \{published data only\}

Hebert JR. Water quality and water quantity and wasting in south India. Tropical \& Geographical Medicine 1984;36(4): 375-81.

Hebert 1985a \{published data only\}

Hebert JR. Effects of components of sanitation on nutritional status: findings from South Indian settlements. International Journal of Epidemiology 1985;14(1):143-52.

Hebert 1985b \{published data only\}

Hebert JR. Effects of water quality and water quantity on nutritional status: Findings from a south Indian community. Bulletin of the World Health Organization 1985; 63(1): $145-55$.

Henry 1981 \{published data only\}

Henry FJ. Environmental sanitation infection and nutritional status of infants in rural St. Lucia, West Indies. Transactions of the Royal Society of Tropical Medicine \& Hygiene 1981;75(4):507-13.

Hoek 2002 \{published data only\}

Hoek W, van der Feenstra SG, Konradsen F. Availability of irrigation water for domestic use in Pakistan: its impact on prevalence of diarrhoea and nutritional status of children. Journal of Health, Population and Nutrition 2002;20(1): 77-84.

Hou 2010 \{published data only\}

Hou C, Fu G, Zeng Q, Liu H. Studies on the effect of changing water in high water-iodine area in Tianjin. Chinese Journal of the Control of Endemic Disease 2010;25(6):444-5.

Li 1996 \{published data only\}

Li FJ, Ou QY, Huang DJ, Liu ZE, Li SM. A study on prevention of diarrhoeal diseases and improvement of case management in children of Hunan province. Disease Surveillance 1996;12(3):87-9.

Lindskog 1987 \{published data only\} Lindskog U, Lindskog P, Gebre-Medhin M. Child health and household water supply: a longitudinal study of

Interventions to improve water quality and supply, sanitation and hygiene practices, and their effects on the nutritional status of children 29

(Review)

Copyright (c) 2013 The Cochrane Collaboration. Published by John Wiley \& Sons, Ltd. 
growth and its environmental determinants in rural Malawi. Human Nutrition - Clinical Nutrition 1987;41(6):409-23.

Lindskog 1988 \{published data only\}

Lindskog U, Lindskog P, Carstensen J, Larsson Y, GebreMedhin M. Childhood mortality in relation to nutritional status and water supply--a prospective study from rural Malawi. Acta Paediatrica Scandinavica 1988;77(2):260-8.

Lindskog 1994 \{published data only\}

Lindskog U, Bjorksten B, Gebre-Medhin M. Infant care in rural Malawi. A prospective study of morbidity and growth in relation to environmental factors. Annals of Tropical Paediatrics 1994;14(1):37-45.

Lopez de Romana 1989 \{published data only\} Lopez de Romana G, Brown KH, Black RE, Kanashiro HC. Longitudinal studies of infectious diseases and physical growth of infants in Huascar, an underprivileged peri-urban community in Lima, Peru. American Journal of Epidemiology 1989;129(4):769-84.

Lye 1984 \{published data only\}

Lye MS. Diarrhoeal diseases in rural Malaysia: risk factors in young children. Annals of the Academy of Medicine 1984; 13(2):156-62.

Ma 2007 \{published data only\}

$\mathrm{Ma} \mathrm{H}$, Bowen A, Ou JM, Zeng G . Evaluating effect of handwashing intervention among primary students of counties in Fujian Province. Chinese Journal of Public Health 2007;23(8):989-91.

Malekafzali 2000 \{published data only\}

Malekafzali H, Abdollahi Z, Mafi A, Naghavi M. Community-based nutritional intervention for reducing malnutrition among children under 5 years of age in the Islamic Republic of Iran. Eastern Mediterranean Health Journal 2000;6(2/3):238-45.

Merchant 2003 \{published data only\}

Merchant AT, Jones C, Kiure A, Kupka R, Fitzmaurice G, Herrera MG, et al.Water and sanitation associated with improved child growth. European Journal of Clinical Nutrition 2003;57:1562-8.

Moy 1991 \{published data only\}

Moy RJ, Booth IW, Choto RG, McNeigh AS. Early growth faltering in rural Zimbabwean children. Central African Journal of Medicine 1991;37(9):275-82.

Nisbet 1974 \{published data only\}

Nisbet BR. The effect of fluoridation of the water supply on the growth of children. Health Bulletin 1974;32(4):140-6.

Parent 2002 \{published data only\}

Parent G, Zagre NM, Ouedraogo A, Guiguembe TR. Are large-scale water facilities in Burkina Faso helping to improve child nutrition?. Cahiers Agricultures 2002;11(1): $51-7$.

Sanou 2011 \{published data only\} Sanou D, Turgeon-O'Brien H, Desrosiers T. Impact of an integrated nutrition intervention on nutrient intakes, morbidity and growth of rural Burkinabe preschool children. African Journal of Food, Agriculture, Nutrition and Development 2011;11(4):4968-84.

Stoler 2011 \{published data only\}

Stoler J, Fink G, Weeks JR, Otoo RA, Ampofo JA, Hill AG. When urban taps run dry: Sachet water consumption and health effects in low income neighbourhoods of Accra, Ghana. Health \& Place 2011;18(2):250-62.

Wang 2010 \{published data only\} Wang M, Li H, Wu R, Zhang GQ, Li J, Li XJ, et al.Survey on resident's iodine level in high iodine area after taking low iodine water in Shouguang City. Preventive Medicine Tribune 2010;16(11):1010-1.

Xiong 2010 \{published data only\}

Xiong M, Dong Y, Zhang Y, et al.Survey of results of modification of toilets in rural areas of Yunnan Province in control of schistosomiasis. China Tropical Medicine 2010; 10(3):300-4.

Xu 2001 \{published data only\}

Xu LQ, Xiao DH, Zhou CH, Zhang XQ, Lan SG, Zhen $\mathrm{XX}$, et al.Cleanliness of hands in diminution of Ascardes lumbricoides infection in children. Chinese Journal of Parasitology \& Parasitic Diseases 2001;19(5):294.

Yang 2006 \{published data only\} Yang SM, Zhao XH, Yang JJ, Zhang GY, Yang JY. Hygiene evaluation of the program of child environment and environmental sanitation in Gansu province. Health, Occupation and Education 2006;24(1):135-6.

Yao 2000 \{published data only\}

Yao H, Chen Y, Liu K, et al.Studies on the levels of iron, magnesium, copper and zinc in serum among population after water improvement for 10 years in areas with endemic Fluorosis-Arsenism. Journal of Environment \& Health 2000; 17(2):98-9.

Zhang 1999 \{published data only\}

Zhang TJ, Wang SL, Wang JR. Evaluation of the effect of health education intervention to prevent diarrhoea among children under 5 years old. Chinese Journal of Health Education 1999;15(7):19-21.

Zhang 2000 \{published data only\} Zhang W, Liu M, Yin W, Zhang H, Li G, Liu L, et al.Evaluation of a long-term effect on improving drinking water and lavatories in rural areas for prevention of diseases. Chinese Journal of Disease Control \& Prevention 2000;4(1): $76-8$.

Zhang 2012 \{published data only\}

Zhang J. The impact of water quality on health: evidence from the drinking water infrastructure program in rural China. Journal of Health Economics 2012;31(1):122-34.

Zhu 1997a \{published data only\} Zhu XL, Du XM, Xue JR, Wang JJ. Macro effects of improving lavatories to prevent diseases in population of trial rural areas. Chinese Journal of Public Health 1997;13 (7):420-1.

Zhu 1997b \{published data only\} Zhu XL, Xia QY, Meng ZY, Wang XC, Shao BC, Yang SY, et al.Assessment of effects of disease prevention by 
intervention measures of school environmental hygiene in rural areas. Journal of Hygiene Research 1997;6:378-80.

\section{References to ongoing studies}

SHARE \{published data only\}

Clasen T, Boisson S, Routray P, Cumming O, Jenkins M, Ensink JHJ, et al.The effect of improved rural sanitation on diarrhoea and helminth infection: design of a clusterrandomised trial in Orissa, India. Emerging Themes in Epidemiology 2012;9(1):7.

SHINE \{published data only\}

Johns Hopkins Bloomberg School of Public Health. Sanitation, Hygiene, Infant Nutrition Efficacy Project (SHINE). http://clinicaltrials.gov/ct2/show/ NCT01824940.

WASH Benefits \{published data only\} Innovations for Poverty Action. WASH Benefits Bangladesh: A Cluster Randomized Controlled Trial of the Benefits of Water, Sanitation, Hygiene Plus Nutrition Interventions on Child Growth. http://clinicaltrials.gov/ show/NCT01590095;. [: NCT01590095]

Innovations for Poverty Action. WASH Benefits Kenya: A Cluster Randomized Controlled Trial of the Benefits of Sanitation, Water Quality, Handwashing, and Nutrition Interventions on Child Health and Development. http:// www.clinicaltrials.gov/ct2/show/NCT01704105.

WSP - Handwashing \{published data only\}

No reference available. Global Scaling Up Handwashing Project. http://www.wsp.org/global-initiatives/globalscaling-handwashing-project.

WSP - Sanitation \{published data only\} No reference available. Global Scaling Up Sanitation Project. http://www.wsp.org/global-initiatives/globalscaling-sanitation-project.

\section{Additional references}

\section{Arnold 2012}

Arnold BF, Ma“ usezahl D, Schmidt W-P, Christen A, Colford JM Jr. Comment on randomised intervention study of solar disinfection of drinking water in the prevention of dysentery in Kenyan children aged under 5 years. Environmental Science and Technology 2012;46(5):3031-2.

\section{Black 2013}

Black RE, Victora CG, Walker SP, Bhutta ZA, Christian P, de Onis $\mathrm{M}$, et al.Maternal and child undernutrition and overweight in low-income and middle-income countries. Lancet 2013 Jun 6 [Epub ahead of print]. [DOI: 10.1016/ S0140-6736(13)60937-X]

\section{Briend 1990}

Briend A. Is diarrhoea a major cause of malnutrition among the under-fives in developing countries? A review of available evidence. European Journal of Clinical Nutrition 1990;44(9):611-28.

\section{Checkley 2008}

Checkley W, Buckley G, Gilman RH, Assis AMO, Guerrant RL, Morris SS, et al.Multi-country analysis of the effects of diarrhoea on childhood stunting. International Journal of Epidemiology 2008;37(4):816.

Clasen 2006

Clasen TF, Roberts IG, Rabie T, Schmidt WP, Cairncross $S$. Interventions to improve water quality for preventing diarrhoea. Cochrane Database of Systematic Reviews 2006, Issue 3. [DOI: 10.1002/14651858.CD004794.pub2]

Clasen 2010

Clasen TF, Bostoen K, Schmidt WP, Boisson S, Fung IC, Jenkins MW, et al.Interventions to improve disposal of human excreta for preventing diarrhoea. Cochrane Database of Systematic Reviews 2010, Issue 6. [DOI: 10.1002/ 14651858.CD007180.pub2]

Ejemot 2008

Ejemot RI, Ehiri JE, Meremikwu MM, Critchley JA. Hand washing for preventing diarrhoea. Cochrane Database of Systematic Reviews 2008, Issue 1. [DOI: 10.1002/ 14651858.CD004265.pub2]

FAO 2010

Food, Agriculture Organisation. State of food insecurity in the world. Food and Agriculture Organisation of the United Nations 2010.

Fung 2008 Fung ICH. Chinese journals: a guide for epidemiologists. Emerging Themes in Epidemiology 2008;5(1):20.

\section{Guerrant 2008}

Guerrant RL, Oriá RB, Moore SR, Oriá MOB, Lima AAM. Malnutrition as an enteric infectious disease with long-term effects on child development. Nutrition Reviews 2008;66 (9):487-505.

\section{Higgins 2011}

Higgins JPT, Green S (editors). Cochrane Handbook for Systematic Reviews of Interventions Version 5.1.0 [updated March 2011]. The Cochrane Collaboration, 2011. Available from www.cochrane-handbook.org.

Humphrey 2009 Humphrey JH. Child undernutrition, tropical enteropathy, toilets, and handwashing. Lancet 2009;374(9694):1032-5.

\section{Hunter 2012}

Hunter PR, Bartram J, Cairncross S. Comment on randomised intervention study of solar disinfection of drinking water in the prevention of dysentery in Kenyan children aged under 5 years. Environmental Science and Technology 2012;46(5)(5):3035; author reply 3036-7.

Pruss-Ustun 2006 Pruss-Ustun A, Corvalan C. Preventing disease through healthy environments. Geneva: WHO, 2006.

RevMan 2012

The Nordic Cochrane Centre, The Cochrane Collaboration. Review Manager (RevMan). 5.2. Copenhagen: The Nordic Cochrane Centre, The Cochrane Collaboration, 2012.

Interventions to improve water quality and supply, sanitation and hygiene practices, and their effects on the nutritional status of children 3 I 


\section{SCN 2004}

SCN. 5th report on the world nutrition situation: nutrition for improved development outcomes. United Nations Standing Committee on Nutrition 2004.

UNICEF/WHO/World Bank 2012

United Nations Children's Fund, World Health Organization, The World Bank. UNICEF-WHO-World Bank joint child malnutrition estimates. UNICEF, New York; WHO, Geneva; The World Bank, Washington, DC, 2012.

\section{WHO/UNICEF 2012}

WHO/UNICEF. WHO/UNICEF Joint Monitoring

Programme (JMP) Report 2012 update. Joint Monitoring

Programme for Water Supply and Sanitation (http://

www.wssinfo.org/flieadmin/user upload/resources/JMP-report-

2012-en.pdf). Geneva and New York: World Health

Organization and United Nations Children's Fund, 2012.

* Indicates the major publication for the study 


\section{CHARACTERISTICS OFSTUDIES}

\section{Characteristics of included studies [ordered by study ID]}

\begin{tabular}{ll} 
Ahmed 1993 & \\
\hline Methods & $\begin{array}{l}\text { Study design: repeat cross-sectional (c/s) study between } 2 \text { clusters, each composed of } 5 \\
\text { villages }\end{array}$ \\
\hline Participants & $\begin{array}{l}\text { Sample size: } 207 \text { children aged } 9 \text { to } 18 \text { mo at baseline } \\
\text { Country: rural Bangladesh } \\
\text { Method of participant selection: area identified due to poor sanitary conditions and } \\
\text { high prevalence of diarrhoea and malnutrition. Census carried out in selected villages to } \\
\text { identify and recruit all households with children < } 19 \text { mo } \\
\text { Description of participants: children aged } 9 \text { to } 18 \text { mo living in the selected villages, } \\
\text { mean age: } 13.0 \text { mo (baseline)/13.7 mo (final). Different children surveyed at baseline } \\
\text { and endline. Households lived in small huts with earthen courtyard - roof structure } \\
\text { varied with SES. Earth surfaces in courtyard used for raising livestock, domestic work, } \\
\text { childcare etc. Household heads engaged in farming, trading, fishing, day labour and } \\
\text { salaried jobs; mothers processed food, cooked, cleaned and cared for children and more } \\
\text { than half of households did not own cultivable land }\end{array}$ \\
\hline
\end{tabular}

Interventions

Aim: to reduce childhood diarrhoea by modifying hygiene behaviours (using positive deviance approach)

Description of intervention: Hygiene promotion intervention - based on positive deviance approach, campaign called 'Porichchhana Jibon' (clean life). Proposed behaviours identified by study authors and implemented on 3 levels: project workers, volunteers and the rest of the community

Description of control: no intervention

Duration: 6 mo (February to July 1986)

Intervention uptake: varied from $85 \%$ to $98 \%$ for different themes

Coverage: intervention: $98 \%$ in intervention group were targeted; $97 \%$ control

Adherence: not stated

Cost: not stated

Process and implementation factors: not stated

Growth (WAZ); mothers' knowledge of hygiene/sanitation; sanitation (using a sanitation scale developed using reports and observations i.e. frequency with which mother puts a mat or sack on the ground underneath her child to prevent contact with earth when playing, cleanliness of play area, how quickly mother cleans baby of its faeces and her hands after, etc); baby's contact with faeces based on mother's recall; observed dryness of play area; prevalence of diarrhoea in past 2 weeks; acute respiratory infections (ARI)

Notes

Risk of bias

\begin{tabular}{|c|}
\hline Bias \\
\hline
\end{tabular}

Random sequence generation (selection High risk

No random sequence generation bias)

Interventions to improve water quality and supply, sanitation and hygiene practices, and their effects on the nutritional status of children 


\section{Ahmed 1993 (Continued)}

\begin{tabular}{|c|c|c|}
\hline Were baseline characteristics similar? & Low risk & $\begin{array}{l}\text { Baseline characteristics were similar across } \\
\text { all outcomes }\end{array}$ \\
\hline $\begin{array}{l}\text { Were baseline outcome measurements sim- } \\
\text { ilar? }\end{array}$ & Low risk & Adequate \\
\hline Allocation concealment (selection bias) & High risk & $\begin{array}{l}\text { Intervention and control groups were se- } \\
\text { lected by the researchers }\end{array}$ \\
\hline $\begin{array}{l}\text { Blinding of participants and personnel } \\
\text { (performance bias) } \\
\text { All outcomes }\end{array}$ & High risk & No blinding \\
\hline $\begin{array}{l}\text { Blinding of outcome assessment (detection } \\
\text { bias) } \\
\text { All outcomes }\end{array}$ & Unclear risk & No information provided \\
\hline $\begin{array}{l}\text { Incomplete outcome data (attrition bias) } \\
\text { All outcomes }\end{array}$ & Unclear risk & Not possible due to study design \\
\hline Selective reporting (reporting bias) & Unclear risk & No study protocol available \\
\hline $\begin{array}{l}\text { Was the study adequately protected against } \\
\text { contamination? }\end{array}$ & Low risk & $\begin{array}{l}\text { Adequate - sites were } 5 \mathrm{~km} \text { apart and only } \\
\text { accessible by a } 2 \text {-hour boat ride for most of } \\
\text { the year, and by a } 1.5 \mathrm{hr} \text { walk for the winter } \\
\text { months }\end{array}$ \\
\hline $\begin{array}{l}\text { Appropriate adjustment for potential con- } \\
\text { founders? }\end{array}$ & Low risk & $\begin{array}{l}\text { Analysis adjusted for age, sex, household } \\
\text { wealth, agriculture wealth and mother's ed- } \\
\text { ucation }\end{array}$ \\
\hline
\end{tabular}

\section{Arnold 2009}

\begin{tabular}{ll} 
Methods & $\begin{array}{l}\text { Study design: c/s }(2007) \text { with intervention and control (2002 census data) matched } \\
\text { by propensity score matching. Study included } 30 \text { villages }(15 \text { each for intervention } \\
\text { and control) with } 20 \text { households in each village selected through stratified systematic } \\
\text { sampling }\end{array}$ \\
\hline Participants & $\begin{array}{l}\text { Sample size: } 929 \text { children aged } \leq 5 \text { years from } 600 \text { households }(300 \text { each for intervention } \\
\text { and control) } \\
\text { Country: rural Guatemala } \\
\text { Method of participant selection: Intervention: villages chosen from a pool of } 90 \text { that } \\
\text { received the intervention from } 2003-2006 \text {. Control: villages from same area that did not } \\
\text { receive intervention, matched by propensity score matching based on pre-intervention } \\
\text { characteristics. Intervention and control villages were included in this study if } 2002 \\
\text { census information was available and had }>50 \text { children }<5 \text { years. Included households } \\
\text { had at least } 1 \text { child }<5 \text { years living in the home and have been living in the village prior } \\
\text { to the start of the intervention }\end{array}$
\end{tabular}

Interventions to improve water quality and supply, sanitation and hygiene practices, and their effects on the nutritional status of children 34 
Description of participants: households with children aged $\leq 5$ years living in villages that had received a NGO-led intervention. The region was dry and mountainous with villages accessed by dirt roads. Agriculture was primary occupation: corn, beans and coffee. Taps, where available, were connected to gravity-fed spring networks, and water sources were typically contaminated with faecal organisms. $67.8 \%$ houses had tap water, the remainder obtained water from community taps or surface water

Interventions

Aim: to assess water treatment behaviour, basic hygiene knowledge and practices, and child health, 6 mo after the conclusion of the intervention

Description of intervention: Water quality and hygiene - promotion of boiling, solar disinfection and chlorination; promotion of handwashing with soap. Intervention used "train the trainer" model, where NGO technicians trained local community women to promote the behaviour change through social marketing and household visits. Approximately 1 community promoter was recruited per 25 participating households. The trained promoters visited eligible households monthly or bi-monthly

Description of control: no intervention

Duration: 36 mo intervention (2003 to 2006). This study was conducted 6 mo after conclusion of the programme (April to June 2007)

Intervention uptake: $8.7 \%$ (intervention) versus 3.3\% (control) households confirmed to be using water treatment at the time of the survey visit; self report was $33.3 \%$ (intervention) versus $21.0 \%$ (control)

Coverage: no formal records but NGO staff suggested that the majority of eligible households targeted by the programme participated

Adherence: not stated

Cost: not stated

Process and implementation factors: not stated

Outcomes

Primary outcomes: diarrhoea, clinical acute lower respiratory-tract infections (ALRI) and child growth (height, weight and mid-upper-arm circumference)

Secondary outcomes: water storage practices, self reported water treatment; confirmed water treatment; self reported handwashing; spot-check observations on hygiene; illness

Notes

Risk of bias

Bias Authors' judgement

Random sequence generation (selection High risk bias)

Were baseline characteristics similar?

Unclear risk

ilar?

\section{Support for judgement}

No random sequence generation

To help increase comparability between intervention and control groups, restriction and propensity score matching based on pre-intervention characteristics was used to select intervention and control villages

Pre-intervention values not available

Interventions to improve water quality and supply, sanitation and hygiene practices, and their effects on the nutritional status of children 
Arnold 2009 (Continued)

\begin{tabular}{l|ll}
\hline Allocation concealment (selection bias) & High risk & $\begin{array}{l}\text { Allocation concealment not possible due to } \\
\text { the nature of the study }\end{array}$ \\
\hline $\begin{array}{l}\text { Blinding of participants and personnel } \\
\text { (performance bias) } \\
\text { All outcomes }\end{array}$ & High risk & No blinding \\
\hline $\begin{array}{l}\text { Blinding of outcome assessment (detection } \\
\text { bias) } \\
\text { All outcomes }\end{array}$ & Unclear risk & No information provided \\
\hline $\begin{array}{l}\text { Incomplete outcome data (attrition bias) } \\
\text { All outcomes }\end{array}$ & Unclear risk & Not possible due to study design \\
\hline $\begin{array}{l}\text { Selective reporting (reporting bias) } \\
\text { Was the study adequately protected against } \\
\text { contamination? }\end{array}$ & Unclear risk & Unclear risk \\
\hline $\begin{array}{l}\text { Appropriate adjustment for potential con- } \\
\text { founders? }\end{array}$ & Low risk & No study protocol available \\
\hline
\end{tabular}

Bowen 2012

Methods

Study design: follow-up study (2009) of a cluster-randomised control trial carried out in 2003. Evaluation in 2009 among 461 households (301 intervention ( 2 arms combined) , 160 control)

Participants

Sample size: 461 children aged $<96$ mo (2009)

Country: urban Pakistan. Multiethnic squatter settlements in Karachi

Method of participant selection: households were identified for the 2009 study by local field workers. Eligible households had a child $<5$ years, at least $1 \mathrm{hr}$ of running water twice weekly and had not received soap or water treatment in previous studies. Households with children $<96$ mo were re-enrolled in the 2009 study

Description of participants: children aged $<96$ mo living in households that were enrolled in the study in 2003

Interventions

Aim: to evaluate associations between handwashing promotion, water disinfection and child growth

Description of intervention: Handwashing promotion : provision of soap and education around handwashing. Handwashing and water quality : provision of soap plus flocculent disinfectant and neighbourhood meetings around hygiene. In 2009 as many children as possible were visited and interviewed about handwashing practices and tested for anthropometric outcomes

Description of control: usual practice maintained

Duration: 9 mo intervention (April to Dec 2003). This study was conducted February

Interventions to improve water quality and supply, sanitation and hygiene practices, and their effects on the nutritional status of children 36 (Review)

Copyright $\odot 2013$ The Cochrane Collaboration. Published by John Wiley \& Sons, Ltd. 
Bowen 2012 (Continued)

to December 2009

Intervention uptake: not stated

Coverage: $83.5 \%$ of original households included in 2009 study

Adherence: not stated

Cost: not stated

Process and implementation factors: not stated

Outcomes

Primary outcomes: developmental outcomes, height-for-age, weight-for-age, BMI

Secondary outcomes: haemoglobin levels, diarrhoea

Notes

Risk of bias

\begin{tabular}{|c|c|c|}
\hline Bias & Authors' judgement & Support for judgement \\
\hline $\begin{array}{l}\text { Random sequence generation (selection } \\
\text { bias) }\end{array}$ & Low risk & $\begin{array}{l}\text { A computer-generated random number } \\
\text { was assigned to each study group }\end{array}$ \\
\hline Were baseline characteristics similar? & Low risk & Adequate \\
\hline $\begin{array}{l}\text { Were baseline outcome measurements sim- } \\
\text { ilar? }\end{array}$ & Unclear risk & $\begin{array}{l}\text { Outcome measurements of this study were } \\
\text { not taken at baseline }\end{array}$ \\
\hline Allocation concealment (selection bias) & High risk & $\begin{array}{l}\text { Clusters were listed in the order they had } \\
\text { been identified. Study groups ( } 5 \text { in 2003) } \\
\text { were assigned a computer-generated ran- } \\
\text { dom number, ordered and consecutively } \\
\text { applied to the list of clusters. Possible to } \\
\text { foresee allocation with this method }\end{array}$ \\
\hline $\begin{array}{l}\text { Blinding of participants and personnel } \\
\text { (performance bias) } \\
\text { All outcomes }\end{array}$ & High risk & No blinding \\
\hline
\end{tabular}

Blinding of outcome assessment (detection Unclear risk

bias)

Group allocation was not disclosed to the

All outcomes

field workers who conducted household interviews during the (2009) study, although some workers had been employed during the 2003 study and might have remembered the original study allocations

Incomplete outcome data (attrition bias) Low risk All outcomes

$461 \mathrm{HH}$ derived from 391 (83.5\% of those eligible) in the original study were enrolled in 2009

Selective reporting (reporting bias)

Unclear risk

Protocol available for cluster trial, but no protocol available for this 3-year follow-up study

Interventions to improve water quality and supply, sanitation and hygiene practices, and their effects on the nutritional status of children

(Review)

Copyright $(2013$ The Cochrane Collaboration. Published by John Wiley \& Sons, Ltd. 
Bowen 2012 (Continued)

\begin{tabular}{l|l|l}
$\begin{array}{l}\text { Was the study adequately protected against } \\
\text { contamination? }\end{array}$ & Unclear risk & Not relevant for study design \\
\hline $\begin{array}{l}\text { Appropriate adjustment for potential con- } \\
\text { founders? }\end{array}$ & Unclear risk & Not relevant for study design \\
\hline
\end{tabular}

Du Preez 2010

Methods

Study design: cluster-randomised controlled trial among 649 households (438 children in intervention group, 386 in control)

Sample size: 824 children aged 6 to 59 mo
Country: peri-urban South Africa
Method of participant selection: households were identified using local information
provided by health workers. Eligible households had no in-house piped water and had
at least 1 resident child aged 6 to 59 mo
Description of participants: children aged 6 to 59 mo living in eligible households that
were from the selected area. Access to piped water, either in the house or outside the yard
is available to $97.7 \%$ of inhabitants

Interventions

Aim: to investigate the effect of solar disinfection (SODIS) of drinking water on the incidence of dysentery and non-dysentery diarrhoea among South African children aged 6 to $59 \mathrm{mo}$

Description of intervention: Water quality intervention: SODIS - $2 \times 2$ L PET bottles were provided for each child. The carers of children were instructed to fill 1 bottle each day and place it in full, unobscured sunlight for a min of 6 hours. Treated water was consumed on the day after exposure and water was to be stored for a max of 48 hours. Carers were advised that children should drink directly from the bottle

Description of control: no bottle provided, usual practice maintained

Duration: 12 mo beginning October 2007

Intervention uptake: not stated

Coverage: not stated

Adherence: $<35 \%$

Cost: not stated

Process and implementation factors: not stated

Outcomes

Primary outcomes: rate of days with dysentery and days without dysentery diarrhoea Secondary outcomes: E.coli concentrations in storage water bottles and SODIS water bottles in intervention households, height, weight

Notes

Risk of bias

\begin{tabular}{lll} 
Bias & Authors' judgement & Support for judgement \\
\hline $\begin{array}{l}\text { Random sequence generation (selection } \\
\text { bias) }\end{array}$ & Low risk & $\begin{array}{l}\text { A table of random numbers was applied to } \\
\text { consecutively numbered households }\end{array}$
\end{tabular}

Interventions to improve water quality and supply, sanitation and hygiene practices, and their effects on the nutritional status of children 38

(Review)

Copyright (? 2013 The Cochrane Collaboration. Published by John Wiley \& Sons, Ltd. 


\section{Du Preez 2010 (Continued)}

\begin{tabular}{|c|c|c|}
\hline Were baseline characteristics similar? & Low risk & Adequate \\
\hline $\begin{array}{l}\text { Were baseline outcome measurements sim- } \\
\text { ilar? }\end{array}$ & Low risk & Adequate \\
\hline Allocation concealment (selection bias) & High risk & Insufficient information provided \\
\hline $\begin{array}{l}\text { Blinding of participants and personnel } \\
\text { (performance bias) } \\
\text { All outcomes }\end{array}$ & High risk & No blinding \\
\hline $\begin{array}{l}\text { Blinding of outcome assessment (detection } \\
\text { bias) } \\
\text { All outcomes }\end{array}$ & Unclear risk & $\begin{array}{l}\text { No information provided about collection } \\
\text { of anthropometric outcomes }\end{array}$ \\
\hline $\begin{array}{l}\text { Incomplete outcome data (attrition bias) } \\
\text { All outcomes }\end{array}$ & Low risk & $\begin{array}{l}121 \text { children lost for the following reasons } \\
\text { - (i) } 7 \text { died; (ii) } 9 \text { moved (iii) carers of } 105 \\
\text { lost interest. Unlikely to affect outcome }\end{array}$ \\
\hline Selective reporting (reporting bias) & High risk & $\begin{array}{l}\text { The collection of nutrition outcomes was } \\
\text { stated in the protocol but the data were not } \\
\text { presented in the published report. This in- } \\
\text { formation was received directly from the } \\
\text { author }\end{array}$ \\
\hline $\begin{array}{l}\text { Was the study adequately protected against } \\
\text { contamination? }\end{array}$ & Unclear risk & Not relevant for study design \\
\hline $\begin{array}{l}\text { Appropriate adjustment for potential con- } \\
\text { founders? }\end{array}$ & Unclear risk & Not relevant for study design \\
\hline
\end{tabular}

\section{Du Preez 2011}

Methods

Participants
Study design: cluster-randomised controlled trial among 765 households (555 children in intervention group, 534 in control). No information available of allocation between households. Analysis at level of the individual

Sample size: 1089 children aged 6 to 59 mo

Country: urban and rural Kenya

Method of participant selection: households were identified using local information provided by health workers. Eligible households stored water in containers in the house, did not have a drinking water in tap in the house/yard and had at least 1 (and not more than 5) child aged 6 to 59 mo

Description of participants: children aged 6 to 59 mo living in eligible households that were from either urban slum townships in the city of Nakuru or poor rural areas. Urban areas had water supplied by standpipes provided by Nakuru Water Sanitation Services Company - conventional water treatment methods were used here to treat ground-and surface-water. The water sources in rural areas were variable: partial supply by standpipes

Interventions to improve water quality and supply, sanitation and hygiene practices, and their effects on the nutritional status of children 39 
Du Preez 2011 (Continued)

and a mix of river, borehole and other miscellaneous sources. $92 \%$ had access to a toilet, $89 \%$ of which were pit latrines and $7 \%$ of which were flush. A median of 15 people shared a toilet

Interventions

Aim: to investigate the effect of solar disinfection (SODIS) of drinking water on the incidence of dysentery, non-dysentery diarrhoea and anthropometric measurements of height and weight among Kenyan children aged 6 to 59 mo

Description of intervention: Water quality intervention: SODIS - $2 \times 2$ L PET bottles were provided for each child. The carers of children were instructed to fill 1 bottle each day and place it in full, unobscured sunlight for a min of 6 hours. Treated water was consumed on the day after exposure and water was to be stored for a max of 48 hours.

Carers were advised that children should drink directly from the bottle

Description of control: no bottle provided, usual practice maintained

Duration: 12 mo beginning September 2007

Intervention uptake: not stated

Coverage: not stated

Adherence: not stated

Cost: not stated

Process and implementation factors: not stated

Outcomes

Primary outcomes: rate of days with dysentery and days without dysentery diarrhoea

Secondary outcomes: height-for-age; weight-for-age; weight-for-height; E.coli concentrations in storage water bottles and SODIS water bottles in intervention households

Notes

Risk of bias

Bias

Authors' judgement

Support for judgement

Random sequence generation (selection Low risk bias)

Each household was assigned an acronym (based on study area) and a number (based on GPS co-ordinates) and listed accordingly. Random numbers between 0 and 1 were generated and applied to the list of enrolled households

$\begin{array}{lll}\text { Were baseline characteristics similar? } & \text { Low risk Adequate }\end{array}$

Were baseline outcome measurements sim- Low risk ilar?

Adequate

Allocation concealment (selection bias) High risk

Households receiving a number $<0.5$ were assigned to the intervention. Inadequate allocation concealment

Blinding of participants and personnel High risk No blinding (performance bias)

All outcomes

Interventions to improve water quality and supply, sanitation and hygiene practices, and their effects on the nutritional status of children 


\section{Du Preez 2011 (Continued)}

\begin{tabular}{l|l|l}
\hline $\begin{array}{l}\text { Blinding of outcome assessment (detection } \\
\text { bias) } \\
\text { All outcomes }\end{array}$ & Unclear risk & No information provided \\
\hline $\begin{array}{l}\text { Incomplete outcome data (attrition bias) } \\
\text { All outcomes }\end{array}$ & Low risk & $\begin{array}{l}24 \text { lost in intervention group and } 20 \text { in con- } \\
\text { trol due to civic unrest. Unlikely to affect } \\
\text { outcome }\end{array}$ \\
\hline $\begin{array}{l}\text { Selective reporting (reporting bias) } \\
\text { Was the study adequately protected against }\end{array}$ & Unclear risk & Study protocol available and data reported \\
contamination? & appropriately \\
\hline $\begin{array}{l}\text { Appropriate adjustment for potential con- } \\
\text { founders? }\end{array}$ & Unclear risk & Not relevant for study design \\
\hline
\end{tabular}

Fenn 2012

Methods

Study design: controlled before-and-after study among 11 villages. No randomisation - communities were purposefully assigned to group

\begin{tabular}{|c|c|}
\hline Participants & $\begin{array}{l}\text { Sample size: } 2476 \text { children at baseline, aged } 6 \text { to } 36 \text { mo } \\
\text { Country: rural Ethiopia } \\
\text { Method of participant selection: selected contiguous communities were purposefully } \\
\text { assigned to receive } 1 \text { of health, nutrition education, water sanitation and hygiene (WASH) } \\
\text { or an integrated intervention comprising all } 3 \text { interventions. Villages were selected with } \\
\text { similar demographic, socioeconomic and livelihood profiles. The WASH intervention } \\
\text { was assigned to villages identified by local authorities as having poor access to water } \\
\text { sources } \\
\text { Description of participants: } \\
\text { Intervention - eligible children living in the villages selected to receive the WASH inter- } \\
\text { vention; mean age } 17 \text { mo; } 64.3 \% \text { had HAZ <-2 SD; SES distribution was } 17.4 \%, 32 \text {. } \\
0 \%, 37.5 \% \text { and } 13.2 \% \text { for poorest, poor, medium and better off, respectively. } 91.6 \% \text { of } \\
\text { the mothers had no education } \\
\text { Control - children aged } 6 \text { to } 36 \text { mo living in the villages selected to act as the control; } \\
\text { mean age } 18 \text { mo; } 62.4 \% \text { had HAZ<-2 SD; SES distribution was } 23.1 \%, 38.6 \%, 25.8 \% \\
\text { and } 12.5 \% \text { for poorest, poor, medium and better off, respectively. } 87.9 \% \text { of the mothers } \\
\text { of control children had no education }\end{array}$ \\
\hline
\end{tabular}

Aim: to reduce linear growth retardation in children aged 6 to 36 mo and measure the effectiveness of different interventions, singularly and in combination, on childhood growth in a food-insecure area. This review includes the results of the WASH and control arms only

Description of intervention: Water supply and sanitation; hygiene - protected water supply; sanitation education and personal and environmental hygiene practices (soap use, handwashing practices, sanitary facility construction, cleanliness of house and construction of separate housing for animals, keeping water clean)

Description of control: no intervention 
Fenn 2012 (Continued)

Duration: 54 mo beginning January 2005

Intervention uptake: not stated

Coverage: not stated

Adherence: not stated

Cost: not stated

Process and implementation factors: not stated

Outcomes

Primary outcomes: difference in mean height-for-age z-score; prevalence of stunting in children aged 6 to 36 mo

Secondary outcomes: health-seeking practices; infant and young child feeding practices; improved preventive practice

Notes

Risk of bias

\begin{tabular}{|c|c|c|}
\hline Bias & Authors' judgement & Support for judgement \\
\hline $\begin{array}{l}\text { Random sequence generation (selection } \\
\text { bias) }\end{array}$ & High risk & No random sequence generation \\
\hline Were baseline characteristics similar? & Low risk & Adequate \\
\hline $\begin{array}{l}\text { Were baseline outcome measurements sim- } \\
\text { ilar? }\end{array}$ & Low risk & $\begin{array}{l}\text { Mean } H A Z \text { was slightly higher in interven- } \\
\text { tion group at baseline }\end{array}$ \\
\hline Allocation concealment (selection bias) & High risk & $\begin{array}{l}\text { Intervention and control groups were se- } \\
\text { lected by the researchers }\end{array}$ \\
\hline $\begin{array}{l}\text { Blinding of participants and personnel } \\
\text { (performance bias) } \\
\text { All outcomes }\end{array}$ & High risk & No blinding \\
\hline $\begin{array}{l}\text { Blinding of outcome assessment (detection } \\
\text { bias) } \\
\text { All outcomes }\end{array}$ & Unclear risk & No information provided \\
\hline $\begin{array}{l}\text { Incomplete outcome data (attrition bias) } \\
\text { All outcomes }\end{array}$ & Unclear risk & Not possible due to study design \\
\hline Selective reporting (reporting bias) & Unclear risk & No study protocol available \\
\hline $\begin{array}{l}\text { Was the study adequately protected against } \\
\text { contamination? }\end{array}$ & Unclear risk & Not stated \\
\hline $\begin{array}{l}\text { Appropriate adjustment for potential con- } \\
\text { founders? }\end{array}$ & Unclear risk & None stated \\
\hline
\end{tabular}

Interventions to improve water quality and supply, sanitation and hygiene practices, and their effects on the nutritional status of children 
Methods

Participants
Study design: longitudinal prospective study with c/s surveys every 3 mo between 2 clusters

Sample size: 312 children aged $<5$ years

Country: rural Guatemala

Method of participant selection: Intervention village: each household was assisted to build latrines in the sanitation village and vaccines were provided along with a public health nurse and doctor for the entire village

Description of participants: Intervention - all inhabitants of the sanitation village. Each household received a latrine and had access to a medical clinic; Control - preschool children $(<5 \mathrm{y})$ living in a village that did not receive any intervention

Interventions

Aim: to improve nutritional status and reduce infection in children aged $<5$ years

Description of intervention: 3 villages were involved in the study - 1 received a nutrition intervention, 1 received a sanitation/health intervention and 1 acted as a control. Only the sanitation/health intervention is detailed in this review. Sanitation/Health intervention - a safe and continuous water supply was provided for the community; assistance was provided for the building of latrines for each $\mathrm{HH}$; vaccines provided; a full-time sanitarian was assigned for the promotion of better hygiene practices; medical clinic established with doctor and public health nurse with the aim of providing medical care for the entire community

Description of control: no intervention

Duration: 60 mo beginning 1959

Intervention uptake: not stated

Coverage: not stated

Adherence: not stated

Cost: not stated

Process and implementation factors: not stated

Outcomes

Outcomes: height, weight, skinfold thickness; head circumference, bone development; mortality; incidence of disease

Notes

Risk of bias

\begin{tabular}{|c|c|c|}
\hline Bias & Authors' judgement & Support for judgement \\
\hline $\begin{array}{l}\text { Random sequence generation (selection } \\
\text { bias) }\end{array}$ & High risk & $\begin{array}{l}\text { No random sequence generation - all chil- } \\
\text { dren in the study villages were included in } \\
\text { the intervention }\end{array}$ \\
\hline Were baseline characteristics similar? & High risk & $\begin{array}{l}\text { Inadequate - control and intervention vil- } \\
\text { lages quite dissimilar with respect to base- } \\
\text { line characteristics }\end{array}$ \\
\hline $\begin{array}{l}\text { Were baseline outcome measurements sim- } \\
\text { ilar? }\end{array}$ & Unclear risk & $\begin{array}{l}\text { Baseline outcome measurements not pre- } \\
\text { sented clearly }\end{array}$ \\
\hline
\end{tabular}
ilar? sented clearly

Interventions to improve water quality and supply, sanitation and hygiene practices, and their effects on the nutritional status of children 


\section{Guzman 1968 (Continued)}

\begin{tabular}{l|l|l}
\hline Allocation concealment (selection bias) & High risk & $\begin{array}{l}\text { Intervention and control groups were se- } \\
\text { lected by the researchers }\end{array}$ \\
\hline $\begin{array}{l}\text { Blinding of participants and personnel } \\
\text { (performance bias) } \\
\text { All outcomes }\end{array}$ & High risk & No blinding \\
\hline $\begin{array}{l}\text { Blinding of outcome assessment (detection } \\
\text { bias) } \\
\text { All outcomes }\end{array}$ & Unclear risk & No information provided \\
\hline $\begin{array}{l}\text { Incomplete outcome data (attrition bias) } \\
\text { All outcomes }\end{array}$ & Unclear risk & $\begin{array}{l}\text { No information regarding numbers of chil- } \\
\text { dren in the follow-up study }\end{array}$ \\
\hline $\begin{array}{l}\text { Selective reporting (reporting bias) } \\
\text { Was the study adequately protected against } \\
\text { contamination? }\end{array}$ & Low risk & No study protocol available \\
\hline $\begin{array}{l}\text { Appropriate adjustment for potential con- } \\
\text { founders? }\end{array}$ & Unclear risk & Adequate: villages are described as being \\
\hline
\end{tabular}

\section{Hasan 1989}

Methods

Participants
Study design: repeated c/s survey between 2 clusters, composed of 5 villages ( 2 intervention, 3 control). No randomisation

Sample size: 405 children (213 intervention, 192 control) aged 12 to $35 \mathrm{mo}$ Country: rural Bangladesh

Method of participant selection: no detail given. Author states that they were "selected carefully to ensure comparability"

Description of participants: children aged 12 to 35 mo living in 1 of the selected villages. These villages had hand pumps that worked only when the water table was above a certain level and therefore did not work during a lot of the dry season. Most households were no more than $100 \mathrm{~m}$ from a body of surface water. Toilet facilities were poor, consisting of platform latrines or open defecation

Interventions
Aim: to assess the health impacts of a water, sanitation and hygiene programme in a community in Bangladesh

Description of intervention: Water quantity and water quality promotion - installation of the 'Tara' hand pump, designed to reach water lying deep in the ground. On average 1 installed per 33 inhabitants. Sanitation - installation of double-pit water seal latrine, 1 per household. Hygiene promotion - hygiene education regarding the use of the hand pumps, latrines (for disposal of child faeces) and washing of hands with ash. Both intervention and control children suffering from diarrhoea were given ORS

Description of control: no intervention

Duration: 48 mo, beginning October 1984

Intervention uptake: not stated 
Hasan 1989 (Continued)

Coverage: $80 \%$ of population lived within $100 \mathrm{~m}$ of the new hand pumps. Latrine installation achieved $90 \%$ coverage. Hygiene education reached 785 women covering $90 \%$ of households

Adherence: not stated

Cost: hand pumps: USD6.89/inhabitant. Latrines: USD4.67/inhabitant. Hygiene education USD3.6/inhabitant. Total cost USD15/inhabitant

Process and implementation factors: not stated

Outcomes

Outcomes: weight-for-age; height-for-age; weight-for-height (NCHS reference); diarrhoeal disease morbidity; intestinal worm infections; choice of water source by household; quantities of hand pump water used; microbiological quality of the water used; use of latrines; defecation practices (especially small children); knowledge, attitudes and practice (KAP) related to hygiene education messages

Notes

Risk of bias

\begin{tabular}{l|l|l}
\hline Bias & Authors' judgement & Support for judgement \\
\hline $\begin{array}{l}\text { Random sequence generation (selection } \\
\text { bias) }\end{array}$ & High risk & No random sequence generation \\
\hline $\begin{array}{l}\text { Were baseline characteristics similar? } \\
\text { Were baseline outcome measurements sim- }\end{array}$ & High risk & Differences found in education and occu- \\
ilar? & pation & Intervention area have lower weight for age \\
\hline $\begin{array}{l}\text { Allocation concealment (selection bias) } \\
\text { baseline }\end{array}$ & High risk & $\begin{array}{l}\text { Intervention and control groups were se- } \\
\text { lected by the researchers }\end{array}$ \\
\hline $\begin{array}{l}\text { Blinding of participants and personnel } \\
\text { (performance bias) } \\
\text { All outcomes }\end{array}$ & High risk & No blinding \\
\hline
\end{tabular}

Blinding of outcome assessment (detection Unclear risk

No information provided

bias)

All outcomes

\begin{tabular}{l|l|l}
\hline $\begin{array}{l}\text { Incomplete outcome data (attrition bias) } \\
\text { All outcomes }\end{array}$ & High risk & Not possible due to study design \\
\hline Selective reporting (reporting bias) & Unclear risk & No study protocol available \\
\hline $\begin{array}{l}\text { Was the study adequately protected against } \\
\text { contamination? }\end{array}$ & Unclear risk & $\begin{array}{l}\text { Control and intervention areas separated } \\
\text { by a distance of } 5 \text { km and no information } \\
\text { given regarding the ease of transport be- }\end{array}$
\end{tabular}

Interventions to improve water quality and supply, sanitation and hygiene practices, and their effects on the nutritional status of children

(Review)

Copyright $(2013$ The Cochrane Collaboration. Published by John Wiley \& Sons, Ltd. 
Hasan 1989 (Continued)

tween the two

$\begin{array}{ll}\text { Appropriate adjustment for potential con- Unclear risk } & \text { None stated }\end{array}$

founders?

Huttly 1990

Methods

Study design: repeated c/s surveys among 5 villages (3 intervention, 2 control). No randomisation

Participants

Sample size: 673 children at baseline. Numbers of children ranged from 632 to 704 for the c/s surveys

Country: rural Nigeria

Method of participant selection: Imo State was selected, by the Nigerian Government, as the site for the phased pilot project. Intervention villages were chosen from areas included in the first stage of the project. Control villages were chosen from those areas designated as part of the second phase. A sampling frame was used to select the households Description of participants: Intervention - children aged $<3$ years living in the 3 farming villages receiving an intervention in Ohaozara local government area, NE Imo State, Nigeria; Control - children living in 2 farming villages acting as a control (an area that would not benefit from the project until 1986). Study areas were separated by several $\mathrm{km}$ of bad road and the villagers in the improved area would not allow anyone from outside the area to use their facilities

Interventions

Aim: to reduce the incidence of water-related diseases and thereby child mortality; to provide at least $20 \mathrm{~L}$ of clean water per person per day

Description of intervention: Water quantity and quality; bygiene - provision of boreholes with hand pumps to the 3 intervention villages; promotion and construction of VIP latrines; health education including information on breastfeeding, nutrition, water use, personal hygiene, environmental sanitation, diarrhoea prevention and ORT

Description of control: no intervention

Duration: 30 mo, beginning 1984

Intervention uptake: Hand pump: $96 \%$ use of these at the end of the intervention period (dry), $80 \%$ use in wet period. VIP latrine: $46 \%$ of households were using them by the end of the study

Coverage: $96 \%$ coverage of boreholes at the end of the intervention period

Adherence: not stated

Cost: not stated

Process and implementation factors: not stated

Outcomes

Outcomes: incidence of diarrhoea, incidence of dracunculiasis, weight-for-height (\% of wasted children)

Notes

Risk of bias

Bias

Authors' judgement

Support for judgement

Interventions to improve water quality and supply, sanitation and hygiene practices, and their effects on the nutritional status of children 


\section{Huttly 1990 (Continued)}

\begin{tabular}{|c|c|c|}
\hline $\begin{array}{l}\text { Random sequence generation (selection } \\
\text { bias) }\end{array}$ & High risk & No random sequence generation \\
\hline Were baseline characteristics similar? & Low risk & Adequate \\
\hline $\begin{array}{l}\text { Were baseline outcome measurements sim- } \\
\text { ilar? }\end{array}$ & High risk & $\begin{array}{l}\text { Control had a lower percentage of children } \\
\text { with a weight-for-age z-score below } 80 \% \text { of } \\
\text { the reference at baseline }\end{array}$ \\
\hline Allocation concealment (selection bias) & High risk & $\begin{array}{l}\text { Intervention and control groups were se- } \\
\text { lected by the researchers }\end{array}$ \\
\hline $\begin{array}{l}\text { Blinding of participants and personnel } \\
\text { (performance bias) } \\
\text { All outcomes }\end{array}$ & High risk & No blinding \\
\hline $\begin{array}{l}\text { Blinding of outcome assessment (detection } \\
\text { bias) } \\
\text { All outcomes }\end{array}$ & Unclear risk & No information provided \\
\hline $\begin{array}{l}\text { Incomplete outcome data (attrition bias) } \\
\text { All outcomes }\end{array}$ & High risk & Not possible due to study design \\
\hline Selective reporting (reporting bias) & Unclear risk & No study protocol available \\
\hline $\begin{array}{l}\text { Was the study adequately protected against } \\
\text { contamination? }\end{array}$ & Unclear risk & Inadequate information given \\
\hline $\begin{array}{l}\text { Appropriate adjustment for potential con- } \\
\text { founders? }\end{array}$ & Unclear risk & None stated \\
\hline
\end{tabular}

\section{Langford 2011}

Methods

Study design: longitudinal study with $\mathrm{c} / \mathrm{s}$ survey each month between 2 clusters. 8 selected slums were divided into 2, North or East, which were then randomised to receive the intervention. Analysis was at the level of the individual

Participants

Sample size: 88 children ( 45 intervention, 43 control) aged 3 to $12 \mathrm{mo}$

Country: urban slum, Kathmandu, Nepal

Method of participant selection: house-to-house visits were carried out to identify all eligible households in the 8 selected slums. Eligible households were those with a child aged 3 to 12 mo

Description of participants: children aged 3 to 12 mo living in the 8 largest Kathmandu slums. Mean age: $7.6 \mathrm{mo}$ (control $=7.5$, intervention $=7.7) . \mathrm{M}=48 \%, \mathrm{~F}=52 \%$

Interventions

Aim: to assess the impact of a handwashing intervention on growth and biomarkers of child health in Nepali slums

Description of intervention:Hygiene promotion intervention - handwashing pro-

Interventions to improve water quality and supply, sanitation and hygiene practices, and their effects on the nutritional status of children 
gramme, launched at a community meeting in each local area, included an interactive educational session, a discussion led by community motivator, and a short play performed by actors from the slum communities. The messages were then intensively promoted for 6 mo with daily home visits from a community motivator to new mothers for 2 weeks. Visits decreased in frequency until the mothers were visited once or twice per week throughout the intervention period. Mothers group meetings were held every 2 weeks at which a new bar of soap was distributed to each mother. Locally designed posters were prominently displayed and distributed to each household

Description of control: no intervention

Duration: 6 mo beginning June 2007

Intervention uptake: not stated

Coverage: not stated

Adherence: not stated

Cost: not stated

Process and implementation factors: all mothers offered 200 rupees (GBP 1.50) each mo at measurement time. All children given a gift of clothing and provided with medical treatment. Mothers in control group offered a session on hygiene and handwashing and free bars of soap at the end of the study

Outcomes

Outcomes: weight-for-length, length-for-age, weight-for-age; biomarkers to assess mucosal damage (L:C ratio values) and immune stimulation (AGP, IgG, albumin, haemoglobin); morbidity: diarrhoea, cough/cold, fever

Notes

\section{Risk of bias}

\section{Bias}

Random sequence generation (selection Low risk bias)

\begin{tabular}{ll}
\hline Were baseline characteristics similar? & Low risk \\
\hline $\begin{array}{l}\text { Were baseline outcome measurements sim- } \\
\text { ilar? }\end{array}$ & High risk
\end{tabular}

Allocation concealment (selection bias) High risk

Blinding of participants and personnel High risk (performance bias)

All outcomes

Blinding of outcome assessment (detection Unclear risk bias)

All outcomes

\section{Support for judgement}

Adequate sequence generation (coin flipping)

\section{Adequate}

Control children better off for all indicators (weight-for-height, height-for-age, weightfor-age) at baseline

Inadequate allocation concealment

No blinding

No information provided 


\begin{tabular}{|c|c|c|}
\hline $\begin{array}{l}\text { Incomplete outcome data (attrition bias) } \\
\text { All outcomes }\end{array}$ & Low risk & $\begin{array}{l}11 \text { of the } 99 \text { children who completed the } \\
\text { study had incomplete profiles and were re- } \\
\text { moved from the final analyses, leaving a fi- } \\
\text { nal sample size of } 88 \text { children. There were } \\
\text { no differences between the attrition ( } \mathrm{n}= \\
\text { 11) and study }(\mathrm{n}=88) \text { group for any vari- } \\
\text { ables. Adequate }\end{array}$ \\
\hline Selective reporting (reporting bias) & Unclear risk & No study protocol available \\
\hline $\begin{array}{l}\text { Was the study adequately protected against } \\
\text { contamination? }\end{array}$ & High risk & $\begin{array}{l}\text { Areas were close to one another therefore } \\
\text { likely that contamination occurred }\end{array}$ \\
\hline $\begin{array}{l}\text { Appropriate adjustment for potential con- } \\
\text { founders? }\end{array}$ & Unclear risk & $\begin{array}{l}\text { Interactions between time and group were } \\
\text { tested for }\end{array}$ \\
\hline
\end{tabular}

\section{Luby 2004}

Methods

Participants
Study design: cluster-randomised controlled trial among 1050 households (600 intervention (300 antibacterial soap, 300 plain soap), 306 control). Allocation at cluster level, analysis at level of the individual/household

Sample size: 4691 children aged < 15 y; anthropometric data for 873 children aged $<5$ y

Country: urban Pakistan. Multiethnic squatter settlements in Karachi

Method of participant selection: households were identified by local field workers. Eligible households were located in the study area, had at least 2 children younger than $15 \mathrm{y}$, at least 1 of whom was younger than $5 \mathrm{y}$, and planned to continue to reside in their homes for the duration of the study

Description of participants: children aged $<5$ y living in households that were enrolled in the study

Interventions

Aim: to evaluate whether promoting washing hands with soap (antibacterial or plain) decreased diarrhoea among children at the highest risk of death from diarrhoea in Karachi squatter settlements

Description of intervention: weekly visits to promote handwashing with soap after defecation and before preparing food, eating and feeding a child. Within intervention neighbourhoods, 300 households received a regular supply of antibacterial soap and 300 households received plain soap

Description of control: usual practice maintained among the 11 control neighbourhoods (306 households)

Duration: 12 mo (April 2002 to 2003)

Intervention uptake: not stated

Coverage: a median of $21 \%$ of households from each neighbourhood were eligible to take part

Adherence: not stated. Handwashing households had a high consumption of soap

Cost: handwashing promotion households received a mean 3.3 bars of the study soap per week; this translates into each household resident using a mean $4.4 \mathrm{~g} / \mathrm{d}$ of soap. Authors 
state that visiting houses individually and giving free soap "is prohibitively expensive for widespread implementation."

Process and implementation factors: not stated

Outcomes Primary outcomes: incidence density of diarrhoea

Secondary outcomes: disease outcome; no. visits to healthcare practitioner; hospitalisation

Notes

Risk of bias

\begin{tabular}{|c|c|c|}
\hline Bias & Authors' judgement & Support for judgement \\
\hline $\begin{array}{l}\text { Random sequence generation (selection } \\
\text { bias) }\end{array}$ & Low risk & $\begin{array}{l}\text { Adequate. A computer-generated random } \\
\text { number was assigned to each neighbour- } \\
\text { hood }\end{array}$ \\
\hline Were baseline characteristics similar? & Low risk & Adequate \\
\hline $\begin{array}{l}\text { Were baseline outcome measurements sim- } \\
\text { ilar? }\end{array}$ & Unclear risk & No baseline outcome measures reported \\
\hline Allocation concealment (selection bias) & High risk & $\begin{array}{l}\text { Inadequate. No efforts to conceal alloca- } \\
\text { tion were described }\end{array}$ \\
\hline $\begin{array}{l}\text { Blinding of participants and personnel } \\
\text { (performance bias) } \\
\text { All outcomes }\end{array}$ & High risk & No blinding \\
\hline $\begin{array}{l}\text { Blinding of outcome assessment (detection } \\
\text { bias) } \\
\text { All outcomes }\end{array}$ & High risk & No blinding \\
\hline $\begin{array}{l}\text { Incomplete outcome data (attrition bias) } \\
\text { All outcomes }\end{array}$ & Low risk & $\begin{array}{l}\text { Proportion of children who died or left the } \\
\text { study is unlikely to result in bias }\end{array}$ \\
\hline Selective reporting (reporting bias) & High risk & $\begin{array}{l}\text { Collection of anthropometric measure- } \\
\text { ments discussed in protocol but nutrition } \\
\text { outcomes not reported in paper }\end{array}$ \\
\hline $\begin{array}{l}\text { Was the study adequately protected against } \\
\text { contamination? }\end{array}$ & Unclear risk & Not relevant for study design \\
\hline $\begin{array}{l}\text { Appropriate adjustment for potential con- } \\
\text { founders? }\end{array}$ & Unclear risk & Not relevant for study design \\
\hline
\end{tabular}

Interventions to improve water quality and supply, sanitation and hygiene practices, and their effects on the nutritional status of children 
Study design: cluster-randomised controlled trial among 1340 households (approximately 260 households per intervention; 282 households for control). Allocation at neighbourhood level, analysis at level of the household/individual

Participants

Sample size: anthropometric data for 2137 children aged $<5$ y

Country: urban Pakistan. Multiethnic squatter settlements in Karachi

Method of participant selection: households were identified by local field workers. Eligible households had a child $<5$ years, at least $1 \mathrm{hr}$ of running water twice weekly and had not received soap or water treatment in previous studies

Description of participants: children aged $<59$ mo living in households that were enrolled in the study

Interventions

Aim: to evaluate the effectiveness of point of use water treatment with flocculent-disinfectant on reducing diarrhoea and the additional benefit of promoting handwashing with soap

Description of intervention: Bleach - provision of diluted bleach and a water vessel; Flocculent-disinfectant - provision of flocculent-disinfectant water treatment and a water vessel; Handwashing promotion - provision of soap and education around handwashing. Handwashing and water quality - provision of soap plus flocculent-disinfectant and neighbourhood meetings around hygiene

Description of control: usual practice maintained

Duration: 9 mo beginning April 2003

Intervention uptake: not stated

Coverage: $19 \%$ households were eligible to take part

Adherence: not stated

Cost: not stated

Process and implementation factors: not stated

$\begin{array}{ll}\text { Outcomes } & \text { Outcomes: diarrhoea }\end{array}$

Notes

Risk of bias

\begin{tabular}{l|l|l} 
Bias & Authors' judgement & Support for judgement \\
\hline $\begin{array}{l}\text { Random sequence generation (selection } \\
\text { bias) }\end{array}$ & Low risk & $\begin{array}{l}\text { Adequate. A computer-generated random } \\
\text { number was assigned to each study group }\end{array}$ \\
\hline $\begin{array}{l}\text { Were baseline characteristics similar? } \\
\text { Were baseline outcome measurements sim- } \\
\text { ilar? }\end{array}$ & Low risk & Adequate \\
\hline $\begin{array}{l}\text { Allocation concealment (selection bias) } \\
\text { nisk risk }\end{array}$ & High & No baseline outcome measures reported \\
\hline
\end{tabular}

Interventions to improve water quality and supply, sanitation and hygiene practices, and their effects on the nutritional status of children 5 I

(Review)

Copyright (? 2013 The Cochrane Collaboration. Published by John Wiley \& Sons, Ltd. 
Luby 2006 (Continued)

with this method

\begin{tabular}{|c|c|c|}
\hline $\begin{array}{l}\text { Blinding of participants and personnel } \\
\text { (performance bias) } \\
\text { All outcomes }\end{array}$ & High risk & No blinding \\
\hline $\begin{array}{l}\text { Blinding of outcome assessment (detection } \\
\text { bias) } \\
\text { All outcomes }\end{array}$ & High risk & No blinding \\
\hline $\begin{array}{l}\text { Incomplete outcome data (attrition bias) } \\
\text { All outcomes }\end{array}$ & Low risk & $\begin{array}{l}\text { Proportion of children who died or left the } \\
\text { study is unlikely to result in bias }\end{array}$ \\
\hline Selective reporting (reporting bias) & High risk & $\begin{array}{l}\text { Collection of anthropometric data not } \\
\text { mentioned in protocol or published paper }\end{array}$ \\
\hline
\end{tabular}

Was the study adequately protected against Unclear risk

Not relevant for study design

contamination?

Appropriate adjustment for potential con- Unclear risk

founders?

Luby 2006 (Floc \& Bleach)

Methods

Study design: cluster-randomised controlled trial among 1340 households (approximately 260 households per intervention; 282 households for control). Allocation at neighbourhood level, analysis at level of the household/individual

Participants

Sample size: anthropometric data for 2137 children aged $<5$ y

Country: urban Pakistan. Multiethnic squatter settlements in Karachi

Method of participant selection: households were identified by local field workers. Eligible households had a child $<5$ years, at least $1 \mathrm{hr}$ of running water twice weekly and had not received soap or water treatment in previous studies

Description of participants: children aged $<59$ mo living in households that were enrolled in the study

Interventions

Aim: to evaluate the effectiveness of point of use water treatment with flocculent-disinfectant on reducing diarrhoea and the additional benefit of promoting handwashing with soap

Description of intervention: Bleach - provision of diluted bleach and a water vessel; Flocculent-disinfectant - provision of flocculent-disinfectant water treatment and a water vessel; Handwashing promotion - provision of soap and education around handwashing. Handwashing and water quality - provision of soap plus flocculent-disinfectant and neighbourhood meetings around hygiene

Description of control: usual practice maintained

Duration: 9 mo beginning April 2003

Intervention uptake: not stated

Coverage: $19 \%$ households were eligible to take part

Adherence: not stated

Interventions to improve water quality and supply, sanitation and hygiene practices, and their effects on the nutritional status of children

(Review)

Copyright $(2013$ The Cochrane Collaboration. Published by John Wiley \& Sons, Ltd. 
Luby 2006 (Floc \& Bleach) (Continued)

Cost: not stated

Process and implementation factors: not stated

\begin{tabular}{l|l} 
Outcomes & Outcomes: diarrhoea \\
\hline Notes & \\
\hline Risk of bias &
\end{tabular}

\begin{tabular}{|c|c|c|}
\hline Bias & Authors' judgement & Support for judgement \\
\hline $\begin{array}{l}\text { Random sequence generation (selection } \\
\text { bias) }\end{array}$ & Low risk & $\begin{array}{l}\text { Adequate. A computer-generated random } \\
\text { number was assigned to each study group }\end{array}$ \\
\hline Were baseline characteristics similar? & Low risk & Adequate \\
\hline $\begin{array}{l}\text { Were baseline outcome measurements sim- } \\
\text { ilar? }\end{array}$ & Unclear risk & No baseline outcome measures reported \\
\hline Allocation concealment (selection bias) & High risk & $\begin{array}{l}\text { Clusters were listed in the order they had } \\
\text { been identified. Study groups were assigned } \\
\text { a computer-generated random number, or- } \\
\text { dered and consecutively applied to the list } \\
\text { of clusters. Possible to foresee allocation } \\
\text { with this method }\end{array}$ \\
\hline $\begin{array}{l}\text { Blinding of participants and personnel } \\
\text { (performance bias) } \\
\text { All outcomes }\end{array}$ & High risk & No blinding \\
\hline $\begin{array}{l}\text { Blinding of outcome assessment (detection } \\
\text { bias) } \\
\text { All outcomes }\end{array}$ & High risk & No blinding \\
\hline $\begin{array}{l}\text { Incomplete outcome data (attrition bias) } \\
\text { All outcomes }\end{array}$ & Low risk & $\begin{array}{l}\text { Proportion of children who died or left the } \\
\text { study is unlikely to result in bias }\end{array}$ \\
\hline Selective reporting (reporting bias) & High risk & $\begin{array}{l}\text { Collection of anthropometric data not } \\
\text { mentioned in protocol or published paper }\end{array}$ \\
\hline $\begin{array}{l}\text { Was the study adequately protected against } \\
\text { contamination? }\end{array}$ & Unclear risk & Not relevant for study design \\
\hline $\begin{array}{l}\text { Appropriate adjustment for potential con- } \\
\text { founders? }\end{array}$ & Unclear risk & Not relevant for study design \\
\hline
\end{tabular}

Interventions to improve water quality and supply, sanitation and hygiene practices, and their effects on the nutritional status of children 
Study design: cluster-randomised controlled trial among 1340 households (approximately 260 households per intervention; 282 households for control). Allocation at neighbourhood level, analysis at level of the household/individual

Participants

Sample size: anthropometric data for 2137 children aged $<5$ y

Country: urban Pakistan. Multiethnic squatter settlements in Karachi

Method of participant selection: households were identified by local field workers. Eligible households had a child $<5$ years, at least $1 \mathrm{hr}$ of running water twice weekly and had not received soap or water treatment in previous studies

Description of participants: children aged $<59$ mo living in households that were enrolled in the study

Interventions

Aim: to evaluate the effectiveness of point of use water treatment with flocculent-disinfectant on reducing diarrhoea and the additional benefit of promoting handwashing with soap

Description of intervention: Bleach - provision of diluted bleach and a water vessel; Flocculent-disinfectant - provision of flocculent-disinfectant water treatment and a water vessel; Handwashing promotion - provision of soap and education around handwashing. Handwashing and water quality - provision of soap plus flocculent-disinfectant and neighbourhood meetings around hygiene

Description of control: usual practice maintained

Duration: 9 mo beginning April 2003

Intervention uptake: not stated

Coverage: $19 \%$ households were eligible to take part

Adherence: not stated

Cost: not stated

Process and implementation factors: not stated

$\begin{array}{ll}\text { Outcomes } & \text { Outcomes: diarrhoea }\end{array}$

Notes

Risk of bias

\begin{tabular}{l|l|l} 
Bias & Authors' judgement & Support for judgement \\
\hline $\begin{array}{l}\text { Random sequence generation (selection } \\
\text { bias) }\end{array}$ & Low risk & $\begin{array}{l}\text { Adequate. A computer-generated random } \\
\text { number was assigned to each study group }\end{array}$ \\
\hline $\begin{array}{l}\text { Were baseline characteristics similar? } \\
\text { Were baseline outcome measurements sim- } \\
\text { ilar? }\end{array}$ & Lnclear risk & Adequate \\
\hline $\begin{array}{l}\text { Allocation concealment (selection bias) } \\
\text { nisk }\end{array}$ & High risk & No baseline outcome measures reported \\
\hline & & $\begin{array}{l}\text { Clusters were listed in the order they had } \\
\text { been identified. Study groups were assigned } \\
\text { a computer-generated random number, or- } \\
\text { dered and consecutively applied to the list } \\
\text { of clusters. Possible to foresee allocation }\end{array}$
\end{tabular}

Interventions to improve water quality and supply, sanitation and hygiene practices, and their effects on the nutritional status of children 54

(Review)

Copyright @ 2013 The Cochrane Collaboration. Published by John Wiley \& Sons, Ltd. 
Luby 2006 (Soap \& Floc) (Continued)

with this method

\begin{tabular}{|c|c|c|}
\hline $\begin{array}{l}\text { Blinding of participants and personnel } \\
\text { (performance bias) } \\
\text { All outcomes }\end{array}$ & High risk & No blinding \\
\hline $\begin{array}{l}\text { Blinding of outcome assessment (detection } \\
\text { bias) } \\
\text { All outcomes }\end{array}$ & High risk & No blinding \\
\hline $\begin{array}{l}\text { Incomplete outcome data (attrition bias) } \\
\text { All outcomes }\end{array}$ & Low risk & $\begin{array}{l}\text { Proportion of children who died or left the } \\
\text { study is unlikely to result in bias }\end{array}$ \\
\hline Selective reporting (reporting bias) & High risk & $\begin{array}{l}\text { Collection of anthropometric data not } \\
\text { mentioned in protocol or published paper }\end{array}$ \\
\hline
\end{tabular}

Was the study adequately protected against Unclear risk

Not relevant for study design

contamination?

Appropriate adjustment for potential con- Unclear risk

founders?

Luby 2006 (Soap)

Methods

Study design: cluster-randomised controlled trial among 1340 households (approximately 260 households per intervention; 282 households for control). Allocation at neighbourhood level, analysis at level of the household/individual

Participants

Sample size: anthropometric data for 2137 children aged $<5$ y

Country: urban Pakistan. Multiethnic squatter settlements in Karachi

Method of participant selection: households were identified by local field workers. Eligible households had a child $<5$ years, at least $1 \mathrm{hr}$ of running water twice weekly and had not received soap or water treatment in previous studies

Description of participants: children aged $<59$ mo living in households that were enrolled in the study

Interventions

Aim: to evaluate the effectiveness of point of use water treatment with flocculent-disinfectant on reducing diarrhoea and the additional benefit of promoting handwashing with soap

Description of intervention: Bleach - provision of diluted bleach and a water vessel; Flocculent-disinfectant - provision of flocculent-disinfectant water treatment and a water vessel; Handwashing promotion - provision of soap and education around handwashing. Handwashing and water quality - provision of soap plus flocculent-disinfectant and neighbourhood meetings around hygiene

Description of control: usual practice maintained

Duration: 9 mo beginning April 2003

Intervention uptake: not stated

Coverage: $19 \%$ households were eligible to take part

Adherence: not stated

Interventions to improve water quality and supply, sanitation and hygiene practices, and their effects on the nutritional status of children

(Review)

Copyright $(2013$ The Cochrane Collaboration. Published by John Wiley \& Sons, Ltd. 
Luby 2006 (Soap) (Continued)

Cost: not stated

Process and implementation factors: not stated

\begin{tabular}{|c|c|}
\hline Outcomes & Outcomes: diarrhoea \\
\hline Notes & \\
\hline
\end{tabular}

\begin{tabular}{|c|c|c|}
\hline Bias & Authors' judgement & Support for judgement \\
\hline $\begin{array}{l}\text { Random sequence generation (selection } \\
\text { bias) }\end{array}$ & Low risk & $\begin{array}{l}\text { Adequate. A computer-generated random } \\
\text { number was assigned to each study group }\end{array}$ \\
\hline Were baseline characteristics similar? & Low risk & Adequate \\
\hline $\begin{array}{l}\text { Were baseline outcome measurements sim- } \\
\text { ilar? }\end{array}$ & Unclear risk & No baseline outcome measures reported \\
\hline Allocation concealment (selection bias) & High risk & $\begin{array}{l}\text { Clusters were listed in the order they had } \\
\text { been identified. Study groups were assigned } \\
\text { a computer-generated random number, or- } \\
\text { dered and consecutively applied to the list } \\
\text { of clusters. Possible to foresee allocation } \\
\text { with this method }\end{array}$ \\
\hline $\begin{array}{l}\text { Blinding of participants and personnel } \\
\text { (performance bias) } \\
\text { All outcomes }\end{array}$ & High risk & No blinding \\
\hline $\begin{array}{l}\text { Blinding of outcome assessment (detection } \\
\text { bias) } \\
\text { All outcomes }\end{array}$ & High risk & No blinding \\
\hline $\begin{array}{l}\text { Incomplete outcome data (attrition bias) } \\
\text { All outcomes }\end{array}$ & Low risk & $\begin{array}{l}\text { Proportion of children who died or left the } \\
\text { study is unlikely to result in bias }\end{array}$ \\
\hline Selective reporting (reporting bias) & High risk & $\begin{array}{l}\text { Collection of anthropometric data not } \\
\text { mentioned in protocol or published paper }\end{array}$ \\
\hline $\begin{array}{l}\text { Was the study adequately protected against } \\
\text { contamination? }\end{array}$ & Unclear risk & Not relevant for study design \\
\hline $\begin{array}{l}\text { Appropriate adjustment for potential con- } \\
\text { founders? }\end{array}$ & Unclear risk & Not relevant for study design \\
\hline
\end{tabular}

Interventions to improve water quality and supply, sanitation and hygiene practices, and their effects on the nutritional status of children 

to a village briefing meeting to introduce SODIS and the trial. Eligible households were permanent households within the village boundaries with children aged between 6 mo and $5 \mathrm{y}$. Households already using other methods of water treatment such as ceramic filtration were excluded

Description of participants: children aged 6 to 59 mo living in eligible households that were from the selected area. $97 \%$ drew water from unprotected boreholes; $25 \%$ of which drew water from shallow tube wells fitted with hand pumps (remainder unprotected wells or surface ponds. Water stored prior to drinking in $95 \%$ of the households and, of these, $71 \%$ stored it in $300 \mathrm{~L}$ lidded containers. $69 \%$ did not treat water before drinking. Mortality rates in this area were 110 to 143 per 1000 live births

Aim: to investigate the effect of solar disinfection (SODIS) of drinking water on the incidence of dysentery and non-dysentery diarrhoea among Cambodian children aged 6 to 59 mo

Description of intervention: Water quality intervention: SODIS. 2 × 2 L PET bottles were provided for each child. The carers of children were instructed to fill 1 bottle each day and place it in full, unobscured sunlight for a min of 6 hrs. Treated water was consumed on the day after exposure and water was to be stored for a max of $48 \mathrm{hrs}$. Carers were advised that children should drink directly from the bottle

Description of control: no bottle provided, usual practice maintained

Duration: 12 mo beginning March 2009

Intervention uptake: not stated

Coverage: not stated

Adherence: $>90 \%$ with only $5 \%$ of children having $<10$ mo follow-up and $2.3 \%$ having $<6$ mo follow-up

Cost: not stated

Process and implementation factors: not stated

Outcomes

Notes
Primary outcomes: rate of days with dysentery and days without dysentery diarrhoea Secondary outcomes: quality of water in SODIS bottles and storage containers in both control and intervention

\section{Risk of bias}

\begin{tabular}{lll}
\hline Bias & Authors' judgement & Support for judgement \\
\hline $\begin{array}{l}\text { Random sequence generation (selection } \\
\text { bias) }\end{array}$ & Low risk & $\begin{array}{l}\text { Households were randomised to interven- } \\
\text { tion and control by a raffle system }\end{array}$ \\
\hline $\begin{array}{l}\text { Were baseline characteristics similar? } \\
\text { tion risk }\end{array}$ & Low & Adequate
\end{tabular}




\section{McGuigan 2011 (Continued)}

\begin{tabular}{|c|c|c|}
\hline $\begin{array}{l}\text { Were baseline outcome measurements sim- } \\
\text { ilar? }\end{array}$ & Low risk & Adequate \\
\hline Allocation concealment (selection bias) & High risk & Insufficient information provided \\
\hline $\begin{array}{l}\text { Blinding of participants and personnel } \\
\text { (performance bias) } \\
\text { All outcomes }\end{array}$ & High risk & No blinding \\
\hline $\begin{array}{l}\text { Blinding of outcome assessment (detection } \\
\text { bias) } \\
\text { All outcomes }\end{array}$ & High risk & $\begin{array}{l}\text { No information provided about the assess- } \\
\text { ment of anthropometric outcomes }\end{array}$ \\
\hline $\begin{array}{l}\text { Incomplete outcome data (attrition bias) } \\
\text { All outcomes }\end{array}$ & Low risk & $\begin{array}{l}95 \% \text { children had }>10 \text { mo follow-up and } \\
\text { there were no significant differences in in- } \\
\text { tervention and control children. Adequate }\end{array}$ \\
\hline Selective reporting (reporting bias) & High risk & $\begin{array}{l}\text { The collection of nutrition outcomes was } \\
\text { stated in the protocol but the data were not } \\
\text { presented in the published report. This in- } \\
\text { formation was received directly from the } \\
\text { author }\end{array}$ \\
\hline
\end{tabular}

Was the study adequately protected against Unclear risk

Not relevant for study design

contamination?

Appropriate adjustment for potential con- Unclear risk founders?

\section{Schlesinger 1983}

Methods

Participants
Study design: longitudinal study. No randomisation

Sample size: 209 children (120 intervention, 89 control) aged < 4 years from 570 families Country: urban slum, Santiago, Chile

Method of participant selection: slum families were chosen to receive sanitary units. Socioeconomic status of these families was assessed (Graffar scale) and participating families belonged to low strata. In general, families were chosen at random, however, the extreme poverty of a few families mandated that units be allocated to them without further waiting. Due to this the intervention arm contained families who were worse off than the control arm (who received units 20 mo after the intervention arm)

Description of participants: Intervention - children aged $<4$ years living in this Santiago slum receiving the sanitary intervention; Control - children aged $<4$ years living in this Santiago slum

Interventions

Aim: to evaluate the bacterial contamination of feeding bottles, seasonal diarrhoea episodes, nutritional status and changes in attitudes, habits and quality of life in intervention families 
Schlesinger 1983 (Continued)

Description of intervention: Sanitary and water supply: the programme included building a brick-and-timber 'sanitary unit' in each plot. This unit (covering $6 \mathrm{~m}^{2}$ ) had a kitchen, bathroom and outdoor sink. The kitchen was equipped with shelves and sink; the bathroom had a lavatory, flush toilet and a shower. Hot water was supplied for the whole unit by a geyser

Description of control: no 'sanitary unit' installed

Duration: 20 mo beginning July 1977

Intervention uptake: weekly interviews by trained registered nurses monitored adequate use of the units. Water consumption in each plot was measured by meters showing that the average water consumption during summer and winter was significantly higher in the intervention group

Coverage: not stated

Adherence: not stated

Cost: not stated

Process and implementation factors: not stated

Primary outcomes: contamination of infant feeding bottles; seasonal diarrhoea, nutritional status (low weight), changes of attitudes, habits and quality of life

Notes

Risk of bias

\begin{tabular}{|c|c|c|}
\hline Bias & Authors' judgement & Support for judgement \\
\hline $\begin{array}{l}\text { Random sequence generation (selection } \\
\text { bias) }\end{array}$ & High risk & No random sequence generation \\
\hline Were baseline characteristics similar? & High risk & $\begin{array}{l}\text { Intervention group were poorer on average } \\
\text { than control group }\end{array}$ \\
\hline $\begin{array}{l}\text { Were baseline outcome measurements sim- } \\
\text { ilar? }\end{array}$ & High risk & $\begin{array}{l}\text { Intervention group had a higher percentage } \\
\text { of low-weight children at baseline }\end{array}$ \\
\hline Allocation concealment (selection bias) & High risk & $\begin{array}{l}\text { Intervention and control groups were cho- } \\
\text { sen by the researchers }\end{array}$ \\
\hline $\begin{array}{l}\text { Blinding of participants and personnel } \\
\text { (performance bias) } \\
\text { All outcomes }\end{array}$ & High risk & No blinding \\
\hline $\begin{array}{l}\text { Blinding of outcome assessment (detection } \\
\text { bias) } \\
\text { All outcomes }\end{array}$ & Unclear risk & No information provided \\
\hline
\end{tabular}

Incomplete outcome data (attrition bias) Low risk Adequate

All outcomes

Selective reporting (reporting bias)

Unclear risk

No study protocol available

Interventions to improve water quality and supply, sanitation and hygiene practices, and their effects on the nutritional status of children

(Review)

Copyright $(2013$ The Cochrane Collaboration. Published by John Wiley \& Sons, Ltd. 


\section{Schlesinger 1983 (Continued)}

Was the study adequately protected against Unclear risk contamination?

Appropriate adjustment for potential con- Unclear risk founders?
Possible that contamination occurred if families in the intervention group allowed the control families to use their facilities. Nothing is reported regarding this, however

None stated

AGP: aminoalkyl glucosaminide 4-phosphate

BMI: body mass index

c/s: cross-sectional

d: day

HAZ: height-for-age z-score

$\mathrm{HH}$ : household

hr: hour

mo: months

NCHS: national center for health statistics

NGO: non-governmental organisation

ORS: oral rehydration salts

PET: Polyethylene terephthalate

SD: standard deviation

SES: socioeconomic status

SODIS: solar disinfection

VIP: ventilated improved pit

WAZ: weight-for-age z-score

$y:$ years

Characteristics of excluded studies [ordered by study ID]

\begin{tabular}{l|l}
\hline Study & Reason for exclusion \\
\hline Anderson 1981 & Baseline data only \\
\hline Anon, 1981 & This paper is a review \\
\hline Anon, 1990 & Study design was not included in protocol: case control \\
\hline Barros 2008 & Study design was not included in protocol: no intervention \\
\hline Buttenheim 2008 & No control arm \\
\hline Checkley 2004 & Study design was not included in protocol: no intervention
\end{tabular}

Interventions to improve water quality and supply, sanitation and hygiene practices, and their effects on the nutritional status of children 
(Continued)

\begin{tabular}{|c|c|}
\hline Chen 2005 & Nutrition was not included as an outcome \\
\hline Chiang 1991 & Baseline data only \\
\hline Chirwa 2008 & Study design was not included in protocol: no intervention \\
\hline Cousens 1990 & Study design was not included in protocol: no intervention \\
\hline Daniels 1991 & Study design was not included in protocol: case control \\
\hline Dong 2009 & Nutrition was not included as an outcome \\
\hline Esrey 1988 & Study design was not included in protocol: no intervention \\
\hline Esrey 1992 & Study design was not included in protocol: no intervention \\
\hline Esrey 1996 & No control arm \\
\hline Etiler 2004 & Study design was not included in protocol: no intervention \\
\hline Farah 2007 & Study design was not included in protocol: no intervention \\
\hline Fernandez 1969 & Study design was not included in protocol: no intervention \\
\hline Fikree 2000 & Study design was not included in protocol: no intervention \\
\hline Gokhale 1994 & Study design was not included in protocol: no intervention \\
\hline Guerrant 1983 & Study design was not included in protocol: no intervention \\
\hline Hartinger 2011a & Baseline data only \\
\hline Hartinger $2011 \mathrm{~b}$ & Baseline data only \\
\hline Hebert 1984 & Study design was not included in protocol: no intervention \\
\hline Hebert $1985 a$ & Study design was not included in protocol: no intervention \\
\hline Hebert $1985 \mathrm{~b}$ & Study design was not included in protocol: no intervention \\
\hline Henry 1981 & Study design was not included in protocol: no intervention \\
\hline Hoek 2002 & No control arm \\
\hline Hou 2010 & Intervention was not included in this review \\
\hline Li 1996 & Nutrition was not included as an outcome \\
\hline
\end{tabular}


(Continued)

\begin{tabular}{|c|c|}
\hline Lindskog 1987 & Study design was not included in protocol: case control \\
\hline Lindskog 1988 & No control arm \\
\hline Lindskog 1994 & No control arm \\
\hline Lopez de Romana 1989 & Study design was not included in protocol: no intervention \\
\hline Lye 1984 & Study design was not included in protocol: no intervention \\
\hline Ma 2007 & Nutrition was not included as an outcome \\
\hline Malekafzali 2000 & $\begin{array}{l}\text { No control arm. Outcome of the WASH intervention was not reported in isolation (there were multiple } \\
\text { other dietary/education interventions and it was not possible to separate out the effect of the WASH } \\
\text { intervention) }\end{array}$ \\
\hline Merchant 2003 & Study design was not included in protocol: no intervention \\
\hline Moy 1991 & Study design was not included in protocol: case control \\
\hline Nisbet 1974 & Intervention was not included in this review \\
\hline Parent 2002 & Intervention was not included in this review \\
\hline Sanou 2011 & No control arm \\
\hline Stoler 2011 & No control arm. Nutrition was not included as a study outcome \\
\hline Wang 2010 & Intervention was not included in this review \\
\hline Xiong 2010 & Nutrition was not included as an outcome \\
\hline $\mathrm{Xu} 2001$ & Nutrition was not included as an outcome \\
\hline Yang 2006 & Nutrition was not included as an outcome \\
\hline Yao 2000 & Intervention was not included in this review \\
\hline Zhang 1999 & Nutrition was not included as an outcome \\
\hline Zhang 2000 & Nutrition was not included as an outcome \\
\hline Zhang 2012 & Intervention was not included in this review \\
\hline Zhu 1997a & Nutrition was not included as an outcome \\
\hline Zhu $1997 b$ & Nutrition was not included as an outcome \\
\hline
\end{tabular}

Interventions to improve water quality and supply, sanitation and hygiene practices, and their effects on the nutritional status of children

(Review)

Copyright $\odot 2013$ The Cochrane Collaboration. Published by John Wiley \& Sons, Ltd. 
WASH: water, sanitation and hygiene

\section{Characteristics of ongoing studies [ordered by study ID]}

\section{SHARE}

\begin{tabular}{|c|c|}
\hline Trial name or title & Improved Sanitation in Rural Orissa, India \\
\hline Methods & The study is a cluster-randomised, controlled trial conducted among 100 villages in Puri district, Orissa, India \\
\hline Participants & 2500 households and 15,000 people \\
\hline Interventions & The construction and use of latrines \\
\hline Outcomes & Height, weight \\
\hline \multicolumn{2}{|l|}{ Starting date } \\
\hline Contact information & Dr Thomas Clasen, LSHTM \\
\hline Notes & $\begin{array}{l}\text { This pioneering study is designed to help close the evidence gap on the effectiveness and cost-effectiveness of } \\
\text { sanitation, particularly rural sanitation in low-income settings. It is a large-scale effectiveness study addressing } \\
\text { many sector challenges, including health outcomes, latrine use as well as coverage, and non-health outcomes }\end{array}$ \\
\hline \multicolumn{2}{|l|}{ SHINE } \\
\hline Trial name or title & Sanitation, Hygiene and Nutrition interventions (SHINE) - Zimbabwe \\
\hline Methods & A cluster-randomised factorial trial \\
\hline \multicolumn{2}{|l|}{ Participants } \\
\hline \multicolumn{2}{|l|}{ Interventions } \\
\hline Outcomes & Anaemia, height, weight \\
\hline \multicolumn{2}{|l|}{ Starting date } \\
\hline Contact information & Prof. Jean Humphrey, Johns Hopkins \\
\hline Notes & $\begin{array}{l}\text { This trial is looking at the effect on tropical enteropathy, anaemia and growth in young children in rural } \\
\text { Zimbabwe and is being carried out in collaboration with ZVITAMBO Project, Harare Zimbabwe, the Johns } \\
\text { Hopkins Bloomberg School of Public Health, and McGill University }\end{array}$ \\
\hline
\end{tabular}


WASH Benefits

\begin{tabular}{ll}
\hline Trial name or title & WASH benefits - Bangladesh \& Kenya \\
\hline Methods & Cluster-randomised controlled trials \\
\hline Participants & $>5000$ newborns per country \\
\hline Interventions & 6 arms: water quality; sanitation; handwashing; combined WASH; nutrition; nutrition and WASH \\
\hline Outcomes & Health and developmental outcomes, including anthropometry \\
\hline Starting date & $\begin{array}{l}\text { Two trials to measure the impact of interventions among newborn infants in rural Bangladesh and Kenya. } \\
\text { These trials aim to determine which individual or combined WASH interventions are effective at achieving } \\
\text { health, social and economic impacts, and to assess impacts on objective measures of health including stunting, } \\
\text { cognition and nutritional absorptive capacity }\end{array}$ \\
\hline Notes & \begin{tabular}{l} 
http:/www.washbenefits.net/ \\
\hline
\end{tabular} \\
\hline
\end{tabular}

\section{WSP - Handwashing}

\begin{tabular}{ll}
\hline Trial name or title & WSP - Global Scaling up Handwashing \\
\hline Methods & RCT \\
\hline Participants & 4 countries: Tanzania, Senegal, Vietnam and Peru; and Tanzania, India and Indonesia \\
\hline Interventions & Arm circumference; weight, length/height, head circumference and anaemia \\
\hline Outcomes & \\
\hline Starting date & $\begin{array}{l}\text { WSP is conducting a RCT looking at the effect of handwashing with soap on a number of indicators including } \\
\text { nutritional outcomes (stunting and wasting) }\end{array}$ \\
\hline Contact information & Notes
\end{tabular}

\section{WSP - Sanitation}

\begin{tabular}{ll}
\hline Trial name or title & WSP - Global Scaling up Sanitation \\
\hline Methods & RCT \\
\hline Participants & 3 countries: Tanzania, India and Indonesia \\
\hline
\end{tabular}

\section{Interventions}

Interventions to improve water quality and supply, sanitation and hygiene practices, and their effects on the nutritional status of children

(Review)

Copyright $\odot 2013$ The Cochrane Collaboration. Published by John Wiley \& Sons, Ltd. 
WSP - Sanitation (Continued)

Outcomes Arm circumference; weight, length/height, head circumference and anaemia

Starting date

Contact information

Notes

WSP is conducting a RCT looking at the effect of improved sanitation on a number of indicators including nutritional outcomes (stunting and wasting)

RCT: randomised controlled trial

WASH: water, sanitation and hygiene 
DATA AND ANALYSES

\section{Comparison 1. Weight-for-age}

\begin{tabular}{|c|c|c|c|c|}
\hline Outcome or subgroup title & $\begin{array}{l}\text { No. of } \\
\text { studies }\end{array}$ & $\begin{array}{c}\text { No. of } \\
\text { participants }\end{array}$ & Statistical method & Effect size \\
\hline 1 Weight-for-age (all studies) & 10 & & Mean Difference (IV, Fixed, 95\% CI) & Totals not selected \\
\hline 1.1 Non-randomised studies & 3 & & Mean Difference (IV, Fixed, 95\% CI) & $0.0[0.0,0.0]$ \\
\hline 1.2 Randomised studies & 7 & & Mean Difference (IV, Fixed, 95\% CI) & $0.0[0.0,0.0]$ \\
\hline 2 Weight-for-age (RCTs only) & 7 & 4627 & Mean Difference (IV, Random, 95\% CI) & $0.05[-0.01,0.12]$ \\
\hline 3 Weight-for-age (gender) & 7 & & Mean Difference (IV, Random, 95\% CI) & Subtotals only \\
\hline 3.1 Boys & 7 & 2344 & Mean Difference (IV, Random, 95\% CI) & $0.00[-0.07,0.08]$ \\
\hline 3.2 Girls & 7 & 2283 & Mean Difference (IV, Random, 95\% CI) & $0.11[0.01,0.21]$ \\
\hline 4 Weight-for-age (age group) & 7 & & Mean Difference (IV, Random, 95\% CI) & Subtotals only \\
\hline $4.1<=2$ years & 7 & 1464 & Mean Difference (IV, Random, 95\% CI) & $0.07[-0.11,0.24]$ \\
\hline $4.2>2$ years & 7 & 3163 & Mean Difference (IV, Random, 95\% CI) & $0.03[-0.01,0.06]$ \\
\hline
\end{tabular}

\section{Comparison 2. Weight-for-height}

\begin{tabular}{lccll} 
Outcome or subgroup title & $\begin{array}{c}\text { No. of } \\
\text { studies }\end{array}$ & $\begin{array}{c}\text { No. of } \\
\text { participants }\end{array}$ & \multicolumn{1}{c}{ Statistical method } & Effect size \\
\hline 1 Weight-for-height (all studies) & 9 & & Mean Difference (IV, Fixed, 95\% CI) & Totals not selected \\
1.1 Non-randomised studies & 2 & & Mean Difference (IV, Fixed, 95\% CI) & $0.0[0.0,0.0]$ \\
1.2 Randomised studies & 7 & & Mean Difference (IV, Fixed, 95\% CI) & $0.0[0.0,0.0]$ \\
2 Weight-for-height (RCTs only) & 7 & 4622 & Mean Difference (IV, Random, 95\% CI) & $0.02[-0.07,0.11]$ \\
3 Weight-for-height (gender) & 7 & & Mean Difference (IV, Random, 95\% CI) & Subtotals only \\
3.1 Boys & 7 & 2343 & Mean Difference (IV, Random, 95\% CI) & $-0.02[-0.12,0.08]$ \\
3.2 Girls & 7 & 2279 & Mean Difference (IV, Random, 95\% CI) & $0.04[-0.08,0.15]$ \\
4 Weight-for-height (age group) & 7 & & Mean Difference (IV, Random, 95\% CI) & Subtotals only \\
$\quad 4.1<=2$ years & 7 & 1464 & Mean Difference (IV, Random, 95\% CI) & $0.05[-0.17,0.27]$ \\
$4.2>2$ years & 7 & 3158 & Mean Difference (IV, Random, 95\% CI) & $-0.01[-0.07,0.05]$ \\
\hline
\end{tabular}

\section{Comparison 3. Height-for-age}

\begin{tabular}{lccll} 
Outcome or subgroup title & $\begin{array}{c}\text { No. of } \\
\text { studies }\end{array}$ & $\begin{array}{c}\text { No. of } \\
\text { participants }\end{array}$ & Statistical method & Effect size \\
\hline 1 Height-for-age (all studies) & 11 & & Mean Difference (IV, Fixed, 95\% CI) & Totals not selected \\
$\quad$ 1.1 Non-randomised studies & 4 & & Mean Difference (IV, Fixed, 95\% CI) & $0.0[0.0,0.0]$ \\
$\quad$ 1.2 Randomised studies & 7 & & Mean Difference (IV, Fixed, 95\% CI) & $0.0[0.0,0.0]$ \\
2 Height-for-age (RCTs only) & 7 & 4627 & Mean Difference (IV, Random, 95\% CI) & $0.08[0.00,0.16]$ \\
3 Height-for-age (gender) & 7 & & Mean Difference (IV, Random, 95\% CI) & Subtotals only \\
$\quad$ 3.1 Boys & 7 & 2344 & Mean Difference (IV, Random, 95\% CI) & $0.01[-0.08,0.11]$ \\
\hline
\end{tabular}

Interventions to improve water quality and supply, sanitation and hygiene practices, and their effects on the nutritional status of children 66 (Review)

Copyright () 2013 The Cochrane Collaboration. Published by John Wiley \& Sons, Ltd. 
3.2 Girls

4 Height-for-age (age group)

$4.1<=2$ years

$4.2>2$ years
2283

1464

3163
Mean Difference (IV, Random, 95\% CI)

Mean Difference (IV, Random, 95\% CI)

Mean Difference (IV, Random, 95\% CI)

Mean Difference (IV, Random, 95\% CI)
$0.15[0.04,0.26]$

Subtotals only

$0.05[-0.13,0.22]$

$0.06[0.00,0.12]$

Comparison 4. Weight

\begin{tabular}{lcclc} 
Outcome or subgroup title & $\begin{array}{c}\text { No. of } \\
\text { studies }\end{array}$ & $\begin{array}{c}\text { No. of } \\
\text { participants }\end{array}$ & Statistical method & Effect size \\
\hline 1 Weight (all studies) & 10 & & Mean Difference (IV, Fixed, 95\% CI) & Totals not selected \\
1.1 Non-randomised studies & 3 & & Mean Difference (IV, Fixed, 95\% CI) & $0.0[0.0,0.0]$ \\
1.2 Randomised studies & 7 & & Mean Difference (IV, Fixed, 95\% CI) & $0.0[0.0,0.0]$ \\
2 Weight (RCTs only) & 7 & 4627 & Mean Difference (IV, Random, 95\% CI) & $0.12[-0.03,0.27]$ \\
\hline
\end{tabular}

\section{Comparison 5. Height}

\begin{tabular}{lcclc} 
Outcome or subgroup title & $\begin{array}{c}\text { No. of } \\
\text { studies }\end{array}$ & $\begin{array}{c}\text { No. of } \\
\text { participants }\end{array}$ & \multicolumn{1}{c}{ Statistical method } & Effect size \\
\hline 1 Height (all studies) & 10 & & Mean Difference (IV, Fixed, 95\% CI) & Totals not selected \\
1.1 Non-randomised studies & 3 & & Mean Difference (IV, Fixed, 95\% CI) & $0.0[0.0,0.0]$ \\
1.2 Randomised studies & 7 & & Mean Difference (IV, Fixed, 95\% CI) & $0.0[0.0,0.0]$ \\
2 Height (RCTs only) & 7 & 4627 & Mean Difference (IV, Random, 95\% CI) & $0.50[-0.10,1.10]$ \\
\hline
\end{tabular}




\section{Analysis I.I. Comparison I Weight-for-age, Outcome I Weight-for-age (all studies).}

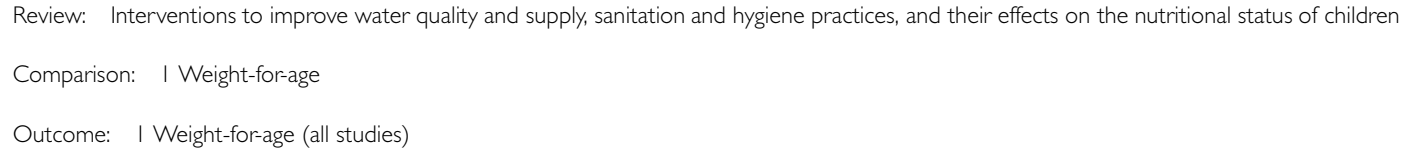

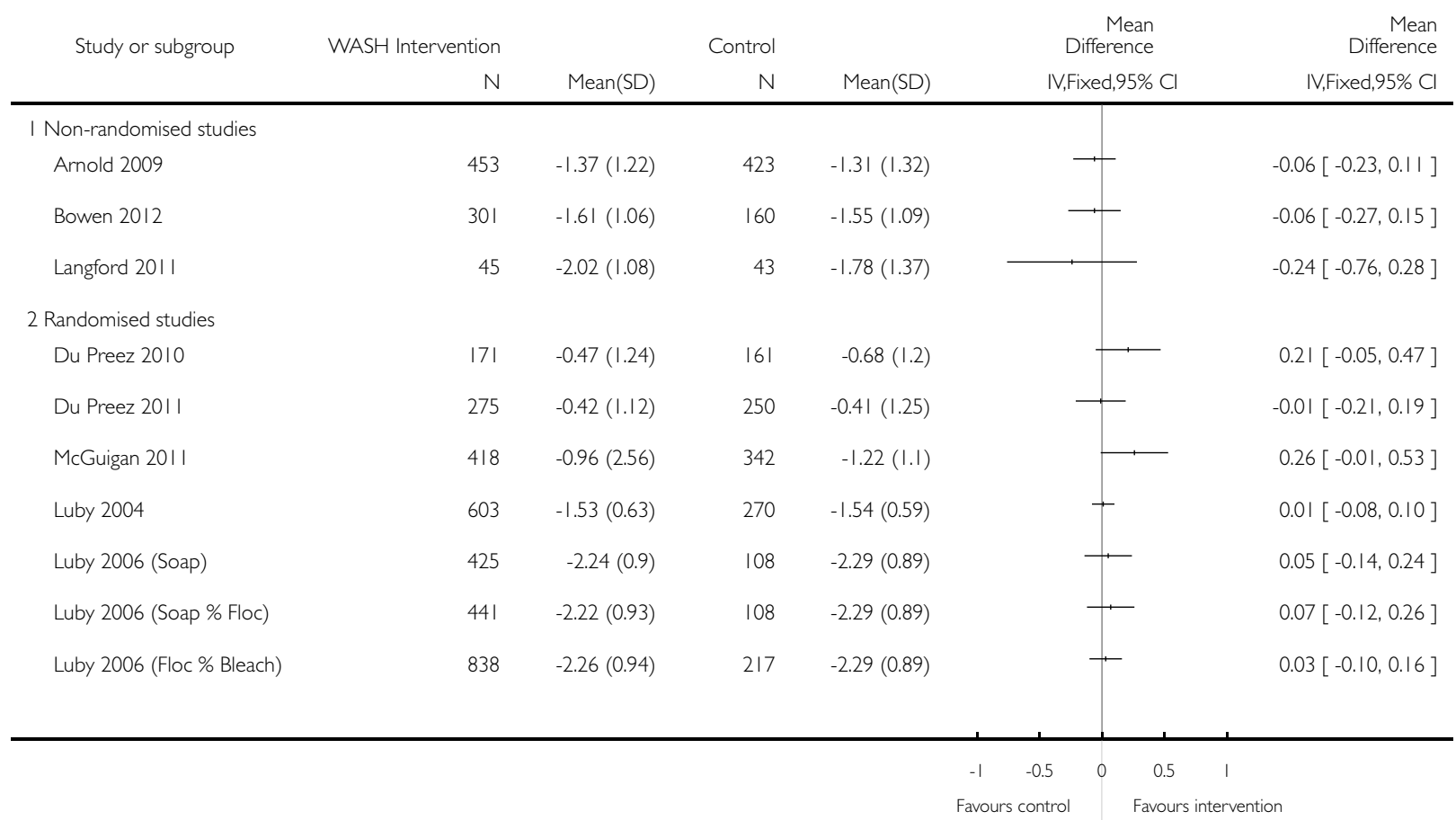




\section{Analysis I.2. Comparison I Weight-for-age, Outcome 2 Weight-for-age (RCTs only).}

Review: Interventions to improve water quality and supply, sanitation and hygiene practices, and their effects on the nutritional status of children

Comparison: I Weight-for-age

Outcome: 2 Weight-for-age (RCTs only)

\begin{tabular}{|c|c|c|c|c|c|c|c|}
\hline \multirow[t]{2}{*}{ Study or subgroup } & \multirow{2}{*}{$\begin{array}{r}\text { WASH Intervention } \\
N\end{array}$} & \multicolumn{3}{|c|}{ Control } & \multirow{2}{*}{$\begin{array}{c}\text { Mean } \\
\text { Difference } \\
\text { IV,Random,95\% Cl }\end{array}$} & \multirow[t]{2}{*}{ Weight } & \multirow{2}{*}{$\begin{array}{r}\text { Mear } \\
\text { Difference } \\
\text { IV,Random,95\% C }\end{array}$} \\
\hline & & Mean(SD) & $\mathrm{N}$ & Mean(SD) & & & \\
\hline Du Preez 2010 & 171 & $-0.47(1.31)$ & 161 & $-0.68(1.28)$ & 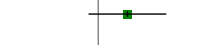 & $5.6 \%$ & $0.21[-0.07,0.49]$ \\
\hline Du Preez 201 I & 275 & $-0.42(1.15)$ & 250 & $-0.4 \mid(1.35)$ & $\longrightarrow$ & $9.3 \%$ & $-0.01[-0.23,0.21]$ \\
\hline McGuigan 2011 & 418 & $-0.96(2.58)$ & 342 & $-1.22(1.11)$ & ए- & $5.8 \%$ & $0.26[-0.01,0.53]$ \\
\hline Luby 2004 & 603 & $-1.53(1)$ & 270 & $-1.54(0.68)$ & 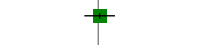 & $33.4 \%$ & $0.01[-0.10,0.12]$ \\
\hline Luby 2006 (Soap) & 425 & $-2.24(1.24)$ & 108 & $-2.29(0.73)$ & $\rightarrow$ & $13.1 \%$ & $0.05[-0.13,0.23]$ \\
\hline Luby 2006 (Soap \% Floc) & 441 & $-2.22(1.27)$ & 109 & $-2.29(0.73)$ & $\longrightarrow$ & $13.2 \%$ & $0.07[-0.11,0.25]$ \\
\hline Luby 2006 (Floc \% Bleach) & 838 & $-2.26(0.76)$ & 216 & $-2.29(1.04)$ & $\mp$ & $19.7 \%$ & $0.03[-0.12,0.18]$ \\
\hline Total (95\% CI) & 3171 & & 1456 & & $\bullet$ & $100.0 \%$ & $0.05[-0.01,0.12]$ \\
\hline \multicolumn{8}{|c|}{ Heterogeneity: $\operatorname{Tau}^{2}=0.0 ; \mathrm{Chi}^{2}=4.4 \mathrm{I}, \mathrm{df}=6(\mathrm{P}=0.62) ;\left.\right|^{2}=0.0 \%$} \\
\hline \multicolumn{8}{|c|}{ Test for overall effect: $Z=|.5|(P=0.13)$} \\
\hline \multicolumn{8}{|c|}{ Test for subgroup differences: Not applicable } \\
\hline & & & & & -0.5 & 1 & \\
\hline
\end{tabular}

Interventions to improve water quality and supply, sanitation and hygiene practices, and their effects on the nutritional status of children 


\section{Analysis I.3. Comparison I Weight-for-age, Outcome 3 Weight-for-age (gender).}

Review: Interventions to improve water quality and supply, sanitation and hygiene practices, and their effects on the nutritional status of children

Comparison: I Weight-for-age

Outcome: 3 Weight-for-age (gender)

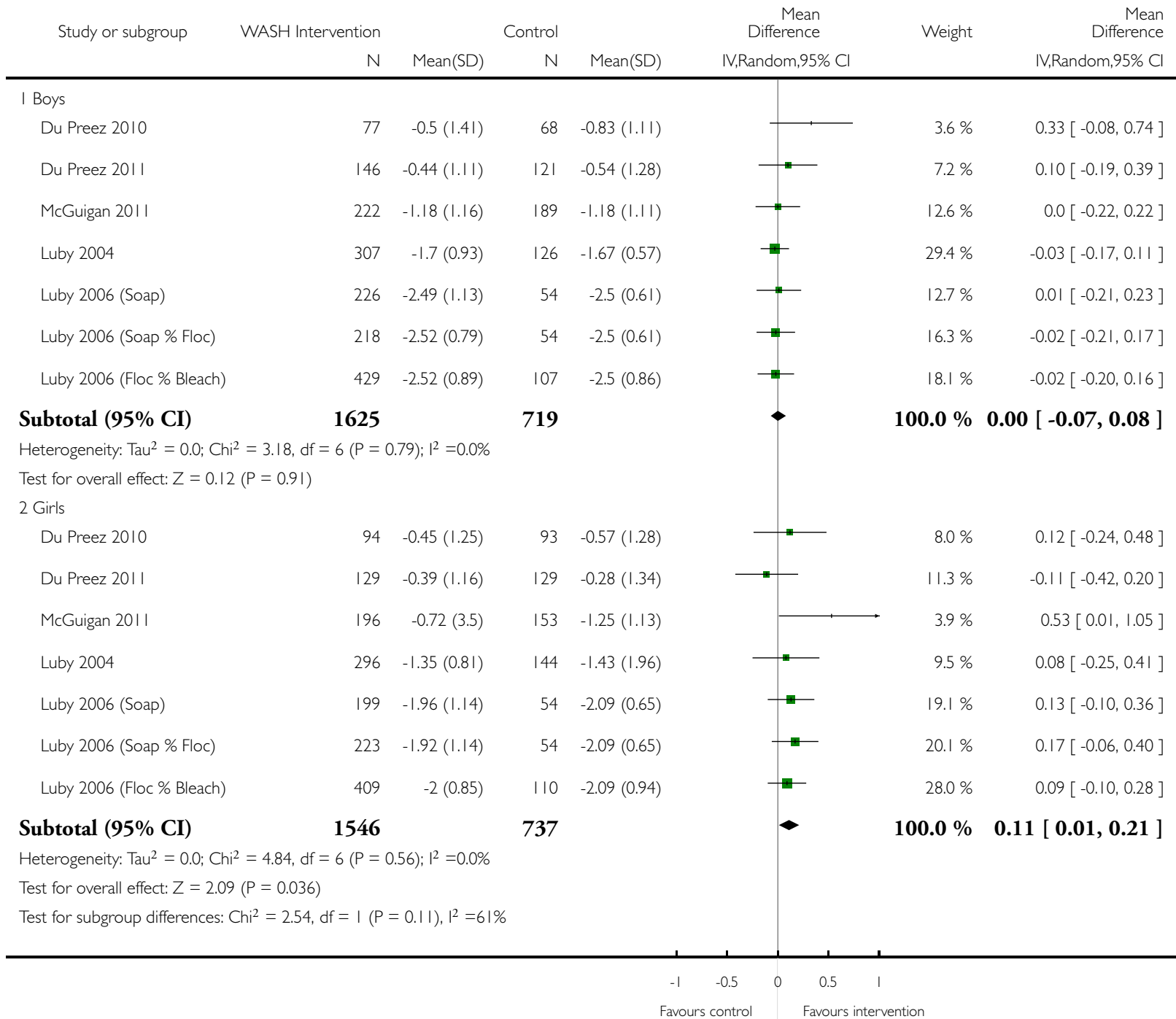

Interventions to improve water quality and supply, sanitation and hygiene practices, and their effects on the nutritional status of children 


\section{Analysis I.4. Comparison I Weight-for-age, Outcome 4 Weight-for-age (age group).}

Review: Interventions to improve water quality and supply, sanitation and hygiene practices, and their effects on the nutritional status of children

Comparison: I Weight-for-age

Outcome: 4 Weight-for-age (age group)

Study or subgroup WASH Intervention

N Mean(SD)

Control

N Mean(SD)

I <= 2 years
Du Preez 2010
Du Preez 201।
McGuigan 20II
Luby 2004
Luby 2006 (Soap)
Luby 2006 (Soap \% Floc)
Luby 2006 (Floc \% Bleach)

Subtotal $(95 \% \mathrm{CI})$

Heterogeneity: $\mathrm{Tau}^{2}=0.02 ; \mathrm{Chi}^{2}=9.46, \mathrm{df}=6(\mathrm{P}=0.15) ; \mathrm{I}^{2}=37 \%$

Test for overall effect: $Z=0.75(P=0.45)$

$2>2$ years

Du Preez 2010
Du Preez 201 I
McGuigan 2011
Luby 2004
Luby 2006 (Soap)
Luby 2006 (Soap \% Floc)
Luby 2006 (Floc \% Bleach)

Subtotal $(95 \% \mathrm{CI})$

Heterogeneity: $\mathrm{Tau}^{2}=0.0 ; \mathrm{Chi}^{2}=1.35, \mathrm{df}=6(\mathrm{P}=0.97) ; \mathrm{I}^{2}=0.0 \%$

Test for overall effect: $Z=1.65(P=0.10)$

Test for subgroup differences: $\mathrm{Chi}^{2}=0.19, \mathrm{df}=\mathrm{I}(\mathrm{P}=0.66), \mathrm{I}^{2}=0.0 \%$

$\begin{array}{rrrr}44 & -0.01(1.6) & 53 & -0.74(1.51) \\ 88 & -0.23(1.23) & 85 & -0.06(1.39) \\ 178 & -0.54(3.71) & 149 & -0.98(1.17) \\ 209 & -1.72(0.81) & 104 & -1.71(0.64) \\ 102 & -3.31(1.34) & 29 & -3.28(0.83) \\ 127 & -3.06(1.46) & 30 & -3.28(0.83) \\ 207 & -3.37(1.29) & 59 & -3.28(1.19) \\ 955 & & \mathbf{5 0 9} & \end{array}$

$127-0.63(1.09)$

$187-0.51(1.03)$

$240-1.27(1.01)$

$394-1.43(0.61)$

$323-1.9(0.38)$

$314-1.88(0.52)$

$631-1.9(0.42)$

2216

947

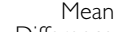

Difference

IV,Random,95\% Cl

Weight

Mean

V.Random,95\%

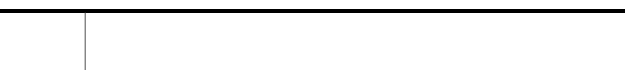

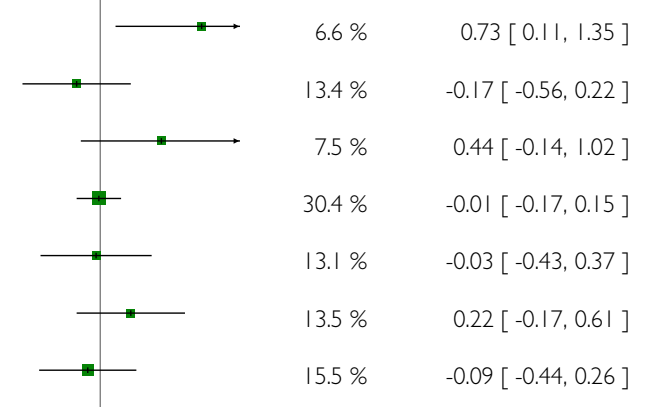

$100.0 \% \quad 0.07[-0.11,0.24]$

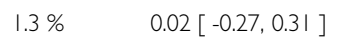

$1.8 \% \quad 0.07[-0.17,0.31]$

$2.8 \% \quad 0.12[-0.07,0.31]$

$7.6 \% \quad 0.01[-0.11,0.13]$

$29.8 \% \quad 0.02[-0.04,0.08]$

$20.5 \% \quad 0.04[-0.03,0.11]$

$36.3 \% \quad 0.02[-0.03,0.07]$

$100.0 \% 0.03[-0.01,0.06]$ 


\section{Analysis 2.I. Comparison 2 Weight-for-height, Outcome I Weight-for-height (all studies).}

Review: Interventions to improve water quality and supply, sanitation and hygiene practices, and their effects on the nutritional status of children

Comparison: 2 Weight-for-height

Outcome: I Weight-for-height (all studies)

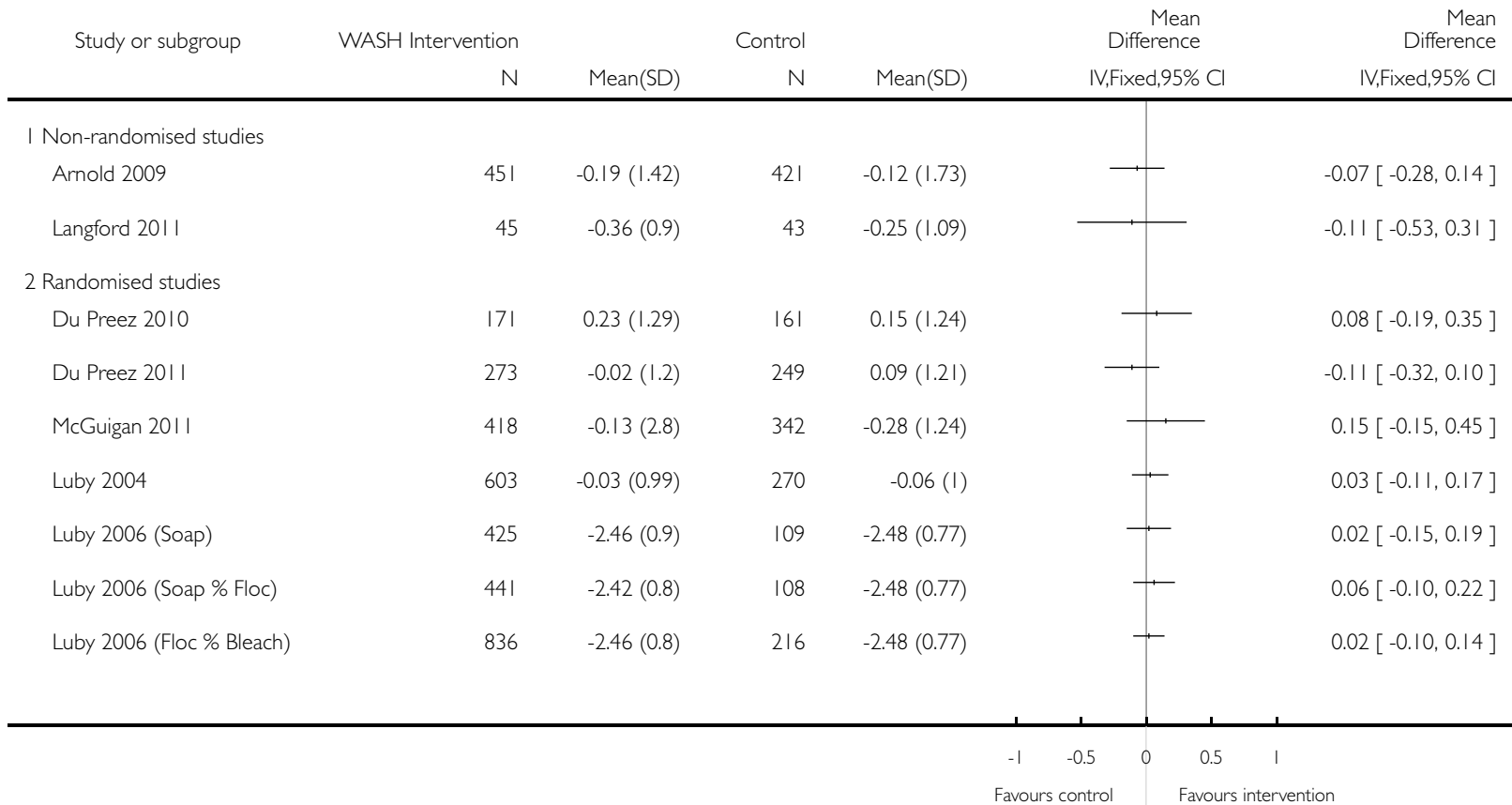

Interventions to improve water quality and supply, sanitation and hygiene practices, and their effects on the nutritional status of children 


\section{Analysis 2.2. Comparison 2 Weight-for-height, Outcome 2 Weight-for-height (RCTs only).}

Review: Interventions to improve water quality and supply, sanitation and hygiene practices, and their effects on the nutritional status of children

Comparison: 2 Weight-for-height

Outcome: 2 Weight-for-height (RCTs only)

\begin{tabular}{|c|c|c|c|c|c|c|c|}
\hline \multirow[t]{2}{*}{ Study or subgroup } & \multirow{2}{*}{$\begin{array}{r}\text { WASH Intervention } \\
\mathrm{N} \\
\end{array}$} & \multicolumn{3}{|c|}{ Control } & \multirow{2}{*}{$\begin{array}{c}\text { Mean } \\
\text { Difference } \\
\text { IV,Random,95\% Cl }\end{array}$} & \multirow[t]{2}{*}{ Weight } & \multirow{2}{*}{$\begin{array}{r}\text { Mear } \\
\text { Difference } \\
\text { IV,Random,95\% C }\end{array}$} \\
\hline & & Mean(SD) & $\mathrm{N}$ & Mean(SD) & & & \\
\hline Du Preez 2010 & $17 \mid$ & $0.23(1.32)$ & 161 & $0.15(1.3)$ & $\longrightarrow$ & $10.5 \%$ & $0.08[-0.20,0.36]$ \\
\hline Du Preez 2011 & 273 & $-0.02(1.09)$ & 249 & $0.09(1.17)$ & $\rightarrow$ & $22.0 \%$ & $-0.11[-0.30,0.08]$ \\
\hline McGuigan 201। & 418 & $-0.13(2.84)$ & 342 & $-0.28(1.28)$ & $\mp$ & $9.0 \%$ & $0.15[-0.15,0.45]$ \\
\hline Luby 2004 & 603 & $-0.03(2.4)$ & 270 & $-0.06(2.43)$ & \begin{tabular}{l|l} 
\\
-1
\end{tabular} & $6.9 \%$ & $0.03[-0.32,0.38]$ \\
\hline Luby 2006 (Soap) & 425 & $-2.46(0.97)$ & 108 & $-2.48(1.07)$ & & $16.9 \%$ & $0.02[-0.20,0.24]$ \\
\hline Luby 2006 (Soap \% Floc) & 441 & $-2.42(0.93)$ & 108 & $-2.48(1.07)$ & 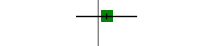 & $17.2 \%$ & $0.06[-0.16,0.28]$ \\
\hline Luby 2006 (Floc \% Bleach) & 836 & $-2.46(1.24)$ & 217 & $-2.48(1.5 \mid)$ & $\longrightarrow$ & $17.5 \%$ & $0.02[-0.20,0.24]$ \\
\hline Total (95\% CI) & 3167 & & 1455 & & - & $100.0 \%$ & $0.02[-0.07,0.11]$ \\
\hline \multicolumn{8}{|c|}{ Heterogeneity: $\operatorname{Tau}^{2}=0.0 ; \mathrm{Chi}^{2}=2.72, \mathrm{df}=6(\mathrm{P}=0.84) ; \mathrm{I}^{2}=0.0 \%$} \\
\hline \multicolumn{8}{|c|}{ Test for overall effect: $Z=0.36(P=0.72)$} \\
\hline \multicolumn{8}{|c|}{ Test for subgroup differences: Not applicable } \\
\hline & & & & & -0.5 & 1 & \\
\hline
\end{tabular}

Interventions to improve water quality and supply, sanitation and hygiene practices, and their effects on the nutritional status of children 


\section{Analysis 2.3. Comparison 2 Weight-for-height, Outcome 3 Weight-for-height (gender).}

Review: Interventions to improve water quality and supply, sanitation and hygiene practices, and their effects on the nutritional status of children

Comparison: 2 Weight-for-height

Outcome: 3 Weight-for-height (gender)

Study or subgroup WASH Intervention

WASH Intervention

N Mean(SD)

I Boys
Du Preez 2010
Du Preez 201 I
McGuigan 201 I
Luby 2004
Luby 2006 (Soap)
Luby 2006 (Soap \% Floc)
Luby 2006 (Floc \% Bleach)

Subtotal (95\% CI)

Heterogeneity: $\mathrm{Tau}^{2}=0.0 ; \mathrm{Chi}^{2}=5.16, \mathrm{df}=6(\mathrm{P}=0.52) ; \mathrm{I}^{2}=0.0 \%$

Test for overall effect: $Z=0.34(P=0.73)$

2 Girls

$$
\begin{aligned}
& \text { Du Preez } 2010 \\
& \text { Du Preez 201 I } \\
& \text { McGuigan } 2011 \\
& \text { Luby } 2004 \\
& \text { Luby } 2006 \text { (Soap) } \\
& \text { Luby } 2006 \text { (Soap \% Floc) } \\
& \text { Luby } 2006 \text { (Floc \% Bleach) }
\end{aligned}
$$

\section{Subtotal $(95 \% \mathrm{CI})$}

Heterogeneity: $\operatorname{Tau}^{2}=0.0 ; \mathrm{Chi}^{2}=3.18, \mathrm{df}=6(\mathrm{P}=0.79) ; \mathrm{I}^{2}=0.0 \%$

Test for overall effect: $Z=0.62(P=0.54)$

Test for subgroup differences: $\mathrm{Chi}^{2}=0.48, \mathrm{df}=\mathrm{I}(\mathrm{P}=0.49), \mathrm{I}^{2}=0.0 \%$

$$
\begin{array}{cc}
94 & 0.2(1.25) \\
128 & -0.001(1.3) \\
196 & 0.065(3.85) \\
296 & 0.079(1.96) \\
199 & -2.13(0.89) \\
223 & -2.2(1.08) \\
407 & -2.24(0.72)
\end{array}
$$

1543

736
Control Mean Weight Mean

N Mean(SD)

IV,Random,95\% Cl

IV,Random,95\% Cl

N,Random, $95 \% \mathrm{Cl}$

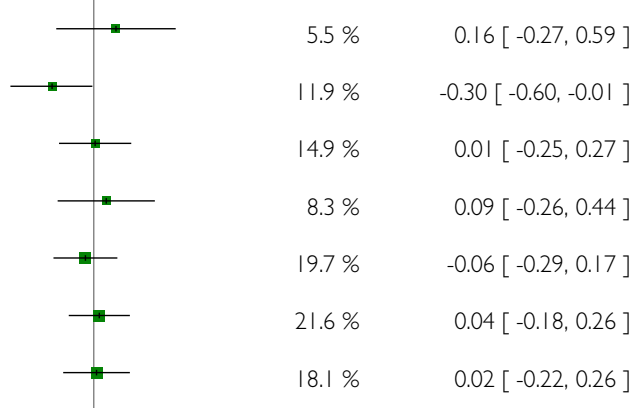

719

$100.0 \%-0.02[-0.12,0.08]$

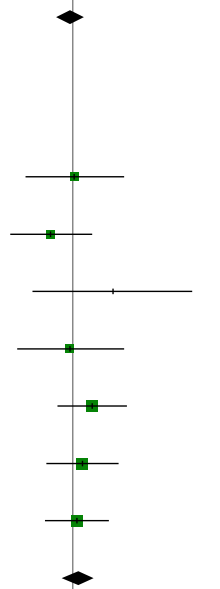

$10.2 \%$

$0.01[-0.34,0.37]$

$14.7 \%$

$-0.16[-0.45,0.14]$

$4.0 \%$

$0.29[-0.29,0.86]$

$8.7 \%$

$-0.02[-0.40,0.37]$

$20.0 \%$

$0.14[-0.11,0.39]$

$18.6 \%$

$0.07[-0.19,0.33]$

$23.8 \%$

$0.03[-0.20,0.26]$

$100.0 \% \quad 0.04[-0.08,0.15]$ 


\section{Analysis 2.4. Comparison 2 Weight-for-height, Outcome 4 Weight-for-height (age group).}

Review: Interventions to improve water quality and supply, sanitation and hygiene practices, and their effects on the nutritional status of children

Comparison: 2 Weight-for-height

Outcome: 4 Weight-for-height (age group)

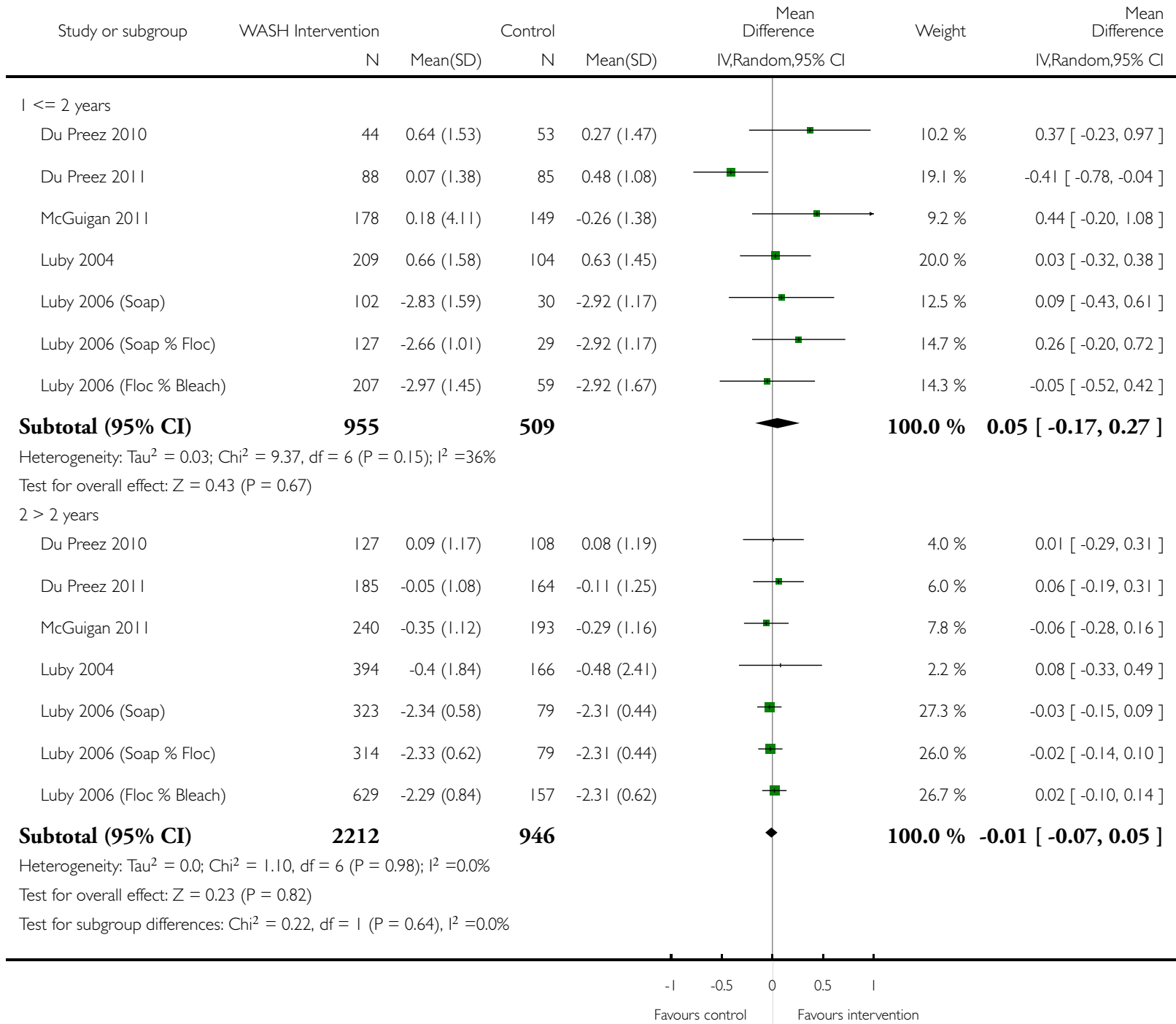

Interventions to improve water quality and supply, sanitation and hygiene practices, and their effects on the nutritional status of children 75 


\section{Analysis 3.I. Comparison 3 Height-for-age, Outcome I Height-for-age (all studies).}

Review: Interventions to improve water quality and supply, sanitation and hygiene practices, and their effects on the nutritional status of children

Comparison: 3 Height-for-age

Outcome: I Height-for-age (all studies)

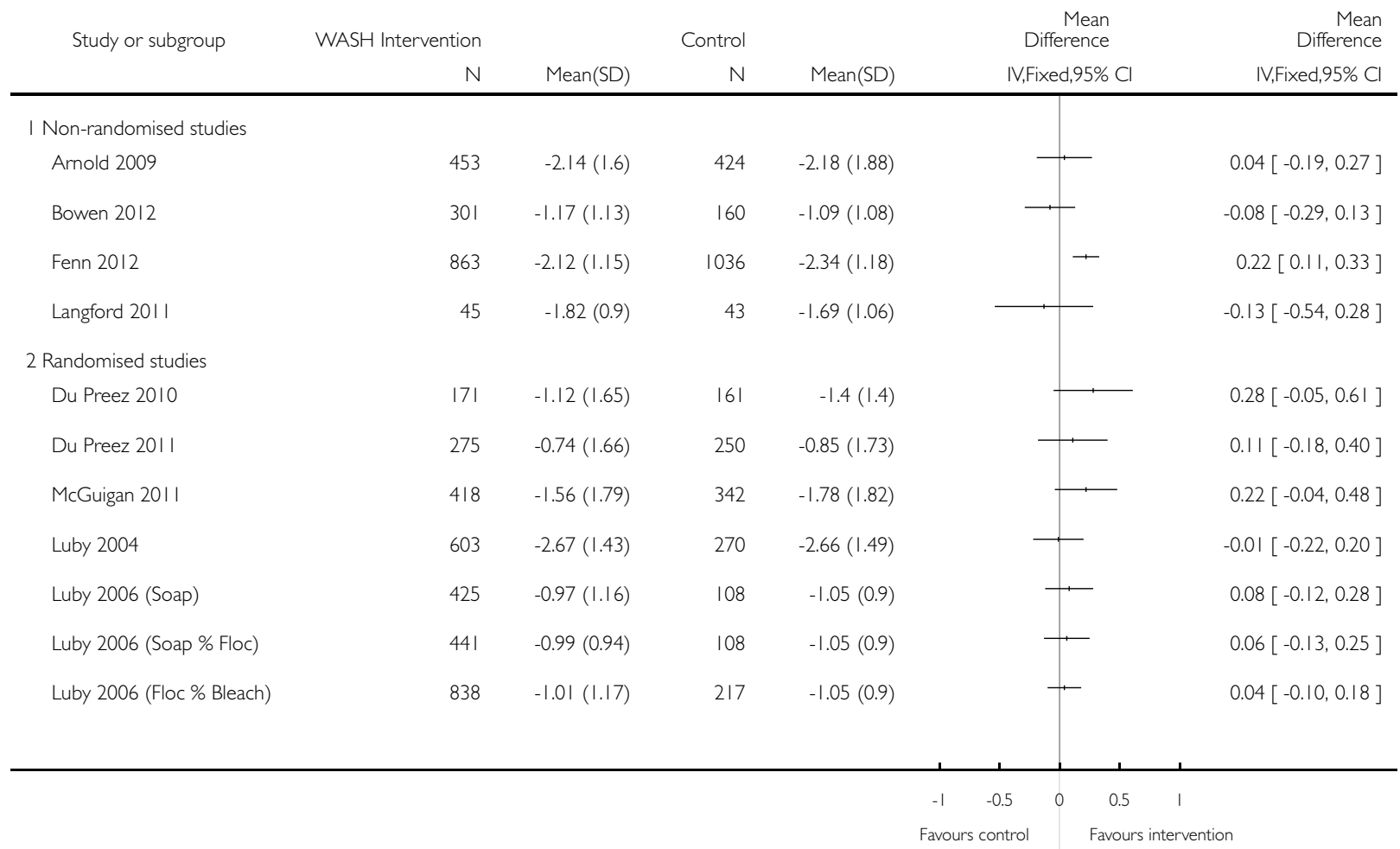

Interventions to improve water quality and supply, sanitation and hygiene practices, and their effects on the nutritional status of children 


\section{Analysis 3.2. Comparison 3 Height-for-age, Outcome 2 Height-for-age (RCTs only).}

Review: Interventions to improve water quality and supply, sanitation and hygiene practices, and their effects on the nutritional status of children

Comparison: 3 Height-for-age

Outcome: 2 Height-for-age (RCTs only)

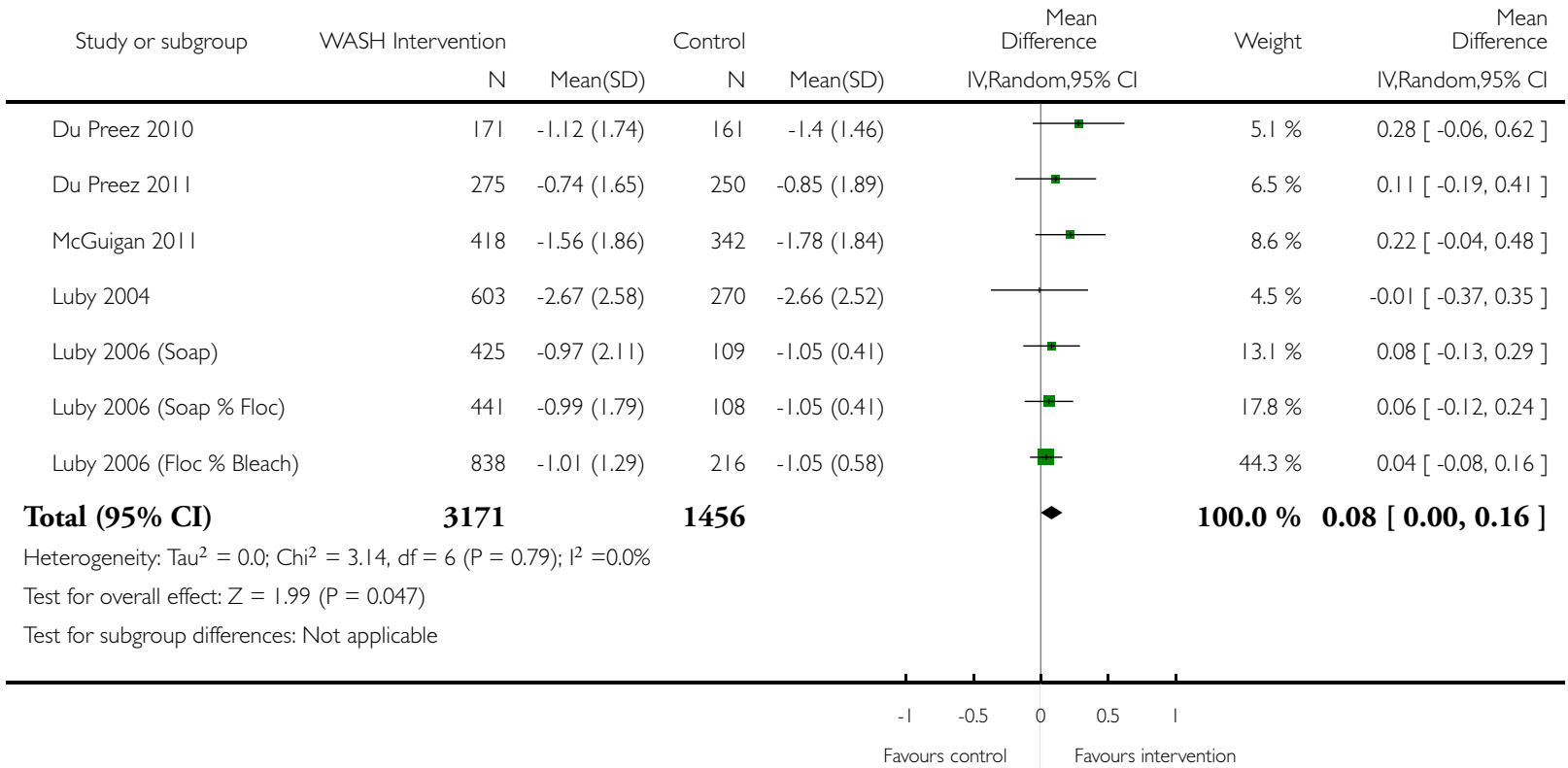

Interventions to improve water quality and supply, sanitation and hygiene practices, and their effects on the nutritional status of children 


\section{Analysis 3.3. Comparison 3 Height-for-age, Outcome 3 Height-for-age (gender).}

Review: Interventions to improve water quality and supply, sanitation and hygiene practices, and their effects on the nutritional status of children

Comparison: 3 Height-for-age

Outcome: 3 Height-for-age (gender)

Study or subgroup MASH Intervention Mean Mean

N Mean(SD) N Mean(SD) IV,Random,95\% Cl IV,Random,95\% Cl

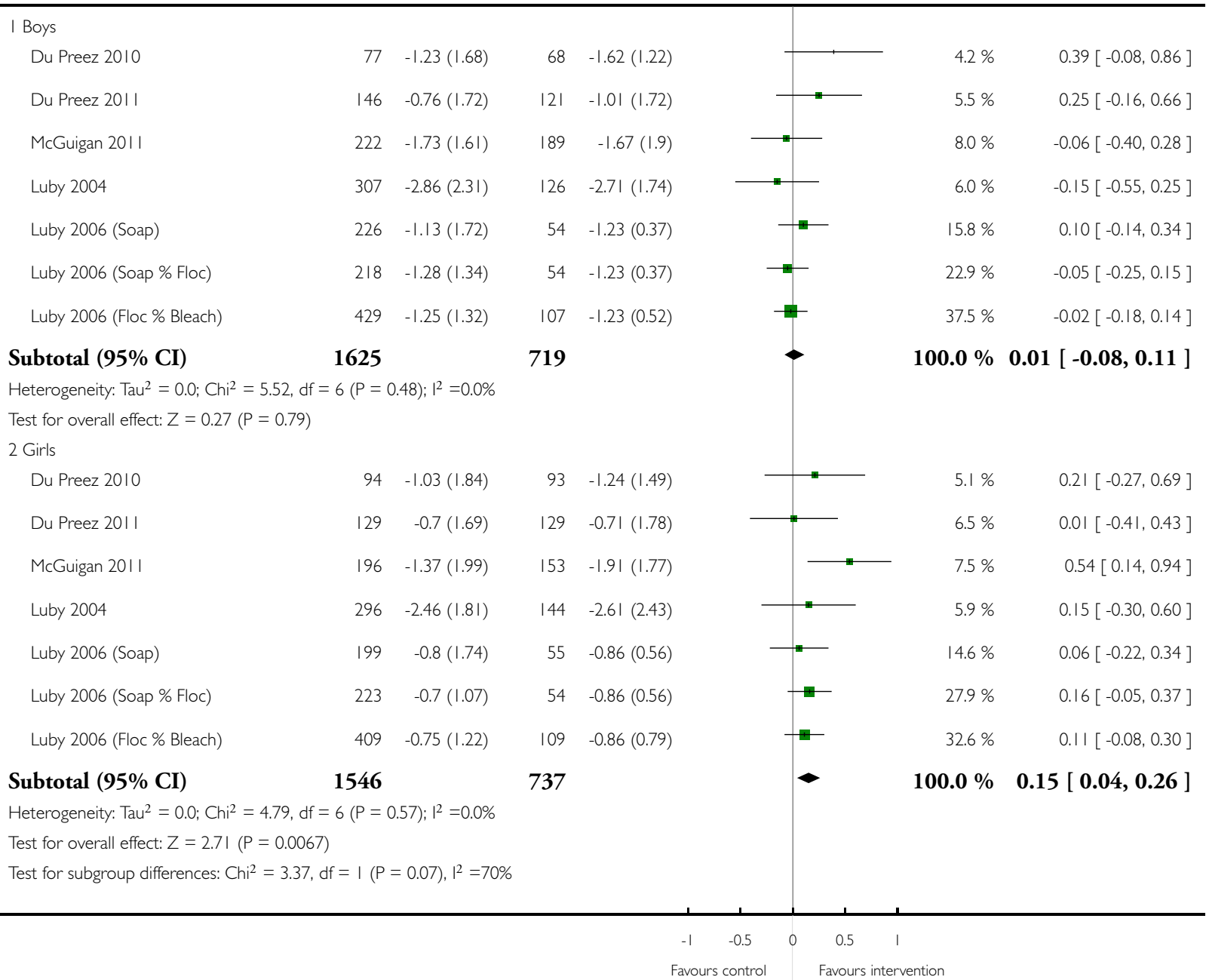

Interventions to improve water quality and supply, sanitation and hygiene practices, and their effects on the nutritional status of children 


\section{Analysis 3.4. Comparison 3 Height-for-age, Outcome 4 Height-for-age (age group).}

Review: Interventions to improve water quality and supply, sanitation and hygiene practices, and their effects on the nutritional status of children

Comparison: 3 Height-for-age

Outcome: 4 Height-for-age (age group)

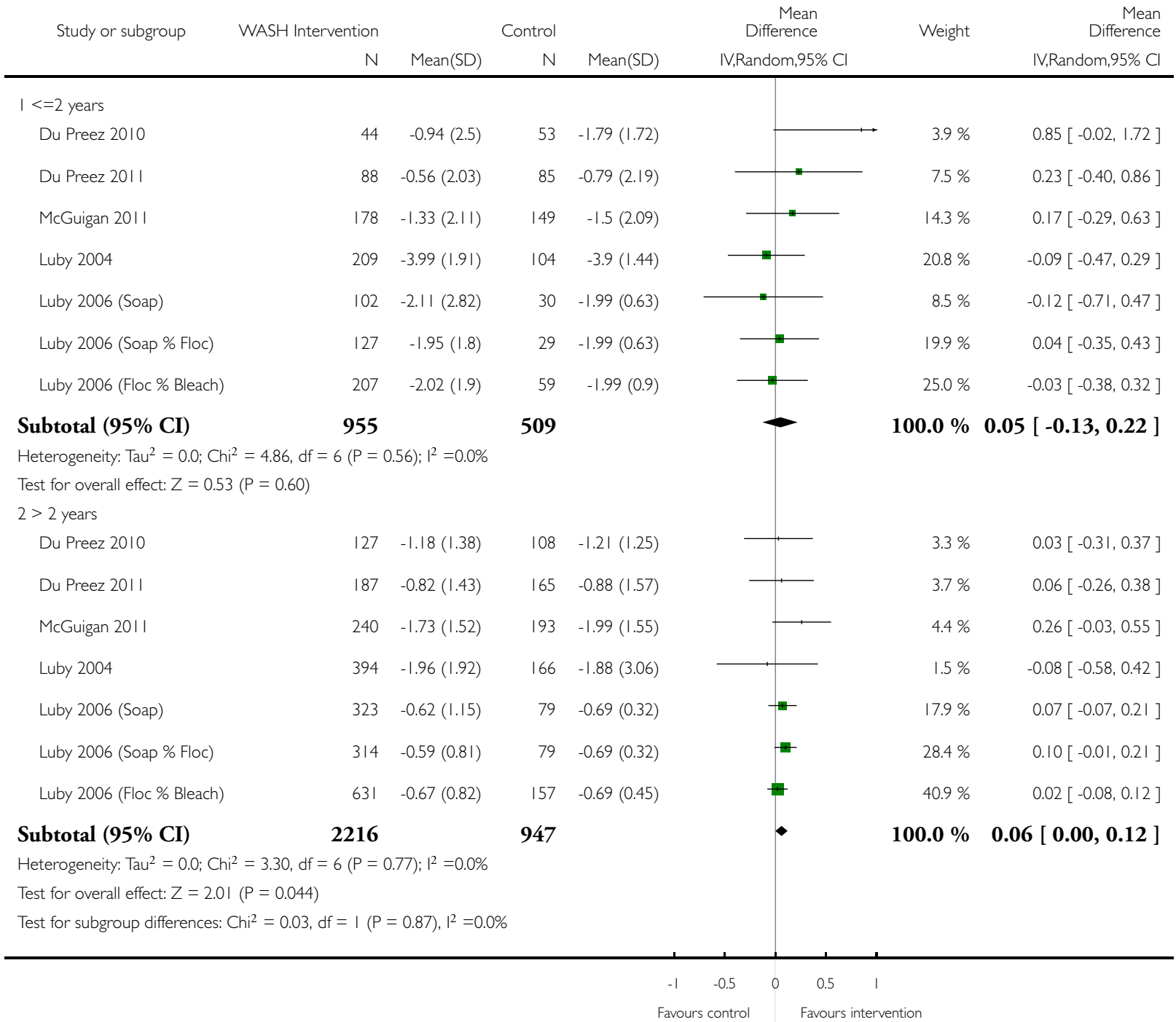

Interventions to improve water quality and supply, sanitation and hygiene practices, and their effects on the nutritional status of children 


\section{Analysis 4.I. Comparison 4 Weight, Outcome I Weight (all studies).}

Review: Interventions to improve water quality and supply, sanitation and hygiene practices, and their effects on the nutritional status of children

Comparison: 4 Weight

Outcome: I Weight (all studies)

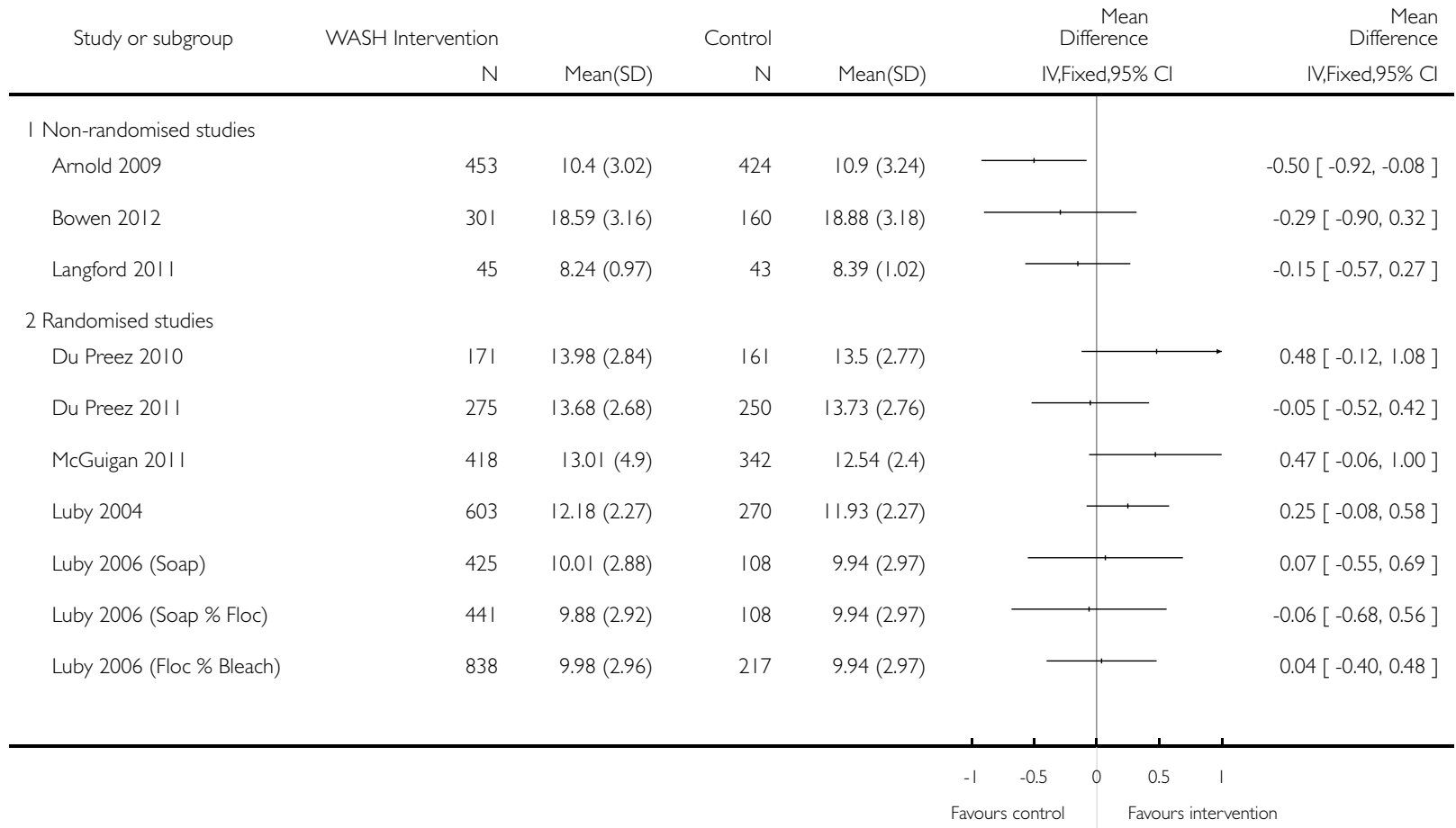

Interventions to improve water quality and supply, sanitation and hygiene practices, and their effects on the nutritional status of children 


\section{Analysis 4.2. Comparison 4 Weight, Outcome 2 Weight (RCTs only).}

Review: Interventions to improve water quality and supply, sanitation and hygiene practices, and their effects on the nutritional status of children

Comparison: 4 Weight

Outcome: 2 Weight (RCTs only)

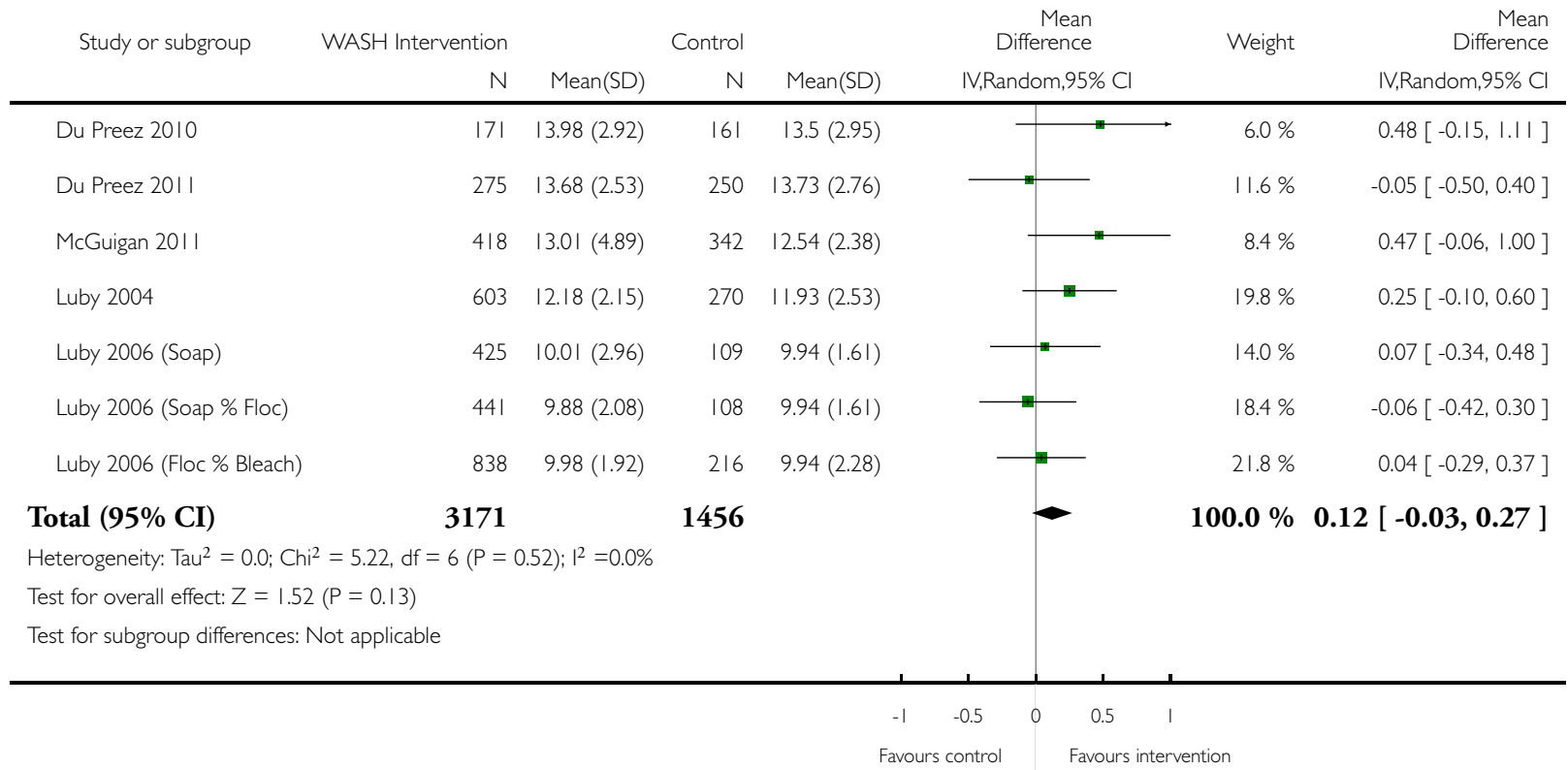

Interventions to improve water quality and supply, sanitation and hygiene practices, and their effects on the nutritional status of children 


\section{Analysis 5.I. Comparison 5 Height, Outcome I Height (all studies).}

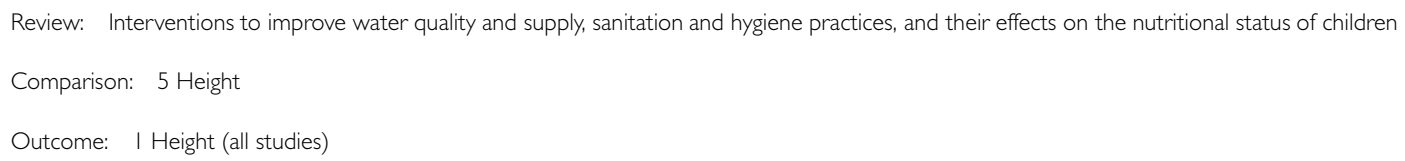

N Mean(SD)

I Non-randomised studies

Arnold 2009

Bowen 2012

$453 \quad 79.8(11.86)$

425

$81.4(11.85)$

Langford 2011

$301 \quad 115.39(7.53)$

160

$116.32(6.8)$

522

$93.07(10.4)$

437

$92.9(11.06)$

2 Randomised studies

Du Preez 2010

171 $93.08(9.7)$

161

$91.6(9.8)$

Du Preez 201

275

$93.2(9.8)$

250

$92.8(10.04)$

McGuigan 201 I

$418 \quad 90.77(9.66)$

342

$89.75(9.54)$

Luby 2004

Luby 2006 (Soap)

603

$87.6(11.8)$

270

$86.8(12.2)$

425

$87.16(14.19)$

108

$86.7(14.5)$

Luby 2006 (Soap \% Floc)

Luby 2006 (Floc \% Bleach)

44I $\quad 86.34($ (14.4)

108

$86.7(14.5)$

$838 \quad 86.99(\mid 4.5)$

217

$86.7(14.5)$

IV,Fixed,95\% Cl

IV,Fixed,95\% Cl

$-1.60[-3.17,-0.03]$

$-0.93[-2.28,0.42]$

$0.17[-1.20,1.54]$

$1.48[-0.62,3.58]$

$0.40[-1.30,2.10]$

$1.02[-0.35,2.39]$

$0.80[-0.93,2.53]$

$0.46[-2.59,3.51$ ]

$-0.36[-3.41,2.69]$

$0.29[-1.87,2.45]$ 


\section{Analysis 5.2. Comparison 5 Height, Outcome 2 Height (RCTs only).}

Review: Interventions to improve water quality and supply, sanitation and hygiene practices, and their effects on the nutritional status of children

Comparison: 5 Height

Outcome: 2 Height (RCTs only)

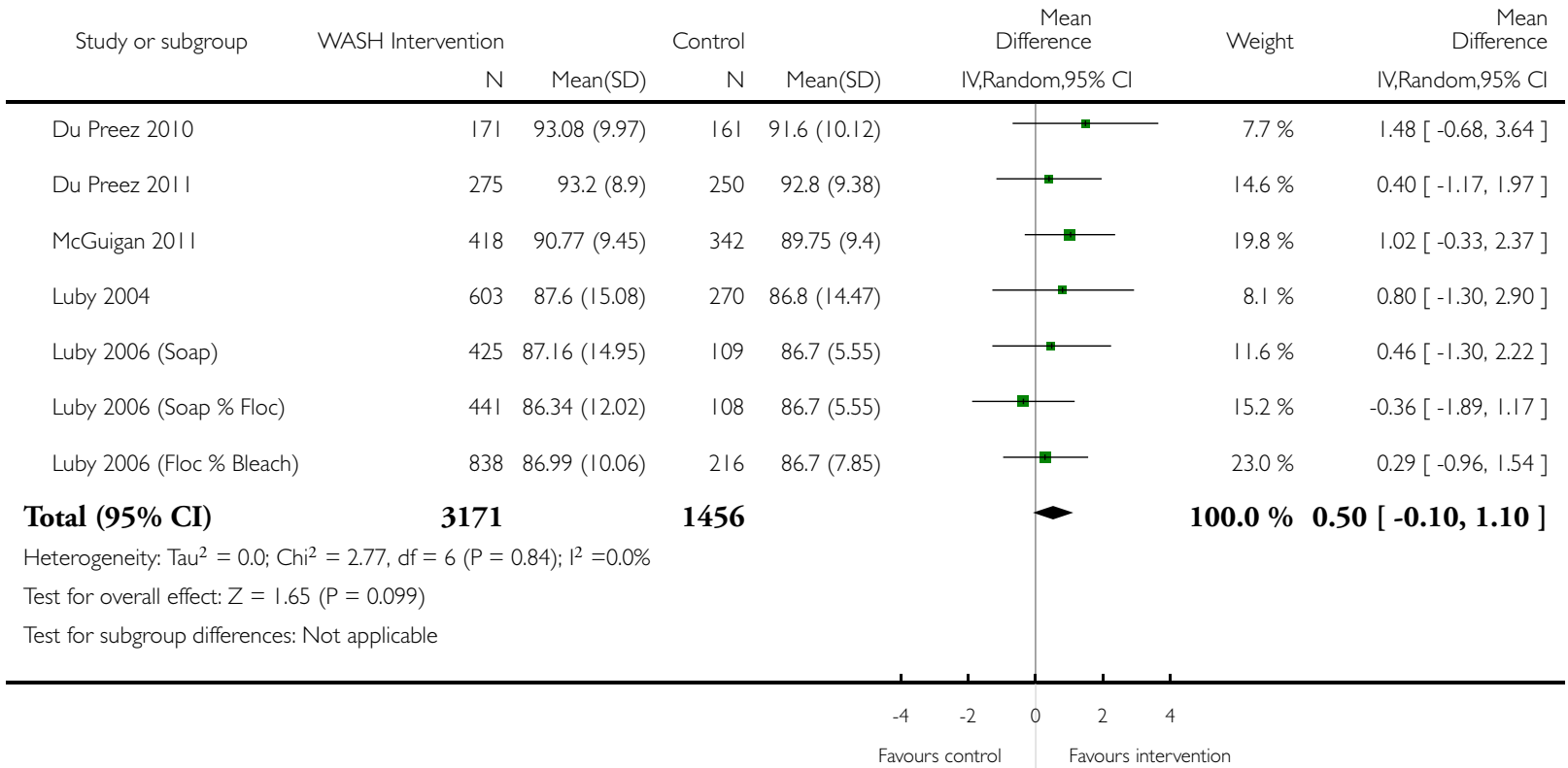

\section{ADDITIONAL TABLES}

Table 1. Outline of included studies

\begin{tabular}{|c|c|c|c|c|}
\hline Lead author & Country & Intervention type & Delivery method & Target group \\
\hline
\end{tabular}

All 4 WASH elements

Hasan 1989 Bangladesh Sanitation and water quantity Installation of a double pit

Children aged 12 to 35 mo and water quality and hygiene water seal latrine per housepromotion hold; installation of 'Tara' hand pump; education regarding use of pumps, latrines and washing of hands with ash 
Table 1. Outline of included studies (Continued)

Water quantity, sanitation and hygiene

Fenn $2012 \quad$ Ethiopia

Water quantity, sanitation and hygiene

Installation of protected water

Children aged 6 to 36 mo

supply; sanitation education;

personal hygiene education

Water quality, quantity and hygiene

Huttly 1990 Nigeria Water quantity, quality and hygiene education

Provision of boreholes with hand pumps and promotion and construction of VIP latrines along with a health education component that included information on breastfeeding, nutrition, water use, personal hygiene, environmental sanitation, diarrhoea prevention and oral rehydration treatment

\section{Water quantity and sanitation}

\begin{tabular}{|c|c|c|c|}
\hline Schlesinger 1983 & Chile & Sanitation and water supply & $\begin{array}{l}\text { Building of a 'sanitary unit' in } \\
\text { each plot. Each unit included } \\
\text { a kitchen, bathroom and an } \\
\text { outdoor sink. The kitchen } \\
\text { was equipped with shelves and } \\
\text { sink; the bathroom had a lava- } \\
\text { tory, flush toilet and a shower. } \\
\text { Hot water was supplied for the } \\
\text { whole unit by a geyser }\end{array}$ \\
\hline
\end{tabular}

\section{Water quality and hygiene}

\begin{tabular}{|c|c|c|c|c|}
\hline Arnold 2009 & Guatemala & $\begin{array}{l}\text { Water quality (boiling/solar } \\
\text { disinfection/chlorination) and } \\
\text { handwashing (with soap) }\end{array}$ & $\begin{array}{l}\text { Train the trainer - training by } \\
\text { NGO of community women } \\
\text { with the aim of promoting san- } \\
\text { itation and hygiene practices } \\
\text { through social marketing and } \\
\text { household visits }\end{array}$ & $\begin{array}{l}\text { Households with children aged } \\
\leq 3 \text { yrs }\end{array}$ \\
\hline
\end{tabular}


Table 1. Outline of included studies (Continued)

\begin{tabular}{|c|c|c|c|c|}
\hline Bowen 2012 & Pakistan & Water quality and hygiene & $\begin{array}{l}\text { Field workers } \\
\text { conducted neighbourhood ed- } \\
\text { ucational meetings (sanitation } \\
\text { and hygiene practices), carried } \\
\text { out biweekly meetings and dis- } \\
\text { tributed soap, and soap + floc- } \\
\text { culent-disinfectant to the } 2 \text { in- } \\
\text { tervention groups }\end{array}$ & $\begin{array}{l}\text { Children }<5 \text { yrs }(2003) \text {. Chil- } \\
\text { dren }<96 \text { mo }(2009)\end{array}$ \\
\hline Luby 2006 & Pakistan & Water quality and hygiene & $\begin{array}{l}\text { Field workers } \\
\text { conducted neighbourhood ed- } \\
\text { ucational meetings (sanitation } \\
\text { and hygiene practices), carried } \\
\text { out biweekly meetings and dis- } \\
\text { tributed soap, and soap + floc- } \\
\text { culent-disinfectant to the } 2 \text { in- } \\
\text { tervention groups }\end{array}$ & Children $<5$ yrs \\
\hline
\end{tabular}

\section{Hygiene}

\begin{tabular}{l|l|l|l|}
\hline Ahmed 1993 & Bangladesh & Hygiene promotion & $\begin{array}{l}\text { Positive deviance model - ed- Children aged } 9 \text { to 18 mo } \\
\text { ucation for sanitation and hy- } \\
\text { giene }\end{array}$ \\
\hline Langford 2011 & Nepal & Hygiene promotion & $\begin{array}{l}\text { Handwashing programmes in Children aged 3 to 12 mo } \\
\text { the community }\end{array}$ \\
\hline Luby 2004 & Pakistan & Hygiene promotion & $\begin{array}{l}\text { Weekly visits in 25 neighbour- Children }<15 \text { yrs } \\
\text { hoods to promote handwash- } \\
\text { ing with soap after defecation } \\
\text { and before preparing food, eat- } \\
\text { ing and feeding a child. Inter- } \\
\text { vention households received a } \\
\text { regular supply of either plain or } \\
\text { antibacterial soap }\end{array}$ \\
\hline
\end{tabular}

\section{Sanitation}

\begin{tabular}{|c|c|c|c|}
\hline Guzman 1968 & Guatemala & Sanitation/health intervention & $\begin{array}{l}\text { A safe and continuous water } \\
\text { supply provided for the com- } \\
\text { munity; assistance provided for } \\
\text { the building of latrines for each } \\
\text { household; health clinic for } \\
\text { community }\end{array}$ \\
\hline
\end{tabular}

Interventions to improve water quality and supply, sanitation and hygiene practices, and their effects on the nutritional status of children 
Table 1. Outline of included studies (Continued)

\section{Water quality}

\begin{tabular}{|c|c|c|c|c|}
\hline Du Preez 2010 & South Africa & Water quality & $\begin{array}{l}\text { Solar water disinfection } \\
\text { (SODIS) }\end{array}$ & Children aged 6 to $59 \mathrm{mo}$ \\
\hline Du Preez 2011 & Kenya & Water quality & SODIS & Children aged 6 to $59 \mathrm{mo}$ \\
\hline McGuigan 2011 & Cambodia & Water quality & SODIS & Children aged 6 to $59 \mathrm{mo}$ \\
\hline
\end{tabular}

NGO: non-governmental organisation

SODIS: solar water disinfection

VIP: ventilated improved pit

WASH: water, sanitation and hygiene

\section{A P P E N D I C ES}

\section{Appendix I. English search strategy}

Dates of coverage: no limit to June 2012

\section{Database: Ovid MEDLINE, EMBASE, Global Health and CAB Abstracts}

I - subject heading

* - truncation term

$\mathrm{ab}$ - abstract

adj-adjacent to

ti - title

? - optional wildcard term

1. Stunt*.ab,ti.

2. Short stature.ab,ti.

3. Growth.ab,ti.

4. Wast*.ab,ti.

5. Thin.ab,ti.

6. Emaciated.ab,ti.

7. Undernourish*.ab,ti.

8. (BMI or body mass index).ab,ti.

9. (Intra-uterine growth retardation or IUGR).ab,ti.

10. Underweight.ab,ti.

11. Weight-for-age.ab,ti.

12. Height-for-age.ab,ti.

13. Length-for-age.ab,ti.

14. Weight-for-height.ab,ti.

15. ((Increas* or improv* or chang*) adj3 height).ab,ti.

16. ((Increas* or improv* or chang*) adj3 weight).ab,ti.

Interventions to improve water quality and supply, sanitation and hygiene practices, and their effects on the nutritional status of children

(Review)

Copyright $\odot 2013$ The Cochrane Collaboration. Published by John Wiley \& Sons, Ltd. 
17. Body fat percentage.ab,ti.

18. Development*.ab,ti.

19. Under?nutrition.ab,ti.

20. Malnutrition.ab,ti.

21. Nutritional status.ab,ti.

22. Nutriti*.ab,ti.

23. (GAM or global acute malnutrition).ab,ti.

24. (SAM or severe acute malnutrition).ab,ti.

25. (PEM or Protein energy malnutrition).ab,ti.

26. Nutritional deficiency status.ab,ti.

27. (An?emia or iron deficiency an?emia).ab,ti.

28. Vitamin a deficienc*.ab,ti.

29. Zinc deficienc*.ab,ti.

30. Iodine deficienc*.ab,ti.

31. (MUAC or mid-upper arm circumference).ab,ti.

32. Skinfold thickness.ab,ti.

33. Anthropometry*.ab,ti.

34. Nutrition Disorders/

35. Child Nutrition Disorders/

36. Infant Nutrition Disorders/

37. Malnutrition/

38. Starvation/

39. Wasting Syndrome/

40. or/1-39 (Combines outcome terms)

41. Child*.ab,ti.

42. Infan*.ab,ti.

43. Baby.ab,ti.

44. Toddler.ab,ti.

45. Pre?school*.ab,ti.

46. young person.ab,ti.

47. (Boy or girl).ab,ti.

48. Child/

49. Child, Preschool/

50. Infant/

51. Adolescent/

52. or/41-51 (Combines Child terms)

53. (Hand\$1 adj3 (wash* or clean* or disinfect*)).ab,ti.

54. Hand hygiene.ab,ti.

55. Hand sterility.ab,ti.

56. Handwashing.ab,ti.

57. (water adj3 (improv\$ or sediment\$ or radiat\$ or irradiat\$ or UV)).ti,ab.

58. Sanita*.ab,ti.

59. (Latrine $\$ 1$ or toilet $\$ 1$ or water closet $\$ 1$ or privy or pour flush or sewer system $\$ 1$ or septic tank $\$ 1$ ).ab,ti.

60. ((Faeces or feces or fecal or faecal or defecation or excrement or waste or excreta) adj3 (dispos* or manag* or service*)).ab,ti.

61. Water purification.ab,ti.

62. Water microbiology.ab,ti.

63. (Water adj5 (disinfect* or connect* or quality or handpump $\$ 1$ or standpipe $\$ 1$ or piped)).ti,ab.

64. (water adj5 (Purif* or treat* or improv* or decontaminat* or filt* or consum* or supply or drink* or quantity or distribut* or stor* or volume) $)$.ab,ti.

65. (water adj3 (safe or improv* or Clean*)).ab,ti.

66. (water adj3 Hygien*).ab,ti.

67. Water Supply/ or Water Purification/ or Water Pollution/ or Sanitation/

68. or/53-67 (Combines water quality interventions)

Interventions to improve water quality and supply, sanitation and hygiene practices, and their effects on the nutritional status of children 


\section{40 and 52 and 68 (All concepts combined)}

\section{Database: MEDLINE In-Process}

* - truncation term

$\$$ - adjacent to

? - optional wildcard term

1. stunt*

2. short stature

3. growth

4. wast* $^{*}$

5. thin

6. emaciated

7. undernourish*

8. BMI

9. body mass index

10. intra-uterine growth retardation

11. IUGR

12. underweight

13. weight-for-age

14. height-for-age

15. length-for-age

16. weight-for-height

17. Increas* height OR improv* height OR chang* height

18. Increas* weight OR improv* weight OR chang* weight

19. body fat percentage

20. development*

21. under?nutrition

22. malnutrition

23. nutritional status

24. nutrition*

25. GAM OR global acute malnutrition

26. SAM OR severe acute malnutrition

27. PEM OR protein energy malnutrition

28. nutritional deficiency status

29. an?emia OR iron deficiency an?emia

30. vitamin a deficienc*

31. zinc deficienc *

32. iodine deficienc *

33. muac OR mid-upper arm circumference

34. skinfold thickness

35. anthropometry*

36. or/1-35 (Combines outcome terms)

37. child*

38. infan *

39. baby

40. toddler

41. pre?school*

42. young person

43. Boy

44. Girl

45. or/37-44 (Combines child terms)

46. hand $\$ 1$ wash* OR hand $\$ 1$ clean* OR hand $\$ 1$ disinfect*

Interventions to improve water quality and supply, sanitation and hygiene practices, and their effects on the nutritional status of children

(Review)

Copyright $(2013$ The Cochrane Collaboration. Published by John Wiley \& Sons, Ltd. 
47. hand hygiene

48. hand sterility

49. handwashing

50. water improve OR water sediment $\$$ OR water radiat\$ OR water irradiati* OR UV

51. sanita*

52. latrine $\$ 1$ OR toilet $\$ 1$ OR water closet $\$ 1$ OR privy OR pour flush OR sewer system $\$ 1$ OR septic tank $\$ 1$

53. faeces dispos* OR feces dispos* OR fecal dispos* OR faecal dispos* OR defecation dispos* OR excrement dispos* OR waste dispos* OR excreta dispos* OR faeces manag* OR feces manag* OR fecal manag* OR faecal manag* OR defecation manag* OR excrement manag* OR waste manag* OR excreta manag* OR faeces service* OR feces service* OR fecal service* OR faecal service* OR defecation service* OR excrement service* OR waste service* OR excreta service*

54. water purification $\mathrm{OR}$ water microbiology

55. water disinfect* OR water connect* OR water quality OR water handpump $\$ 1$ OR water standpipe $\$ 1$ OR water piped

56. water Purif* OR water treat* OR water improv* OR water decontaminat* OR water filt* OR water consum* OR water supply OR water drink* OR water quantity OR water distribut* OR water stor* OR water volume

57. water safe OR water improv* OR water Clean* OR water Hygien*

58. or/46-57 (Combines WASH terms)

59.36 and 45 and 58 (all concepts combined)

\section{Database: Ovid Econlit}

$\$$ - truncation term

$a b-a b s t r a c t$

adj - adjacent to

ti - title

? - optional wildcard term

1. Stunt\$.ab,ti.

2. Short stature.ab,ti.

3. Growth.ab,ti. OR Wast\$.ab,ti.

4. Thin.ab,ti.

5. Emaciated.ab,ti.

6. Undernourish\$.ab,ti.

7. (BMI OR body mass index).ab,ti.

8. (Intra-uterine growth retardation OR IUGR).ab,ti.

9. Underweight.ab,ti.

10. Weight-for-age.ab,ti.

11. Height-for-age.ab,ti.

12. Length-for-age.ab,ti.

13. Weight-for-height.ab,ti.

14. ((Increas\$ OR improve\$ OR chang\$) adj3 height).ab,ti.

15. ((Increas\$ OR improve\$ OR chang\$) adj3 weight).ab,ti.

16. Body fat percentage.ab,ti.

17. Development\$.ab,ti.

18. Under?nutrition.ab,ti.

19. Malnutrition.ab,ti.

20. Nutritional status.ab,ti.

21. Nutriti\$.ab,ti.

22. (GAM OR global acute malnutrition).ab,ti.

23. (SAM OR severe acute malnutrition).ab,ti.

24. (PEM OR Protein energy malnutrition).ab,ti.

25. Nutritional deficiency status.ab,ti.

26. (An?emia OR iron deficiency an?emia).ab,ti.

27. Vitamin a deficienc\$.ab,ti.

28. Zinc deficienc\$.ab,ti.

Interventions to improve water quality and supply, sanitation and hygiene practices, and their effects on the nutritional status of children 
29. Iodine deficienc\$.ab,ti.

30. (MUAC OR mid-upper arm circumference).ab,ti.

31. Skinfold thickness.ab,ti.

32. Anthropometry\$.ab,ti

33. Or/1-32 (combines outcome terms)

34. Child\$.ab,ti.

35. Infan\$.ab,ti.

36. Baby.ab,ti.

37. Toddler.ab,ti.

38. Pre?school\$.ab,ti.

39. young person.ab,ti.

40. (Boy OR girl).ab,ti.

41. Or/34-40 (combines child terms)

42. (Hand\$1 adj3 (wash\$ OR clean\$ OR disinfect\$)).ab,ti.

43. Hand hygiene.ab,ti.

44. Hand sterility.ab,ti.

45. Handwashing.ab,ti.

46. (water adj3 (improv\$ OR sediment\$ OR radiat\$ OR irradiat\$ OR UV)).ti,ab.

47. Sanita\$.ab,ti.

48. (Latrine\$1 OR toilet $\$ 1$ OR water closet $\$ 1$ OR privy OR pour flush OR sewer system \$1 OR septic tank\$1).ab,ti.

49. ((Faeces OR feces OR fecal OR faecal OR defecation OR excrement OR waste OR excreta) adj3 (dispos\$ OR manag\$ OR service\$)).ab,ti.

50. Water purification.ab,ti.

51. Water microbiology.ab,ti.

52. (Water adj5 (disinfect\$ OR connect\$ OR quality OR handpump\$1 OR standpipe\$1 OR piped)).ti,ab.

53. (water adj5 (Purif\$ OR treat\$ OR improve\$ OR decontaminat\$ OR filt\$ OR consum $\$$ OR supply OR drink\$ OR quantity OR distribut\$ OR stor\$ OR volume)).ab,ti.

54. (water adj3 (safe OR improve\$ OR Clean\$)).ab,ti.

55. (water adj3 Hygien\$).ab,ti.

56. Or/42-55 (combines WASH terms)

57.33 and 41 and 56 (all concepts combined

\section{Database: Greenfile}

* - truncation term

$\mathrm{N}$ - adjacent to

? - optional wildcard term

1. Stunt* or

2. Short stature or

3. Growth or

4. Wast* or

5. Thin or

6. Emaciated or

7. Undernourish* or

8. BMI or body mass index or

9. Intra-uterine growth retardation or

10. IUGR or

11. Underweight or

12. Weight-for-age or

13. Height-for-age or

14. Length-for-age or

15. Weight-for-height or

16. Increas* N3 height or

Interventions to improve water quality and supply, sanitation and hygiene practices, and their effects on the nutritional status of children 
17. improve* $\mathrm{N} 3$ height or

18. chang* $\mathrm{N} 3$ height or

19. Increas* N3 weight or

20. improve* N3 weight or

21. chang* N3 weight or

22. Body fat percentage or

23. Development* or

24. Under?nutrition or

25. Malnutrition or

26. Nutritional status or

27. Nutriti* or

28. GAM or global acute malnutrition or

29. SAM or severe acute malnutrition or

30. PEM or Protein energy malnutrition or

31. Nutritional deficiency status or

32. An?emia or

33. iron deficiency an?emia or

34. Vitamin a deficienc* or

35. Zinc deficienc* or

36. Iodine deficienc* or

37. MUAC or mid-upper arm circumference or

38. Skinfold thickness or

39. Anthropometry*

AND

40. Child* or

41. Infan* or

42. Baby or

43. Toddler or

44. Pre?school* or

45. young person or

46. Boy or

47. girl

AND

48. Hand ${ }^{*} 1 \mathrm{~N} 3$ wash* $^{*}$ or

49. Hand* N3 clean* or

50. Hand* N3 disinfect* or

51. Hand hygiene or

52. Hand sterility or

53. Handwashing or

54. water N3 improv* or

55 . water $\mathrm{N} 3$ sediment* or

56. water N3 radiat* or

57. water N3 irradiat* or

58. UV or

59. Sanita* or

60. Latrine* 1 or

61. toilet ${ }^{*} 1$ or

62. water closet $^{*} 1$ or

63. privy or

64. pour flush or

65. sewer system* 1 or

66. septic $\operatorname{tank}^{*} 1$ or

67. Faeces N3 dispos* or

Interventions to improve water quality and supply, sanitation and hygiene practices, and their effects on the nutritional status of children

(Review)

Copyright $(2013$ The Cochrane Collaboration. Published by John Wiley \& Sons, Ltd. 
68. feces N3 dispos* or 69. fecal N3 dispos* or

70. faecal N3 dispos* or

71. defecation N3 dispos* or

72. excrement N3 dispos* or

73. waste $\mathrm{N} 3$ dispos* or

74. excreta $\mathrm{N} 3$ dispos* or

75. Faeces N3 manag* or

76. feces N3 manag* or

77. fecal N3 manag* or

78. faecal N3 manag* or

79. defecation N3 manag* or

80. excrement N3 manag* or

81. waste N3 manag* or

82. excreta N3 manag* or

83. Faeces N3 service* or

84. feces N3 service* or

85. fecal N3 service* or

86. faecal N3 service* or

87. defecation N3 service* or

88. excrement N3 service* or

89. waste N3 service* or

90. excreta N3 service* or

91. Water purification or

92. Water microbiology or

93. Water N5 disinfect* or

94. Water N5 connect* or

95. Water N5 quality or

96. Water N5 handpump*1 or

97. standpipe* 1 or

98. Water N5 piped or

99. water N5 Purif* or

100. water N5 treat* or

101. water N5 improve* or

102. water N5 decontaminat* or

103. water N5 filt* or

104. water N5 consum* or

105. water N5 supply or

106. water N5 drink* or

107. water N5 quantity or

108. water N5 distribut* or

109. water $\mathrm{N} 5$ stor* or

110. water N5 volume or

111. water N3 safe or

112. water N3 improve* or

113. water N3 Clean* or

114. water N3 Hygien*

\section{Database: Web of Science}

* - truncation term

adj - adjacent to

? - optional wildcard term

Interventions to improve water quality and supply, sanitation and hygiene practices, and their effects on the nutritional status of children

(Review)

Copyright $\odot 2013$ The Cochrane Collaboration. Published by John Wiley \& Sons, Ltd. 
1. stunt* or

2. short stature or

3. growth or

4. wast* or

5. thin or

6. emaciated or

7. undernourish* or

8. BMI or body mass index or

9. intra-uterine growth retardation or

10. IUGR or

11. underweight or

12. weight-for-age or

13. height-for-age or

14. length-for-age or

15. weight-for-height or

16. Increas* height or

17. improv* height or

18. chang* height or

19. Increas* weight or

20. improv* weight or

21. chang* weight or

22. body fat percentage or

23. development* or

24. under?nutrition or

25. malnutrition or

26. nutritional status or

27. nutrition* or

28. GAM or global acute malnutrition or

29. SAM or severe acute malnutrition or

30. PEM or protein energy malnutrition or

31. nutritional deficiency status or

32. an?emia or

33. iron deficiency an?emia or

34. vitamin a deficienc* or

35. zinc deficienc ${ }^{*}$ or

36. iodine deficienc ${ }^{*}$ or

37. muac or

38. mid-upper arm circumference or

39. skinfold thickness or

40. anthropometry*

AND

41. child* or

42. infan * or

43. baby or

44. toddler or

45. pre?school* or

46. young person or

47. Boy or

48. girl

AND

49. hand* 1 wash* or

50. hand* 1 clean or

51. hand*1 disinfect* or

Interventions to improve water quality and supply, sanitation and hygiene practices, and their effects on the nutritional status of children

(Review)

Copyright $\odot 2013$ The Cochrane Collaboration. Published by John Wiley \& Sons, Ltd. 
52. hand hygiene or hand sterility or

53. handwashing or

54. water improve or

55. water sediment* or

56. water radiat* or

57 . water irradiati* ${ }^{*}$

58. UV or

59. sanita* or

60. latrine* 1 or

61. toilet* 1 or

62. water closet $^{*} 1$ or

63. privy or

64. pour flush or

65. sewer system* 1 or

66. septic $\operatorname{tank}^{*} 1$ or

67. faeces dispos* or

68. feces dispos* or

69. fecal dispos* or

70. faecal dispos* or

71. defecation dispos* or

72. excrement dispos* ${ }^{*}$ or

73. waste dispos* or

74. excreta dispos* or

75. faeces manag* or

76. feces manag* or

77. fecal manag* or

78. faecal manag* or

79. defecation manag* or

80. excrement manag* or

81. waste manag* or

82. excreta manag* or

83. faeces service* or

84. feces service* or

85. fecal service* or

86. faecal service* or

87. defecation service* or

88. excrement service* or

89. waste service* or

90. excreta service* or

91. water purification or

92. water microbiology or

93. water disinfect* ${ }^{*}$ or

94. water connect* or

95. water quality or

96. water handpump* 1 or

97. water standpipe* 1 or

98. water piped or

99. water Purif* or

100. water treat ${ }^{*}$ or

101. water improv* or

102. water decontaminat* or

103. water filt* or

104. water consum* ${ }^{*}$ or

Interventions to improve water quality and supply, sanitation and hygiene practices, and their effects on the nutritional status of children

(Review)

Copyright $\odot 2013$ The Cochrane Collaboration. Published by John Wiley \& Sons, Ltd. 
105. water supply or

106. water drink* or

107. water quantity or

108. water distribut* or

109. water stor* or

110. water volume or

111. water safe or

112. water improv* or

113. water Clean* or

114. water Hygien*

\section{Appendix 2. Chinese search terms}

\begin{tabular}{|c|c|c|c|}
\hline \multirow[t]{2}{*}{ Category } & 关于营养/健康状况 & 关于水和卫生 & 关于青少年 \\
\hline & Nutrition/Health & Water/Sanitation & Object of study \\
\hline Database & 数据库: CBM & & \\
\hline \multirow[t]{11}{*}{ Search terms } & 身高/体重 & 改水/改测/洗手/㭟便/（㭟便无害化）/水净化 & $<18$ 岁 \\
\hline & Height/weight & $\begin{array}{l}\text { Improve drinking water/lavatories/ } \\
\text { excrement (harmless)/Water purifica- } \\
\text { tion }\end{array}$ & $<18$ years \\
\hline & 血红蛋白/转铁蛋白 & 改水/改则/洗手/簧便/( 賞便无害化) / 水净化 & $<18$ 岁 \\
\hline & Haemoglobin/transferrin & $\begin{array}{l}\text { Improve drinking water/lavatories/ } \\
\text { excrement (harmless)/Water purifica- } \\
\text { tion }\end{array}$ & $<18$ years \\
\hline & 皮脂厚度/脂肪合量 & 改水/改刚/洗手/粪便／（粪便无害化）/水净化 & $<18$ 岁 \\
\hline & Skinfold thickness/fat content & $\begin{array}{l}\text { Improve drinking water/lavatories/ } \\
\text { excrement (harmless)/Water purifica- } \\
\text { tion }\end{array}$ & $<18$ years \\
\hline & 莒养不良/上臂围 & 改水/改则/洗手/粪便/（粪便无害化）/水净化 & $<18$ 岁 \\
\hline & $\begin{array}{l}\text { Malnutrition/upper arm circumfer- } \\
\text { ence }\end{array}$ & $\begin{array}{l}\text { Improve drinking water/lavatories/ } \\
\text { excrement (harmless)/Water purifica- } \\
\text { tion }\end{array}$ & $<18$ years \\
\hline & 出生体重/小于胎数儿 & 改水/改网/洗手/粪便/( 粪便无害化) / 水净化 & $<18$ 岁 \\
\hline & Birth weight/gestational age children & $\begin{array}{l}\text { Improve drinking water/lavatories/ } \\
\text { excrement (harmless)/Water purifica- } \\
\text { tion }\end{array}$ & $<18$ years \\
\hline & 肠道感染 & 改水/改则/洗手/粪便/( 粪便无害化 $)$ / 水净化 & $<18$ 岁 \\
\hline
\end{tabular}

Interventions to improve water quality and supply, sanitation and hygiene practices, and their effects on the nutritional status of children 


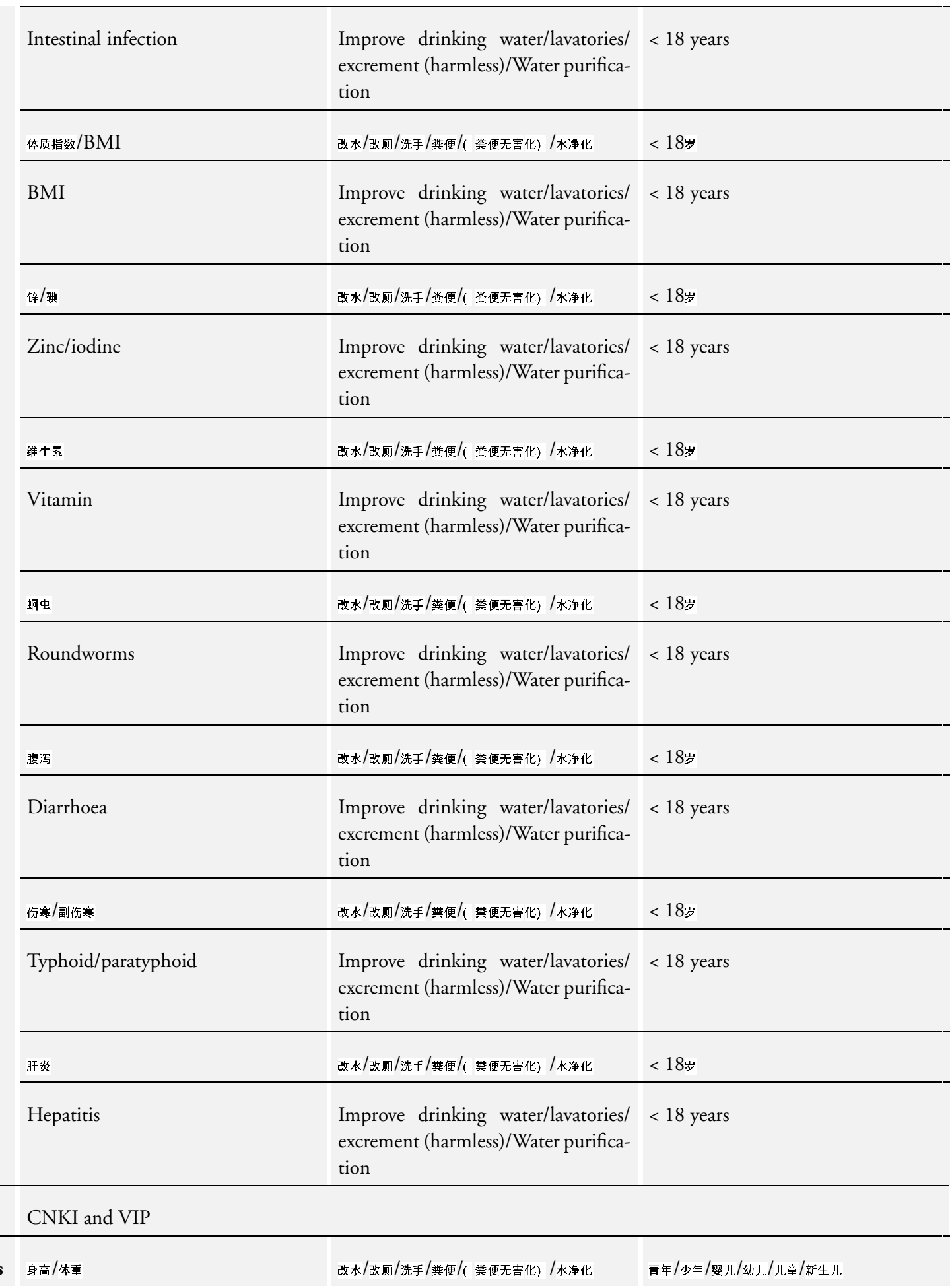

Improve drinking water/lavatories/ < 18 years excrement (harmless)/Water purifica-

Improve drinking water/lavatories/ < 18 years excrement (harmless)/Water purifica-

$$
\text { 锌/ }
$$

(1)




\begin{tabular}{|c|c|c|}
\hline Height/weight & $\begin{array}{l}\text { Improve drinking water/lavatories/ } \\
\text { excrement (harmless)/Water purifica- } \\
\text { tion }\end{array}$ & $\begin{array}{l}\text { Youth/Junior/Infant/young children/ } \\
\text { children/infants }\end{array}$ \\
\hline 血红蛋白/转铁蛋白 & 改水/改则/洗手/粪便/( 粪便无害化) / 水净化 & 青年/少年/管儿/幼儿/儿童/新生儿 \\
\hline Hemoglobin/transferrin & $\begin{array}{l}\text { Improve drinking water/lavatories/ } \\
\text { excrement (harmless)/Water purifica- } \\
\text { tion }\end{array}$ & $\begin{array}{l}\text { Youth/Junior/Infant/young children/ } \\
\text { children/infants }\end{array}$ \\
\hline 皮脂厚度 $/$ 脂肪合量 & 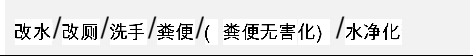 & 青年/少年/姦儿/幼儿/儿童/新生儿 \\
\hline Skinfold thickness/fat content & $\begin{array}{l}\text { Improve drinking water/lavatories/ } \\
\text { excrement (harmless)/Water purifica- } \\
\text { tion }\end{array}$ & $\begin{array}{l}\text { Youth/Junior/Infant/young children/ } \\
\text { children/infants }\end{array}$ \\
\hline 营养不良/上管围 & 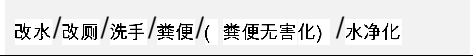 & 青年/少年/姦儿/幼儿/儿童/新生儿 \\
\hline $\begin{array}{l}\text { Malnutrition/upper arm circumfer- } \\
\text { ence }\end{array}$ & $\begin{array}{l}\text { Improve drinking water/lavatories/ } \\
\text { excrement (harmless)/Water purifica- } \\
\text { tion }\end{array}$ & $\begin{array}{l}\text { Youth/Junior/Infant/young children/ } \\
\text { children/infants }\end{array}$ \\
\hline 出生体重/小于胎龄儿 & 改水/改四/洗手/粪便/( 粪便无害化) / 水净化 & 青年/少年/䯃儿/幼儿/儿童/新生儿 \\
\hline Birth weight/gestational age children & $\begin{array}{l}\text { Improve drinking water/lavatories/ } \\
\text { excrement (harmless)/Water purifica- } \\
\text { tion }\end{array}$ & $\begin{array}{l}\text { Youth/Junior/Infant/young children/ } \\
\text { children/infants }\end{array}$ \\
\hline 肠道感染/腹泻 & 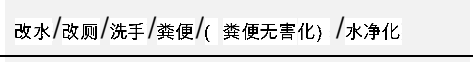 & 青年/少年/姦儿/幼儿/儿童/新生儿 \\
\hline Intestinal infection/diarrhoea & $\begin{array}{l}\text { Improve drinking water/lavatories/ } \\
\text { excrement (harmless)/Water purifica- } \\
\text { tion }\end{array}$ & $\begin{array}{l}\text { Youth/Junior/Infant/young children/ } \\
\text { children/infants }\end{array}$ \\
\hline 体质指数/BMI & 改水/改则/洗手/粪便/( 粪便无害化) / 水净化 & 青年/少年/糸儿/幼儿/儿童/新生儿 \\
\hline BMI & $\begin{array}{l}\text { Improve drinking water/lavatories/ } \\
\text { excrement (harmless)/Water purifica- } \\
\text { tion }\end{array}$ & $\begin{array}{l}\text { Youth/Junior/Infant/young children/ } \\
\text { children/infants }\end{array}$ \\
\hline 锌/碘/维生素 & 改水/改则/洗手/粪便/( 粪便无害化) / 水净化 & 青年/少年/姦儿/幼儿/儿童/新生儿 \\
\hline Zinc/iodine/vitamin & $\begin{array}{l}\text { Improve drinking water/lavatories/ } \\
\text { excrement (harmless)/Water purifica- } \\
\text { tion }\end{array}$ & $\begin{array}{l}\text { Youth/Junior/Infant/young children/ } \\
\text { children/infants }\end{array}$ \\
\hline 旰炎 & 改水/改则/洗手/粪便/( 粪便无害化) / 水净化 & 青年/少年/妿儿/幼儿/儿童/新生儿 \\
\hline Hepatitis & $\begin{array}{l}\text { Improve drinking water/lavatories/ } \\
\text { excrement (harmless)/Water purifica- }\end{array}$ & $\begin{array}{l}\text { Youth/Junior/Infant/young children/ } \\
\text { children/infants }\end{array}$ \\
\hline
\end{tabular}

Interventions to improve water quality and supply, sanitation and hygiene practices, and their effects on the nutritional status of children 97 


\begin{tabular}{|c|c|c|}
\hline 蜔虫 & 改水/改则/洗手/粸便/( 粪便无害化) / 水净化 & 青年/少年/婴儿/幼儿/儿童/新生儿 \\
\hline Roundworms & $\begin{array}{l}\text { Improve drinking water/lavatories/ } \\
\text { excrement (harmless)/Water purifica- } \\
\text { tion }\end{array}$ & $\begin{array}{l}\text { Youth/Junior/Infant/young children/ } \\
\text { children/infants }\end{array}$ \\
\hline 伤寒/副伤寒 & 改水/改则/洗手/粪便 $/($ 粪便无害化 $)$ / 水净化 & 青年/少年/姦儿/幼儿/儿童/新生儿 \\
\hline Typhoid/paratyphoid & $\begin{array}{l}\text { Improve drinking water/lavatories/ } \\
\text { excrement (harmless)/Water purifica- } \\
\text { tion }\end{array}$ & $\begin{array}{l}\text { Youth/Junior/Infant/young children/ } \\
\text { children/infants }\end{array}$ \\
\hline
\end{tabular}

\section{H I S T O R Y}

Protocol first published: Issue 10, 2011

Review first published: Issue 8, 2013

\begin{tabular}{lll}
\hline Date & Event & Description \\
\hline 12 August 2011 & Amended & Protocol FINAL \\
\hline 3 August 2011 & Amended & Protocol: Amended according to external peer reviewer feedback \\
\hline 18 May 2011 & Amended & Protocol: Amended according to internal reviewer feedback. \\
\hline
\end{tabular}

\section{CONTRIBUTIONS OF AUTHORS}

The following assignation of tasks has been agreed to by all authors.

Draft the protocol: all

Study selection: LW, SB

Review Chinese databases: YC

Extract data from studies: LW, SB

Enter data into RevMan: LW

Carry out the analysis: LW, EA

Interpret the analysis: LW, EA, ADD

Draft the final review: all

Disagreement resolution: ADD

Update the review: ADD

Interventions to improve water quality and supply, sanitation and hygiene practices, and their effects on the nutritional status of children

(Review)

Copyright $\odot 2013$ The Cochrane Collaboration. Published by John Wiley \& Sons, Ltd. 


\section{DECLARATIONSOF INTEREST}

Subsequent to the inception of this review and the publication of the review protocol, ADD has been seconded part-time as a Senior Research Fellow in the Agriculture Team of the Research and Evidence Division at the UK Department for International Development (DFID). YV and SC are employees of WaterAid, an international non-governmental organisation that works to promote the provision of safe water, improved sanitation and hygiene globally. YV and SC were involved in the conceptualisation of the review, contributed to the literature search and provided comments on the review drafts. YV and SC were not involved in data extraction, data analysis or interpretation of the findings. All other authors have no known potential conflict of interest.

\section{SOURCES OF SUPPORT}

\section{Internal sources}

- No sources of support supplied

\section{External sources}

- Department of International Development (DFID), UK.

This research was made possible with UK aid from DFID as part of the SHARE research programme (www.SHAREresearch.org).

\section{DIFFERENCESBETWEEN PROTOCOLANDREVIEW}

None. 